Maiza Ritomy Ide

\author{
Estudo comparativo dos efeitos de um \\ protocolo de cinesioterapia respiratória \\ desenvolvido em dois diferentes meios, \\ aquático e terrestre, na função respiratória \\ de idosos
}

Dissertação apresentada ao Programa de Fisiopatologia Experimental da Faculdade de Medicina da Universidade de São Paulo para obtenção do título de Mestre em Ciências

Área de concentração: Fisiopatologia Experimental

Orientador: Dra. Fátima Aparecida Caromano

São Paulo

2004 
Maiza Ritomy Ide

\section{Estudo comparativo dos efeitos de um protocolo de cinesioterapia respiratória desenvolvido em dois diferentes meios, aquático e terrestre, na função respiratória de idosos}

Dissertação apresentada ao Programa de Fisiopatologia Experimental da Faculdade de Medicina da Universidade de São Paulo para obtenção do título de Mestre em Ciências

Área de concentração: Fisiopatologia Experimental

Orientador: Dra. Fátima Aparecida Caromano

São Paulo

2004 


\section{Dedicatória e Agradecimentos}

Agradeço e dedico este trabalho...

A Deus, pela força que me fez incansável, por todas as portas, pontes e elos, pela capacidade inesgotável de querer e sonhar. Pelos horizontes sempre a frente, pela capacidade de buscar. Pela saúde perfeita, liberdade, independência...

... ao meu pai Miguel, apoio incondicional em todos os momentos, eterno exemplo sabedoria, amor, confiança... ... minha mãe Luiza...

... a Cláudia, minha irmã tão doce, paciente e querida. Por todos os dias que me levou de um canto a outro, por todos os momentos e instantes... ... ao Fer, meu irmão...

... a minha orientadora Fátima, por quem serei eternamente grata, por todas as oportunidades, amizade, confiança, paciência, sabedoria, dedicação... e sobretudo pelo tempo em que privou o Hugo de seus braços para estar aqui...

... as minhas primas Eloísa e Dorinha, Fabinho, Yuji, Mário, Tia Sumie e Tio Afonso, por todo o apoio e por tornar meus dias em São Paulo tão agradáveis e produtivos...

... a Andressa Bielski, verdadeira amiga em todos os momentos, mesmo longe, para sempre amiga....

... ao AndréJ, Jack, Fulvio, meus amigos de tanto tempo, nem sempre tão próximos mas nunca distantes, por todas as festas que fizemos e deixamos de fazer para que eu estivesse aqui...

... a professora e amiga Celeide, que, como coordenadora do curso de fisioterapia da UNIOESTE não mediu esforços para tornar mais fácil... 
.... a minha amiga Marize, menina do coração enorme, exemplo de vida, força, amizade e superação, que tanto me ajudou na execução deste projeto...

... a Nidia e Maria, alunas tão queridas, inteligentes e dedicadas, com quem pretendo estar e trabalhar sempre....

... aos acadêmicos Luana, Juliana Montijo, Drica, Lígia, Lilian, Carine, Ingrid, Thiago, Cassius, Anna Paula e Cássia, que colaboraram com o projeto e sem os quais ele seria impossível...

... ao professor Jefferson, primeiro a semear a pesquisa em meu quintal... ... aos 81 sujeitos que integraram o projeto...

... A Laetitia, minha amiga e professeur, e Mariana, mon amie tão querida...

.... a todos os meus alunos, que um pouco do meu tempo deixaram de ter durante o ano que passou...

... a Cida, querida, querida, querida, anjinho que entrou na minha vida durante os créditos, e espero que nunca saia...

... ao Professor Marcelo, que tantas portas abriu e tudo fez para facilitar minhas saídas...

... aos pacientes do meu consultório, que incontáveis vezes tive que deixar para estar aqui...

...à Biba... minha distante amiga...

... a todos meus professores da graduação, cujo caráter e ensinamentos eu espero levar por toda a vida: Fabinho, Lia, Roberta, Cida, Roger, César, Edson, Celita, Cláudia, Suhaila, Brunetto...

... e a todos, não poucos, que um dia passaram por meu caminho nos incontáveis quilômetros percorridos que me conduziram até aqui e trouxeram um novo sentido à minha vida, mesmo que por instantes tão pequenos e aparentemente insignificantes. 
Esta dissertação está de acordo com:

Referências: adaptado de International Comittee of Medical Journals Editors (Vancouver)

Universidade de São Paulo. Faculdade de Medicina. Serviço de Biblioteca e Documentação. Guia de apresentação para dissertações, teses e monografias. Elaborado por Anneliese Carneiro da Cunha, Maria Julia de A.L. Freddi, Maria F. Crestana, Marinalva de Souza Aragão, Suely Campos Cardoso, Valéria Vilhena. São Paulo: Serviço de Biblioteca e Documentação; 2004.

Abreviaturas dos títulos dos periódicos de acordo com List of Journals Indexed in Index Medicus. 


\section{SUMÁRIO}

Lista de figuras

Lista de tabelas

Lista de abreviaturas

Lista de siglas

Lista de símbolos

$\underline{\text { Resumo }}$

Summary

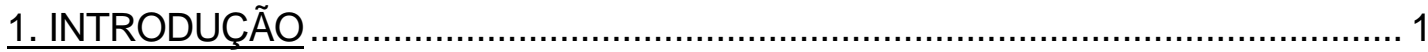

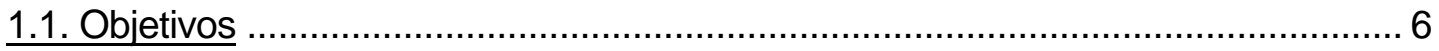

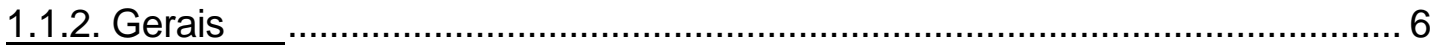

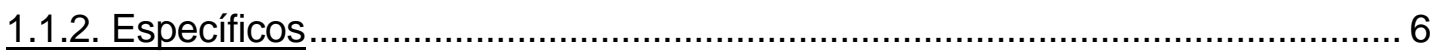

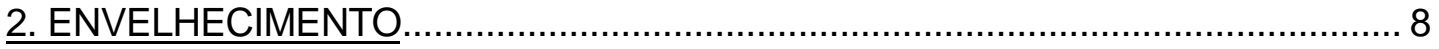

2.1. Exercício físico geral e envelhecimento ..................................................... 10

2.1.1. Aspectos preventivos do exercício no idoso............................................... 11

2.1.2. Inatividade e vantagens da prática de atividade física................................... 11

2.2. Alterações fisiológicas sistêmicas do envelhecimento .................................... 17

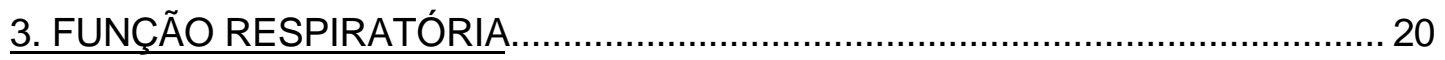

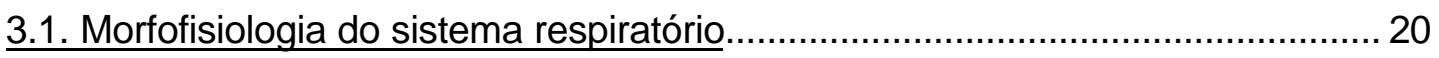

3.2. Influência do peso corporal na função respiratória .......................................... 25

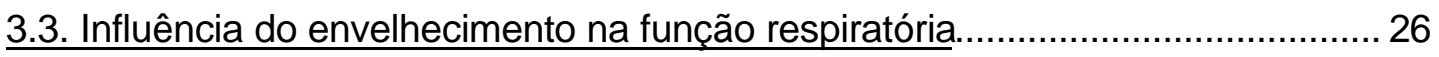

3.3.1. Envelhecimento e músculos estriados esqueléticos .................................. 32

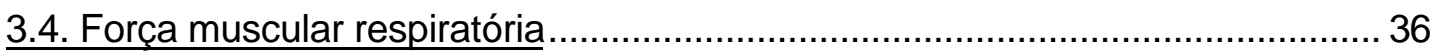

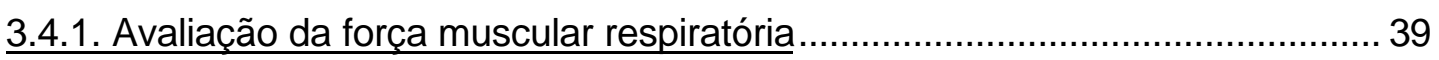


3.4.2. Treino de força muscular respiratória ........................................................... 45

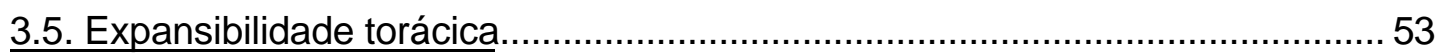

3.5.1. Avaliação da expansibilidade torácica .........................................................56

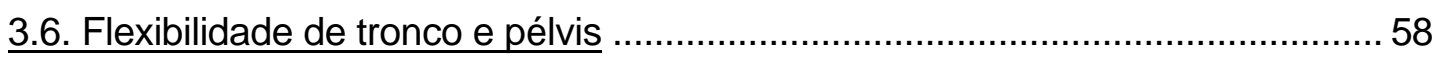

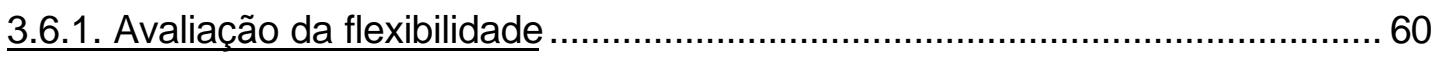

4. EXERCÍCIOS RESPIRATÓRIOS TERAPÊUTICOS ...........................................6 66

4.1. Influência da imersão e exercício na função respiratória.................................... 73

4.1.1. Efeitos físicos e fisiológicos da água........................................................... 73

4.1.2. Imersão, exercício e função respiratória ..................................................... 77

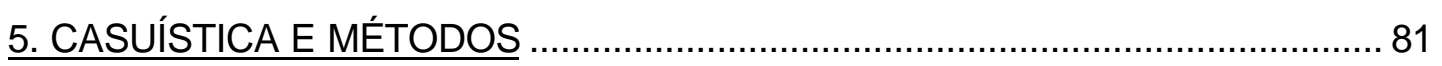

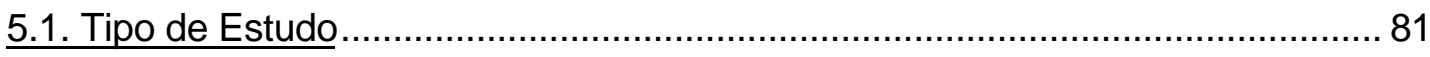

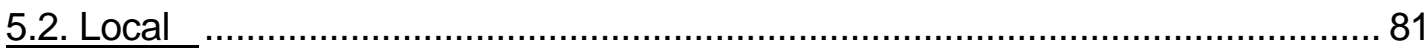

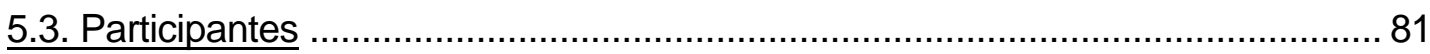

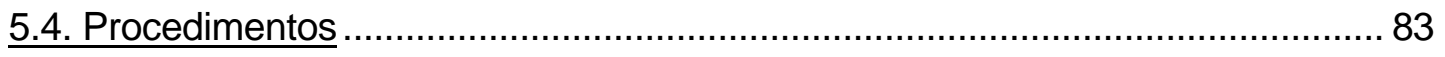

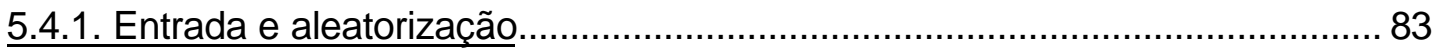

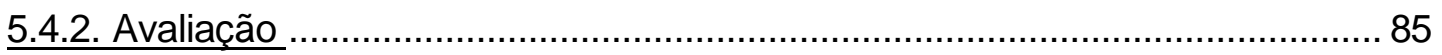

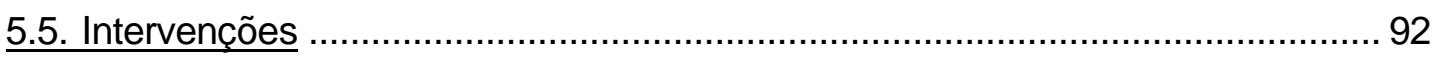

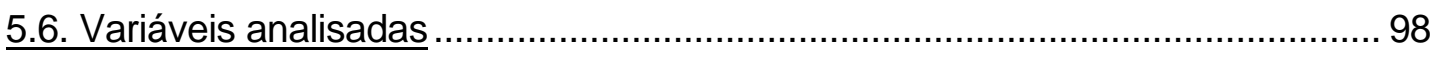

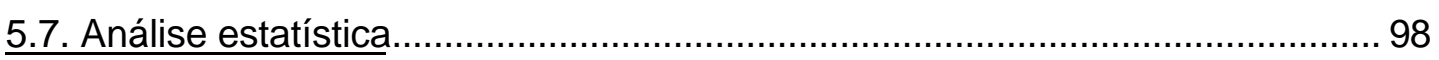

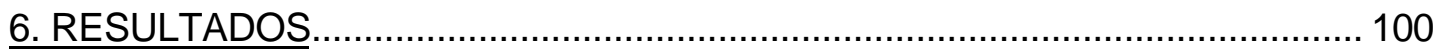

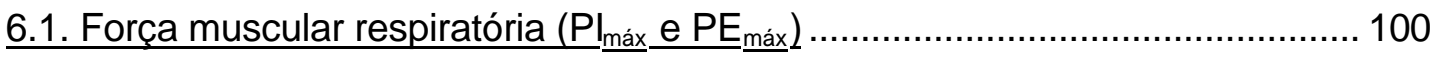

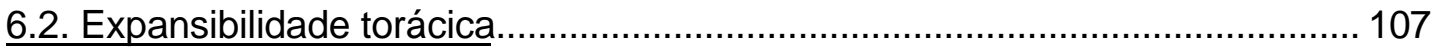

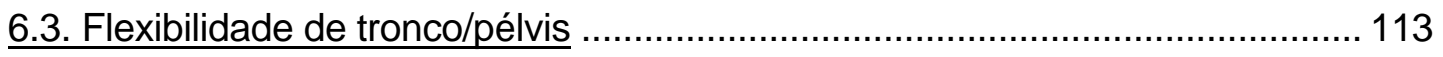

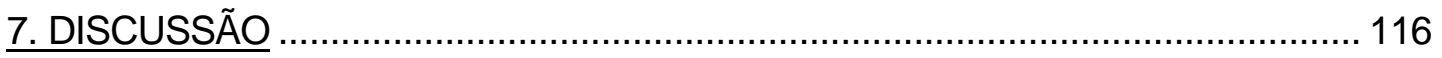

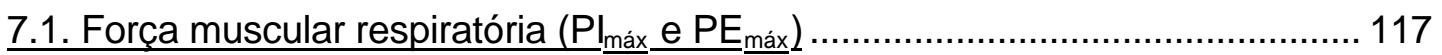


7.1.1. Comportamento da $\mathrm{PI}_{\text {máx }}$

7.1.2. Comportamento da $P E_{\text {máx }}$ 122

7.2. Expansibilidade torácica. 127

7.3. Flexibilidade anterior de tronco/pélvis 129

8. CONCLUSÕES. 132

9. ANEXOS 133

Anexo A - Protocolo de entrevista geral. 134

Anexo B - Fotos das atividades desenvolvidas pelos grupos de intervenção (água e solo) 134

Anexo C - Fotos das atividades desenvolvidas pelo grupo controle 137

10. REFERÊNCIAS BIBLIOGRÁFICAS 138

Apêndice

1) Termo de aprovação do comitê de ética

2) Termo de consentimento livre e esclarecido 


\section{LISTA DE FIGURAS}

Figura 1 - Comprimento normal dos músculos da coluna, isquiotibiais e músculos gastrocnêmio-sóleo

Figura 2 - Comprimento excessivo dos músculos da coluna, isquiotibiais curtos, comprimento normal de gastrocnêmio-sóleo ....

Figura 3 - Comprimento excessivo dos músculos superiores da coluna, leve encurtamento dos músculos na coluna média e inferior e no gastrocnêmio-sóleo. Isquiotibiais com comprimento normal .

Figura 4 - Comprimento normal dos músculos da coluna superior, músculos da coluna inferior, isquiotibiais e gastrocnêmio-sóleo curtos.

Figura 5 - Avaliação da expansibilidade torácica.

Figura 6 - Mensuração da distância "d", entre a placa vertical e o processo estilóide da ulna

Figura 7 - Avaliação da flexibilidade utilizando o teste dedo-chão modificado...... .89

Figura 8 - Manovacuômetro utilizado para mensuração das pressões respiratórias máximas

Figura 9 - Avaliação das pressões respiratórias máximas .91

Quadro 1 - Protocolo de cinesioterapia respiratória aplicado aos grupos água e solo

Quadro 2 - Protocolo de atividades aplicadas ao grupo controle.....

Figura 10 - Realização do protocolo aquático, com ombros constantemente submersos

Figura 11 - Realização do protocolo em grupo, com atenção individual e uso de recursos diversos

Gráfico 1 - Trajetórias da pressão inspiratória máxima dos sujeitos alocados no grupo áqua pré e pós intervenção.

Gráfico 2 - Trajetórias da pressão inspiratória máxima dos sujeitos alocados no grupo solo pré e pós intervenção

Gráfico 3 - Trajetórias da pressão inspiratória máxima dos sujeitos alocados no grupo controle pré e pós intervenção

Gráfico 4 - Trajetórias da pressão expiratória máxima dos sujeitos alocados no grupo água pré e pós intervenção. 
Gráfico 5 - Trajetórias da pressão expiratória máxima dos sujeitos alocados no grupo solo pré e pós intervenção

Gráfico 6 - Trajetórias da pressão expiratória máxima nos sujeitos alocados no grupo controle pré e pós intervenção

Gráfico 7 - Trajetórias médias da pressão inspiratória máxima nos grupos água, solo e controle.

Gráfico 8 - Trajetórias médias da pressão expiratória máxima nos grupos água, solo e controle.

Gráfico 9 - Trajetórias da expansibilidade ao nível axilar dos sujeitos alocados no grupo água pré-pós intervenção

Gráfico 10 - Trajetórias da expansibilidade ao nível axilar dos sujeitos alocados no grupo solo pré-pós intervenção.

Gráfico 11 - Trajetórias da expansibilidade ao nível axilar dos sujeitos alocados no grupo controle pré-pós intervenção

Gráfico 12 - Trajetórias da expansibilidade ao nível xifóide dos sujeitos alocados no grupo água pré-pós intervenção

Gráfico 13 - Trajetórias da expansibilidade ao nível xifóide dos sujeitos alocados no grupo solo pré-pós intervenção.

Gráfico 14 - Trajetórias da expansibilidade ao nível xifóide dos sujeitos alocados no grupo controle pré-pós intervenção

Gráfico 15 - Trajetórias médias da expansibilidade torácica ao nível axilar nos grupos água, solo e controle

Gráfico 16 - Trajetórias médias da expansibilidade torácica ao nível xifóide nos grupos água, solo e controle

Gráfico 17 - Trajetórias da flexibilidade dos sujeitos alocados no grupo água pré-pós intervenção

Gráfico 18 - Trajetórias da flexibilidade dos sujeitos alocados no grupo solo pré-pós intervenção

Gráfico 19 - Trajetórias da flexibilidade dos sujeitos alocados no grupo controle prépós intervenção.

Gráfico 20 - Flexibilidade média de tronco/pélvis nos grupos água, solo e controle pré e pós a realização dos protocolos propostos

Figura 12 - Atendimento do grupo água .135

Figura 13 - Atendimento do grupo água. 


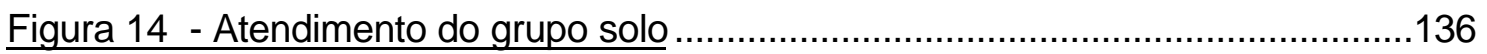

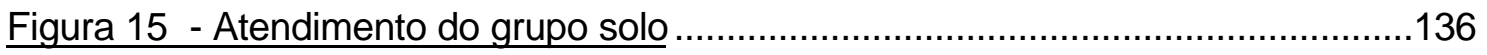

Figura 16 - Palestra ministrada ao grupo controle ...................................................137

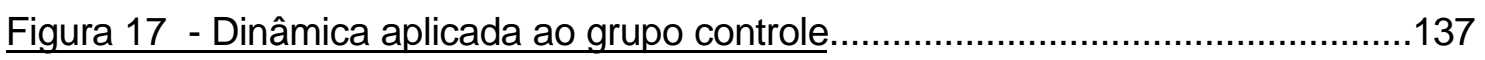




\section{LISTA DE TABELAS}

Tabela 1 - Caracterização de quadro clínico de acordo com valores da pressão inspiratória máxima.

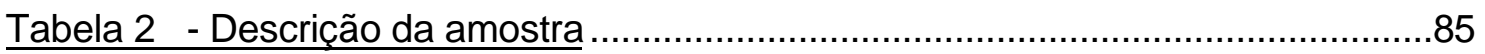

Tabela 3 - Pressão inspiratória máxima nos grupos água, solo e controle................100

Tabela 4 - Comparação das pressões respiratórias máximas pós-pré intervenção nos grupos água, solo e controle utilizando o teste t-pareado......................104

Tabela 5 - Comparação da pressão inspiratória máxima pós-pré intervenção utilizando a análise de variância e Teste de Dunett. 106

Tabela 6 - Expansibilidade torácica dos sujeitos alocados no grupo água, solo e controle.

Tabela 7 - Comparação da expansibilidade pós-pré intervenção nos grupos água, solo e controle utilizando o teste t-pareado

Tabela 8 - Comparação da expansibilidade pós-pré intervenção entre os grupos utilizando o teste t-pareado

Tabela 9 - Flexibilidade de tronco/pélvis dos sujeitos alocados nos grupos água, solo e controle.

Tabela 10 - Estimativa das médias da flexibilidade pós-intervenção ajustadas pelos valores de flexibilidade iniciais. 


\section{LISTA DE ABREVIATURAS}

apud citado por

ed. edição

et al. e outros

n. número

p. página

v. volume

$\mathrm{p} \quad$ nível descritivo

$\mathrm{IC}_{95 \%} \quad$ intervalo de confiança de $95 \%$

$\mathrm{VO}_{2 \text { máx }} \quad$ consumo máximo de oxigênio

$\mathrm{VO}_{2} \quad$ consumo de oxigênio 
LISTA DE SIGLAS

$\begin{array}{ll}\text { DPOC } & \text { DOENÇA PULMONAR OBSTRUTIVA CRÔNICA } \\ \mathrm{G}_{1} & \text { GRUPO } 1 \text { (GRUPO ÁGUA) } \\ \mathrm{G}_{2} & \text { GRUPO } 2 \text { (GRUPO SOLO) } \\ \mathrm{G}_{3} & \text { GRUPO } 3 \text { (GRUPO CONTROLE) } \\ \mathrm{PaCO}_{2} & \text { PRESSÃO PARCIAL DE DIÓXIDO DE CARBONO NO SANGUE } \\ & \text { PRESSÃO PARCIAL DE OXIGÊNIO NO SANGUE } \\ \mathrm{PaO}_{2} & \text { PRTERIAL } \\ & \text { PRESSÃO EXPIRATÓRIA MÁXIMA } \\ \text { PE }_{\text {máx }} & \text { VOLUME EXPIRATÓRIO FORÇADO NO PRIMEIRO SEGUNDO } \\ \mathrm{PI}_{\text {máx }} & \end{array}$ 


\section{LISTA DE SÍMBOLOS}

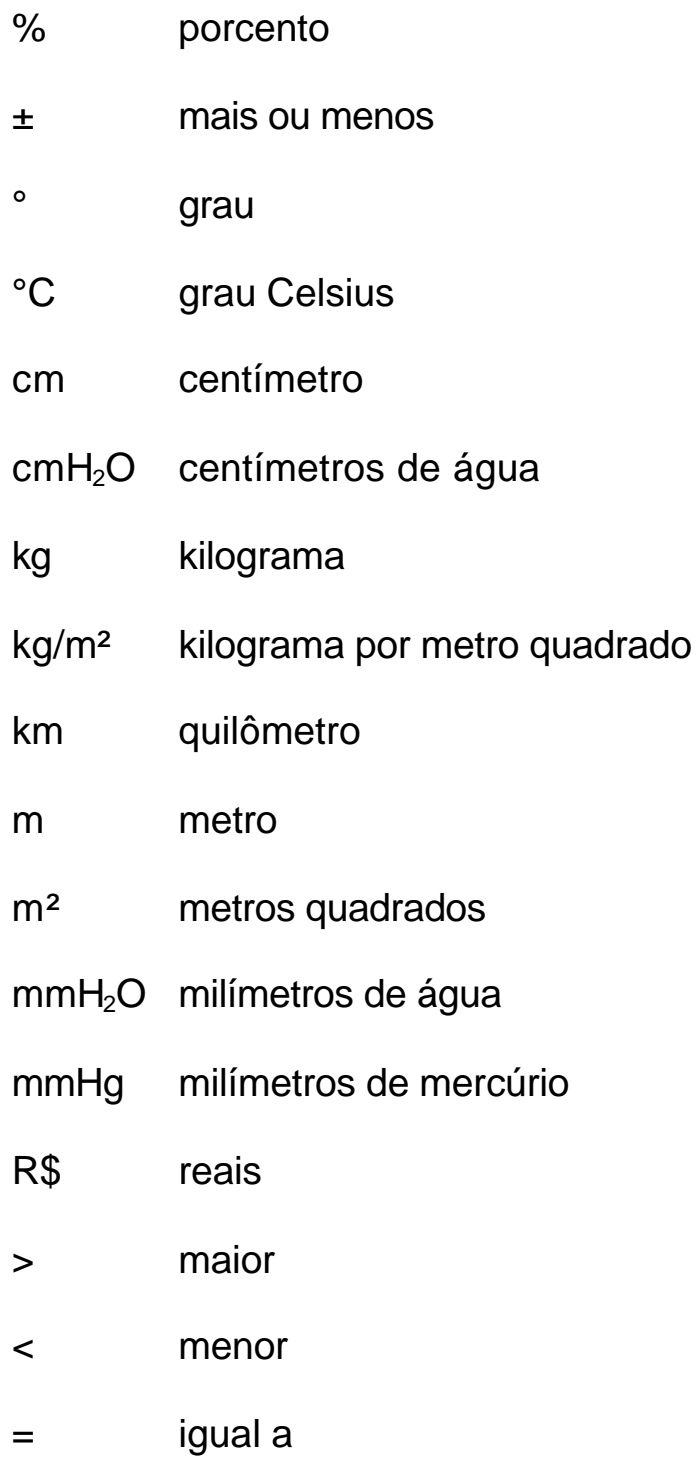




\section{RESUMO}

Ide MR. Estudo comparativo do efeito de um protocolo de cinesioterapia respiratória desenvolvido em dois diferentes meios, aquático e terrestre, na função respiratória de idosos [dissertação]. São Paulo: Faculdade de Medicina, Universidade de São Paulo; 2004. 148p.

O envelhecimento populacional é uma preocupação governamental. Conduz a perdas fisiológicas sistêmicas, incluindo prejuízos respiratórios. Observa-se um maior investimento em prevenção, menos dispendioso e socialmente mais viável que intervenções terapêuticas. A cinesioterapia é um recurso fisioterapêutico muito utilizado, mas conta com pouco embasamento científico, principalmente quando relacionada à prevenção em idosos e em meio aquático. Este estudo objetivou analisar os efeitos de um protocolo de cinesioterapia respiratória sobre a força muscular respiratória, expansibilidade torácica e flexibilidade de tronco/pélvis em idosos saudáveis, além de verificar os efeitos do meio de realização sobre o mesmo. Completaram o estudo 59 sujeitos com idades entre 60 e 65 anos, não fumantes nem praticantes de atividade física regular. Foram submetidos à avaliação da força muscular inspiratória e expiratória, expansibilidade torácica e flexibilidade e randomizados em três grupos. $O \mathrm{G}_{1}$ foi submetido a um protocolo de cinesioterapia respiratória em ambiente aquático. $\mathrm{O} \mathrm{G}_{2}$ utilizou o mesmo protocolo em ambiente terrestre. $\mathrm{O}_{3}$ atuou como controle. Os protocolos foram aplicados três vezes por semana, por dez semanas consecutivas. Após este período, os sujeitos foram reavaliados e os resultados comparados com os obtidos pré-intervenção e entre os grupos. A força muscular respiratória e expansibilidade torácica foram analisadas utilizando o teste t-student para amostras pareadas e através do teste do Sinal. A comparação entre os grupos utilizou a variância paramétrica e não paramétrica e o teste de Dunnett para comparar $\circ G_{1}$ e $G_{2}$ versus $G_{3}$. A flexibilidade foi analisada a partir da análise de covariância. Adotou-se um nível de significância de $5 \%$. A força inspiratória apresentou melhora significativa no $\mathrm{G}_{1}$ em relação ao $\mathrm{G}_{3}$, sugerindo efeitos mediados pelo meio aquático. Entretanto, esta análise deve ser cuidadosa, visto que a relevância estatística foi alcançada com o auxílio de uma não explicada redução nos escores do $\mathrm{G}_{3}$. Em relação à expansibilidade torácica, somente o $\mathrm{G}_{1}$ apresentou melhora significativa quando comparado com seus próprios escores pré-intervenção. Porém, estas alterações não foram relevantes se comparadas ao $\mathrm{G}_{3}$. A força expiratória e a flexibilidade de tronco/pélvis não sofreram alterações. Conclui-se que a cinesioterapia respiratória realizada em meio aquático melhora a força muscular inspiratória de idosos saudáveis. Entretanto, não influencia a força expiratória nem a flexibilidade de tronco/pélvis, independente do meio de realização. Apesar da significativa melhora obtida pelo $G_{1}$, a expansibilidade torácica não sofreu alteração estatisticamente significativa.

Descritores: 1.IDOSO/fisiologia 2.ENVELHECIMENTO/fisiologia 3.TESTES DE FUNÇÃO RESPIRATÓRIA 4.ENSAIOS CONTROLADOS ALEATÓRIOS 5.TERAPIA POR EXERCÍCIO/métodos 6.FISIOTERAPIA/métodos 7.HIDROTERAPIA/métodos 


\section{Summary}

Ide, MR. Comparative effects of a respiratory exercise protocol developed in two different ways, aquatic and terrestrial, in the respiratory function of elderly.

[dissertation]. São Paulo: "Faculdade de Medicina, Universidade de São Paulo"; 2004. $148 p$.

Aging of the worldwide population is a governmental concern. It causes physiological alterations, including pulmonary damages. It is observed plus attention to prevention, less expensive and socially more viable than therapeutic interventions. The respiratory exercise is very used resource, but it does not count on with consistent scientific basement, mainly when related to the preventive aspect in aged and involving the aquatic way. This study intends to analyze the effect of a protocol of respiratory exercises on the respiratory muscle strength, thoracic mobility and flexibility of trunk/pelvis in healthful aged. It also intends to verify the effect of the way of accomplishment of the protocol. Fifth-nine subjects between 60 and 65 years, not smoking nor practicing of regular physical activity had completed the study. They had their inspiratory and expiratory muscle strength, thoracic mobility and flexibility measured and they were randomized in three groups. The $G$ was submitted to a protocol of respiratory exercise in aquatic environment. The $G_{2}$ did the same protocol, but in the earth. The $G_{3}$ acted as control. The protocols had been applied three times a week, for ten consecutive weeks. After this, the subjects had been reevaluated and the results were compared with their own result before the exercises and between the groups. The respiratory muscle strength and thoracic expansibility were analyzed using paired t-test and Sign test. The comparison between the groups used parametric and non-parametric variance and Dunnett test to compare $G_{1}$ and $G_{2}$ versus $G_{B}$. Flexibility were analyzed using covariance analyze. A significance level of $5 \%$ was adopted. Inspiratory force improve comparing $\mathrm{G}$ and $\mathrm{G}_{3}$, suggesting effect mediated by the aquatic way. However, this analysis must be careful, since that the statistics relevance was reached with help of an unexplained reduction in the $G_{6}$. In relation to the thoracic expansibility, only G1 showed significant improvement. However, these excellent alterations had not been significant if compared with the control. The expiratory muscle force and flexibility of trunk/pelvis had not been modified. One concludes that the respiratory exercise improves the inspiratory muscle strength of aged healthful. However, it does not influence the expiratory force nor the flexibility of trunk/pelvis, independent of the way of accomplishment. Despite the significant improvement gotten for the G1, the thoracic expansibility did not suffer significant statistic alteration.

Keywords: 1.AGED/fisiology 2.ELDERLY/fisiology 3.RESPIRATORY FUNCTION TESTS 4.RANDOMIZED CLINICAL TRIAL 5.THERAPY BY EXERCISES/methods 6.PHYSICAL THERAPY/methods 7.HYDROTHERAPY/methods 


\section{INTRODUÇÃO}

O envelhecimento populacional é um fenômeno observado há muitos anos em países desenvolvidos. A partir dos anos 80 , este fenômeno tem destaque também em grande parte dos países do mundo (OMS, 1984), inclusive no Brasil, que se destaca por uma das maiores taxas mundiais de crescimento no número de idosos (Berquó, 1996).

O processo de envelhecimento desencadeia no indivíduo uma série de alterações fisiológicas, sendo as primeiras detectadas ao fim da terceira década de vida. Geralmente são discretas e progressivas, não causando insuficiência absoluta em nenhum órgão (Jacob Filho e Souza, 2000). As alterações são observadas em todos os sistemas do organismo, sendo que as principais alterações funcionais que afetam o desempenho físico são a perda de força muscular (Arabadjis et al., 1990) e a redução da amplitude de movimentos articulares (Payton e Poland, 1983).

O sistema respiratório sofre amplas modificações fisiológicas. Acredita-se que o declínio do sistema cardiorespiratório inicie-se aos 20 (Payton e Poland, 1983) e acelere após os 70 anos (Griffith et al., 2001). Observa-se uma redução na elasticidade pulmonar, além da fusão das articulações sinoviais entre o esterno e cartilagens costais. As alterações do envelhecimento na coluna vertebral culminam em aumento na cifose torácica, o que leva a um prejuízo biomecânico aos músculos respiratórios (Hilmann, 1982). Estas alterações culminam em redução na força muscular respiratória, ventilação voluntária máxima, volume de reserva inspiratória e expiratória e trocas gasosas. Observa-se ainda um aumento no volume residual.

As mudanças na função pulmonar relacionadas com a idade são clinicamente relevantes, visto que uma função pulmonar precária é associada a taxas elevadas de mortalidade (Santana et al., 2001). Azeredo (2002) cita que quadros de fraqueza ou 
fadiga muscular podem contribuir de maneira significativa para a presença de falência respiratória, seja ela crônica ou aguda. A fadiga inspiratória pode ainda limitar a capacidade de exercício, sobretudo em sujeitos com doença pulmonar obstrutiva crônica (DPOC) (Pryor e Webber, 2002). É considerada também uma das maiores causas não anestésicas da indicação de suporte ventilatório mecânico (Azeredo, 2002) e pode levar a dispnéia (Pryor e Webber, 2002).

Sekizawa (1998) cita que as doenças respiratórias afetam grande parte da população de idosos, podendo estar associadas ao ciclo disfunção-doença - o quadro clínico se inicia devido a uma disfunção física, tendo como conseqüência uma doença - ou ser intercorrência clínica comum em vários quadros clínicos. Trabalhos envolvendo a população americana mostram que as doenças respiratórias ocupam o sexto lugar entre as doenças associadas com perda de habilidades e independência. Ressalta-se ainda que todas as doenças com lugar de destaque nestas listagens como patologias cardíacas (infarto, hipertensão, insuficiência cardíaca), acidente vascular encefálico e reumatopatias - podem ter como complicação clínica-funcional desordens pulmonares. Além disso, patologias com menor relação à perda de habilidade e independência - como câncer, fraturas e diabetes - também podem estar associadas a patologias respiratórias (Ferrucci et al., 1996). Quando se realiza um tratamento visando implementar a função respiratória, invariavelmente se melhoram as condições osteomioarticulares do tronco e a bomba de retorno venoso, o que reflete em melhora na maioria dos quadros clínicos acima citados (Sekizawa, 1998).

Estudos relatam a relação entre uma função pulmonar deficitária e um aumento na mortalidade por todas as causas. Esta relação parece persistir mesmo quando há influência do tabagismo. Apesar das DPOCs causarem apenas uma pequena fração de morte na população geral, a associação com mortalidade total não tem causa de explicação óbvia. Pode ser devido a fator de confusão, pois a função pulmonar 
precária pode ser um sinal de outras doenças que levam a morte ou pode ser um indicativo do papel causal no desenvolvimento e progressão de doenças não respiratórias (Sorlie et al., 1989).

Com base na alta incidência de internações e mortes decorrentes de patologias respiratórias, principalmente no inverno, observa-se grande interesse das entidades governamentais mundiais, inclusive brasileiras, no controle e prevenção de doenças respiratórias na população idosa. Atitudes como a "Campanha Nacional de Vacinação do Idoso", vinculada desde há quatro anos pelo governo federal no primeiro semestre de cada ano, mostram a preocupação do governo com o impacto dos problemas respiratórios em sujeitos de idade avançada. Somente em 2002 foram investidos $R \$$ 77,7 milhões neste programa, que entre outras vacinas disponibilizou a que imunizou idosos acima de 60 anos contra a gripe (Fundação Nacional de Saúde, 2002). Gross et al. (1995) comprovaram a eficiência da vacina contra a gripe para idosos acima de 65 anos, com redução do risco de hospitalização, pneumonia e mortalidade. Gutierrez et al. (2001) concluíram ainda que a vacina contra influenza reduz o número de episódios caracterizados como gripe. Campanhas como esta mostram que a tendência é que se invista em prevenção, visto que o tratamento e reabilitação são comprovadamente mais dispendiosos.

Entretanto, as pesquisas relacionadas ao exercício do aparelho respiratório quase sempre abordam patologias respiratórias crônicas e cuidados com sujeitos em terapia intensiva, restritos ao leito ou confinados à residência. Poucos estudos dedicam-se a população idosa considerada normal. Embora seja difícil estabelecer limites entre alterações fisiológicas e patológicas na população idosa, acredita-se que o idoso saudável seja aquele ativo que não apresente complicações cardiorespiratórias e osteomioarticulares que afetem sua independência. $O$ idoso 
saudável é ativo na comunidade, realiza suas atividades independentemente, inclusive alimentação, higiene e vestuário.

A cinesioterapia respiratória é uma modalidade fisioterapêutica voltada ao sistema pulmonar que utiliza exercícios principalmente de tronco e membros superiores, associados a incursões e movimentos respiratórios. Atualmente é muito utilizada em programas de prevenção e/ou reabilitação. Entretanto, como grande parte dos recursos de nossa profissão, a cinesioterapia respiratória não conta com embasamento científico sólido, necessitando maior quantidade de estudos que comprovem seus reais efeitos. A falta de embasamento científico é particularmente evidente quando os exercícios respiratórios são aplicados com fins preventivos na população idosa e o meio de desenvolvimento dos exercícios não é terrestre.

A comparação entre os ambientes aquático e terrestre visa buscar evidências sobre os efeitos do meio na efetividade do tratamento. $O$ ambiente aquático apresenta inúmeras vantagens quando comparado ao ambiente terrestre. Grande parte delas são mediadas pelos efeitos fisiológicos do meio, advindos principalmente dos efeitos térmicos e mecânicos da água. Os efeitos térmicos permitem que o exercício seja realizado sobre a ação do calor, favorecendo a complacência dos tecidos moles e articulações. Os efeitos mecânicos, particularmente a pressão hidrostática e o empuxo, induzem o sistema respiratório a trabalhar sob constante sobrecarga. Apesar do aumento observado na quantidade de estudos e sucessos terapêuticos relacionados ao meio aquático, trabalhos envolvendo a população idosa saudável dificilmente são encontrados.

Diferente da cinesioterapia respiratória ativa livre, o exercício respiratório resistido é uma modalidade de cinesioterapia respiratória comum na literatura. A maioria dos estudos utiliza incentivadores inspiratórios ou outros aparatos que causem resistência ao fluxo aéreo para melhorar a força e/ou "endurance" da musculatura respiratória - 
particularmente a inspiratória. São encontrados poucos trabalhos que mencionem a cinesioterapia respiratória realizada de maneira fisiológica, com inspirações e expirações sem carga externa. Desconhecem-se trabalhos que observem os efeitos destes programas na expansibilidade torácica e flexibilidade de tronco e pélvis, particularmente em indivíduos que já enfrentam conseqüências do envelhecimento.

Assim, uma possibilidade preventiva de baixo custo, que possibilite melhora nos parâmetros relacionados ao sistema respiratório - como força muscular respiratória, mobilidade e expansibilidade torácica - de idosos poderá ser de grande valia, uma vez que um sistema respiratório mais eficiente poderia prevenir ou otimizar a recuperação frente a patologias respiratórias comuns nesta população, como as pneumonias. Doença infecciosa, a pneumonia é a patologia mais freqüente na população idosa e maior causa de morte por infecção na idade avançada (Crausman, 2001).

Diversos e renomados trabalhos citam a espirometria como técnica de avaliação da função respiratória. Entretanto, este trabalho utilizou testes simples como cirtometria, mensuração das pressões expiratórias máximas e avaliação fotográfica da flexibilidade. A espirometria é um método bastante confiável e realizável por clínicos e fisioterapeutas, porém caro, e por isso dificilmente repetido a curtos intervalos de tempo. Talvez até por falta ou desconhecimento de outras opções, não raro é utilizado para a tomada de decisões essencialmente fisioterapêuticas, embora se trata de um parâmetro médico. Deste modo, procurou-se utilizar neste estudo parâmetros que sejam facilmente utilizados na prática clínica, com aparelhos de custo consideravelmente menor e com uma abordagem mais diretamente voltadas ao interesse fisioterapêutico.

Azeredo (2002) cita que quando alguma patologia afeta os músculos respiratórios, a função muscular só é reversível com o tempo, de modo que não se dispõe de tratamento médico específico até o momento. Tal fato leva a crer que novas 
modalidades terapêuticas precisam ser propostas e testadas, com o objetivo de auxiliar o organismo em sua recuperação após algum quadro patológico ou mesmo frente a alterações decorrentes do processo de envelhecimento.

Enfim, existe uma necessidade urgente de inovação, criatividade e abertura para novas idéias, com o objetivo de habilitar o idoso a aproveitar os seus últimos anos de vida com prazer (Reichel e Gallo, 2001).

\subsection{Objetivos}

\subsubsection{Gerais}

- Elaborar, aplicar e avaliar os efeitos de um protocolo de cinesioterapia respiratória na população entre 60 e 65 anos, desenvolvidos em diferentes ambientes aquático e terrestre.

\subsubsection{Específicos}

- Avaliar e comparar os efeitos de um protocolo de cinesioterapia respiratória (desenvolvido em dois diferentes meios - aquático e terrestre) na força muscular respiratória de idosos entre 60 e 65 anos.

- Avaliar e comparar os efeitos de um protocolo de cinesioterapia respiratória (desenvolvido em dois diferentes meios - aquático e terrestre) na expansibilidade torácica de idosos entre 60 e 65 anos.

- Avaliar e comparar os efeitos de um protocolo de cinesioterapia respiratória (desenvolvido em dois diferentes meios - aquático e terrestre) planejado para 
exercitar a amplitude de movimento da caixa torácica e força muscular respiratória na flexibilidade anterior de tronco e pélvis em idosos entre 60 e 65 anos. 


\section{ENVELHECIMENTO}

O envelhecimento tem várias definições, dadas por diversos pontos de vista. Biologistas definem este processo como um conjunto de alterações experimentadas por um organismo vivo, do nascimento à morte. Sociólogos e psicólogos chamam atenção para o fato de que, além das alterações biológicas, processos de desenvolvimento social e psicológico de um indivíduo e alterações funcionais podem ser observados (Papaléo, 2002). Timo laria (1996) coloca ainda que o envelhecimento pode ser compreendido como um conjunto de alterações estruturais e funcionais do organismo, que se acumulam de forma progressiva, especificamente em função da idade.

A maioria da literatura relacionada ao assunto considera idoso o indivíduo a partir dos 65 anos. Entretanto, a Organização das Nações Unidas considera que em países em desenvolvimento, nos quais a expectativa de vida é menor, é considerado idoso o sujeito com mais de 60 anos (Papaléo, 2002).

O aumento da proporção de idosos na população mundial é uma realidade que movimenta diversos setores governamentais. A partir dos anos 80 , o envelhecimento populacional tornou-se um fenômeno que atingiu grande parte do mundo, tanto países desenvolvidos quanto em desenvolvimento (OMS, 1984).

A partir da década de 60, o Brasil experimentou o declínio da fecundidade em algumas regiões mais desenvolvidas do Brasil, declamando o início de um processo de envelhecimento populacional. O índice de envelhecimento da população (relação entre número de sujeitos maiores que 64 anos pelo número de indivíduos menores de 15 anos) saltou de 6,4 em 1960 para 13,9 em 1991 (Chaimowicz, 1997).

Segundo Berquó (1996), a população brasileira acima de 65 anos atingiu, em 1991, mais de sete milhões de pessoas. Estima-se que tal população atinja 32 milhões 
em 2025 (Kalache et al., 1987). No período de 2000 a 2050 deverá ser observado um aumento de $5,1 \%$ para $14,2 \%$ na proporção de idosos (Chaimowicz, 1997) e entre 2010 e 2030, a população mundial de idosos deve crescer em torno de 75\% (Bellanti et al., 2000), de modo que a questão da terceira idade emerge como problema para investigação e planejamento de políticas públicas e de saúde, em razão do inevitável crescimento de demanda ao sistema de saúde (Veras et al., 1987). Somando-se a isso, o declínio na mortalidade entre idosos tem contribuído substancialmente para ganho na expectativa de vida, o que aumenta ainda mais a proporção de indivíduos idosos (Pierce, 1996).

Programas de saúde voltados à população idosa, com o objetivo de amenizar as limitações orgânicas e psicossociais decorrentes do envelhecimento, são amplamente incentivados. Eles contribuem para a qualidade de vida desta população, reduzem o índice de infecções decorrentes de disfunções e a sobrecarga econômica no sistema de saúde (Meyers, 1989).

O impacto futuro do envelhecimento populacional no sistema de saúde e na sociedade em geral se deverá em grande parte a perda funcional, perda de independência e necessidade de cuidados a longo prazo dos indivíduos com idade avançada (Guralnik et al., 1993). Os órgãos de saúde pública priorizam identificar fatores que não somente influenciem a longevidade, mas também mantenham a independência e bom estado funcional (Pierce, 1996). Guralnik et al. (1993) citam que alguns fatores podem limitar as atividades do idoso e serem preditivos de perda de independência na senescência, como aumento na idade, renda precária, patologias crônicas e baixo nível educacional. 


\subsection{Exercício físico geral e envelhecimento}

O protocolo de exercícios propostos neste trabalho é visivelmente voltado a melhorar a função respiratória. Entretanto, trata-se de um programa de exercícios em grupo, o qual não deixa de atuar sobre diversos sistemas. Além disso, acredita-se que o programa também atuou sobre o bem-estar e outras variáveis psicossociais dos indivíduos atendidos.

A prática de atividade física é reconhecida como responsável por grande número de benefícios fisiológicos e psicológicos para a saúde. Outro aspecto interessante é a promoção do convívio social do indivíduo, reduzindo as alterações psicossociais como ansiedade e depressão - comuns nesta idade (Teixeira, 1996). Vários estudos documentam os efeitos psicológicos do exercício. Stamford (1973) apud Payton e Poland (1983) encontraram diferenças significativas em dois dos quatro testes comumente utilizados pela psicologia em sujeitos institucionalizados depois de um programa de 12 semanas de exercício.

Além disso, Fried et al. (1994) remetem a um fato simples, mas que altera a perspectiva da prevenção de disfunções decorrentes do envelhecimento: as perdas morfológicas e funcionais nos vários sistemas ocorrem em velocidade e intensidade diferentes, mas de forma simultânea. Desta forma, um programa de prevenção de disfunções para idosos deveria desenvolver a capacidade de vários órgãos e sistemas concomitantemente (Caromano, 1998; Rauchbach, 1990; Fried et al., 1991; Devons, 2002).

\footnotetext{
* Stamford BA. Effects of chronic institutionalization on the physical working capacity \& trainability of geriatric men. Journal of Gerontology, 1973;28:441-6.
} 


\subsubsection{Aspectos preventivos do exercício no idoso}

A prática de exercício físico é uma medida de prevenção primária em idosos (Murphy e Cicilline, 2001). Conceituados órgãos relacionados com a saúde, como o "American College of Sports Medicine" e a Organização Mundial de Saúde, indicam a prática regular e contínua de atividade física, visando resguardar a qualidade de vida, a socialização e a autonomia dos idosos (Dipietro e Dziura, 2000).

Os exercícios físicos preventivos têm por objetivos manter a independência do idoso e maximizar o desempenho funcional (Rosemond e Mercer, 2002). Tal atitude propicia a preservação ou recuperação parcial das funções orgânicas afetadas pelo envelhecimento, ao mesmo tempo em que auxilia na prevenção de patologias diversas (Astrand e Rodahl, 1980). O sedentarismo, ao contrário, induz a perdas na maioria dos sistemas orgânicos, compromete as habilidades motoras, deteriora a saúde (Mills, 1994) e aumenta o risco de morbidade e mortalidade decorrentes do desenvolvimento de doenças crônicas (Rego et al., 1990; Ramos et al., 1993).

Os tratamentos voltados à população idosa são classificados três categorias. A primeira aborda a prevenção e restauração de seqüelas de desuso em idosos saudáveis. A segunda, de prevenção e restauração de seqüelas em doenças crônicas ou agudas. A terceira, reabilitação de perdas funcionais causadas por trauma ou doença. O exercício é capaz de reverter muitos dos sintomas e prevenir grande parte das patologias na população idosa (Payton e Poland, 1983).

\subsubsection{Inatividade e vantagens da prática de atividade física}

A atividade física insuficiente é responsável por cerca de $30 \%$ de todas as mortes por cardiopatias, câncer de cólon e diabetes (McArdle et al., 1996). O exercício na 
idade avançada auxilia na melhora da função, contribui para o bem-estar, aumenta a expectativa de vida e pode auxiliar no cuidado com doenças cardiovasculares, hipertensão, diabetes, osteoporose, depressão e outras patologias (Morey et al., 1996). Mesmo naqueles que iniciam a atividade física entre os 60 e 75, o exercício regular reduz a mortalidade por todas as causas (Brennan, 2002).

Cerca de 24\% dos indivíduos acima de 60 anos nos EUA são sedentários. Aproximadamente 54\% exercitam-se em níveis sub-ótimos. Estima-se que $42 \%$ dos homens e mulheres entre os 60 e 69 anos estão acima do peso (Brennan, 2002).

Quatro principais fatores podem levar a limitações na atividade física: restrição da atividade neuromuscular, imobilização física, posicionamento estático em relação à gravidade e privação sensorial. A imobilização total resulta em perda de força muscular de aproximadamente $3 \%$ ao dia, ou 18 a $20 \%$ por semana. Apesar da força e resistência serem obviamente influenciados pela imobilidade, os efeitos deletérios também são aplicados sobre outros sistemas, como o cardiovascular, respiratório e nervoso. Também ocorre redução na concentração de cálcio ósseo, que necessita de um tempo muito maior para que retorne aos níveis normais após a cessação da imobilidade (Payton e Poland, 1983).

As vantagens da prática de exercícios físicos para idosos dependem de como se processa o envelhecimento e da rotina praticada. Sabe-se que os benefícios à saúde ocorrem mesmo quando a prática é iniciada em uma fase tardia da vida, por sedentários ou portadores de patologias crônicas (Morey et al., 1996).

Os exercícios físicos são correlacionados a prevenção e/ou melhora do quadro clínico de algumas das principais doenças associadas ao sedentarismo, como coronariopatias, diabetes, hipertensão arterial, hipercolesterolemia, acidente vascular cerebral, osteoporose, osteoartrite e câncer de próstata, mama e cólon intestinal (Blair e Conelly, 1996) e infeções (Sekizawa, 1998). 
A prática de exercícios físicos reduz o risco de doenças coronarianas, pela melhora na capacidade cardiopulmonar, circulação miocárdica, metabolismo cardíaco e aprimoramento das propriedades mecânicas do coração. Além disso, atua sobre os fatores de risco para patologias como hipertensão arterial, alteração dos níveis plasmáticos de glicose e insulina, obesidade e anormalidades no perfil lipoprotéico (Astrand e Rodahl, 1980; Faludi et al., 1996; McArdle et al., 1996).

Diversos estudos apontam os benefícios potenciais do condicionamento para indivíduos idosos. Um estudo realizado por Sheldahl e colaboradores (1993) comparou dois grupos em relação a respostas a um programa de exercício aeróbico. O primeiro grupo era composto por 13 indivíduos de meia idade, entre 35 e 50 anos. O segundo, por 14 idosos com idades entre 60 e 71 anos. Os grupos foram submetidos a treino com bicicleta ergométrica e "stepper" três vezes por semana, por seis meses. Os resultados mostraram que as adaptações em resposta ao exercício aeróbico foram semelhantes nos dois grupos. Os idosos apresentaram ainda maior interesse no programa de exercícios proposto.

Os benefícios do exercício aeróbico são amplamente divulgados, em sujeitos de todas as idades. Há indicativos de que o treino leve a adaptações mais lentas na população idosa. Entretanto, não é claro se isso se deva a uma taxa mais lenta de adaptação ao treino ou a um aumento mais gradual na intensidade dos exercícios, que é observado quando o programa é dirigido à população idosa (Sheldahl et al., 1993).

Quanto ao sistema neuromotor, sabe-se da possibilidade de aprendizagem de novas habilidades motoras e até a recuperação parcial ou total de habilidades perdidas (Payton e Poland, 1983). As alterações neuromotoras aumentam o risco de quedas e fraturas em idosos. Por tratar-se de graves problemas de saúde, a maioria dos programas de reeducação motora enfatiza o treinamento dos membros inferiores (Mor et al., 1989; Guralnik et al., 1993). 
O bem-estar depende de fundamentos como a capacidade de liberdade e movimentos confortáveis. A redução na mobilidade geral interferem claramente na população idosa, debilitando atividades simples de vida diária. Sabe-se que o declínio na capacidade aeróbica decorrente do envelhecimento também contribui para este decréscimo na mobilidade. Para a maioria dos indivíduos saudáveis, o exercício é a mais importante e efetiva intervenção para corrigir alterações relacionadas a mudanças músculoesqueléticas decorrentes da idade (Buckwalter, 1997).

A identificação precoce e com exatidão da fraqueza muscular é particularmente importante, pois, segundo Stuberg e Metcalf (1988), até $50 \%$ da força muscular pode ser perdida antes mesmo de ser detectada a presença de dificuldades nas atividades da vida diária (Kendall et al., 1995). É vital que se faça distinção entre mudanças fisiológicas e patológicas no músculo em envelhecimento, com o objetivo de se organizar programas de reabilitação que se adaptem às necessidades do idoso (Thompson, 1994).

De modo geral, a melhora da função músculoesquelética consiste na normalização da relação entre a tensão e o comprimento dos músculos, aumento no suprimento sangüíneo, melhora do metabolismo muscular, aumento da deposição de sais de cálcio ao longo das linhas de tração e compressão dos ossos envolvidos com a atividade física e aumento na capacidade dos ligamentos e tendões se submeterem à força de tensão. Essas modificações melhoram a qualidade da contração muscular, resistência óssea e organização do equilíbrio, postura e marcha (Thompson, 1994). 


\subsubsection{Vantagens do exercício físico sobre o sistema respiratório}

O sistema respiratório também é afetado pela imobilidade. A redução da mobilidade diminui os movimentos respiratórios, excreção de gases e leva a distúrbios nas trocas gasosas (Payton e Poland, 1983).

Os músculos ventilatórios são beneficiados diretamente por um programa de exercícios gerais. Essa função aprimorada pode ser atribuída parcialmente ao aumento nos níveis de enzimas aeróbicas e capacidade oxidativa que se observa nos músculos ventilatórios com o treinamento (McArdle et al., 1996). Estudos comprovam os efeitos do exercício nas fibras do músculo diafragma. Mostraram que exercícios de "endurance" aumentam a capacidade oxidativa das fibras tipo I e Ila da parte costal deste músculo (Powers et al., 1992; Powers et al., 2000). Concluíram também que o número de células diminuiu e a quantidade de capilares sangüíneos aumentou nas fibras tipo I, Ila e Ilb. O exercício não alterou os tipos de fibras do diafragma (Powers et al., 1992).

Com o exercício, observa-se também uma maior capacidade dos músculos inspiratórios gerarem força e sustentarem um determinado nível de pressão inspiratória após o treinamento. Isto poderia reduzir as sensações de desconforto pulmonar local e dispnéia, observadas freqüentemente em indivíduos destreinados durante um exercício prolongado. Uma "endurance" aprimorada dos músculos ventilatórios, combinada a uma menor necessidade ventilatória para o exercício submáximo obtida com o treinamento, retardaria o início da fadiga diafragmática observada freqüentemente no exercício, tanto a curto quanto longo prazo (McArdle et al., 1996).

A fadiga nos músculos inspiratórios pode ocorrer como resultado do exercício prolongado de alta intensidade. Apesar do treinamento com exercícios exercer pouco 
efeito sobre a função pulmonar estática e dinâmica, ele é benéfico para aprimorar a capacidade individual de sustentar altos níveis de ventilação submáxima (McArdle et al., 1996).

Não se sabe se o exercício regular praticado durante toda a vida do indivíduo consegue compensar plenamente o envelhecimento da dinâmica pulmonar. Entretanto, o treinamento aeróbico em idosos aumenta a cinética da permuta gasosa até um nível que se aproxima dos valores obtidos por jovens e aptos. Idosos que realizam treino de "endurance" apresentam melhor capacidade funcional que idosos sedentários. Além disso, achados relacionados a parâmetros espirométricos levam a crer que a prática de atividade física regular pode retardar o declínio da função pulmonar relacionada ao envelhecimento (McArdle et al., 1996).

Um estudo realizado por Neder e colaboradores (2003) selecionou 120 indivíduos sedentários entre 20 e 80 anos de idade. Os sujeitos foram divididos em três grupos, de acordo com a faixa etária. Foram avaliados diversos parâmetros relacionados ao sistema respiratório, como volume corrente, tempo inspiratório, expiratório, capacidade inspiratória de repouso, dentre outras. O envelhecimento e o sexo feminino estiveram associados com um padrão respiratório taquipnéico. O declínio no tempo respiratório total foi proporcional a redução no tempo inspiratório e expiratório. O presente estudo indica que os menores volumes disponíveis para a inspiração tem um profundo efeito sobre o padrão respiratório durante o exercício em idosos e mulheres. Apesar do padrão respiratório rápido e superficial ter a capacidade de reduzir o pico de esforço inspiratório e, conseqüentemente, a sensação de esforço respiratório, este padrão induz a níveis aumentados de ventilação do espaço morto anatômico, isto é, uma menor eficiência ventilatória.

O efeito do envelhecimento nos ajustes da mecânica respiratória que ocorrem durante o exercício dinâmico tem sido extensamente descritos. Um padrão respiratório 
mais superficial é particularmente deletério para idosos, que caracteristicamente exibem um alargamento do espaço morto. Estudos prévios mostram que o volume pulmonar ao final da expiração durante o exercício aumenta com a idade (Neder et al., 2003).

Independente do programa de exercício físico, a manutenção da prática é fundamental para a permanência dos seus benefícios, o que deve ser considerado durante a organização e administração dos exercícios (Sheldahl et al., 1993; Williams e Lord, 1995; Caromano, 1998; Devons, 2002).

\subsection{Alterações fisiológicas sistêmicas do envelhecimento}

As modificações que ocorrem nos diversos sistemas levam a uma redução da reserva funcional, o que compromete a manutenção da homeostasia, e conseqüentemente a capacidade de adaptação às modificações do meio externo e/ou interno (Jacob Filho e Souza, 2000).

As principais alterações funcionais que afetam o desempenho físico são a perda de força muscular (Arabadjis et al., 1990) e a redução da amplitude de movimentos articulares (Payton e Poland, 1983). Associadas às alterações ósseas e articulares e/ou dos tecidos moles, estas alterações promovem modificações no posicionamento dos segmentos corporais, durante a sustentação do corpo em bipedestação e marcha (Daniels e Worthingham, 1981) e, posteriormente, na biomecânica respiratória (Tolep e Kelsen, 1983).

Com o avançar da idade também ocorre declínio na capacidade aeróbica. Esta perda relaciona-se a limitações no sistema cardiopulmonar e pode ser observada pela redução da freqüência cardíaca máxima a ser atingida durante atividades musculares, expressa pela relação "220 menos a idade em anos" (McArdle et al., 1996) e pelo 
aumento da freqüência cardíaca de repouso. Esta última pode estar associada à redução do volume de ejeção cardíaco e conseqüentemente do débito cardíaco (produto entre o volume de ejeção e a freqüência cardíaca). A pressão sangüínea aumenta, principalmente a sistólica. A capacidade de perfusão sangüínea periférica fica reduzida (Hagberg, 1985). Estas alterações diminuem a capacidade de resposta ao estresse físico e mental (Payton e Poland, 1983). Segundo Fielding (1995), o consumo máximo oxigênio $\left(\mathrm{VO}_{2 \text { máx }}\right)$ em indivíduos sedentários declina $1 \%$ a cada ano após a terceira década de vida e a força muscular dinâmica e isométrica sofrem reduções significativas após a quinta década.

Ocorrem alterações evidentes na composição do corpo, com o aumento do tecido adiposo que tende a se depositar nos omentos, região perirrenal e em substituição ao parênquima perdido dos diversos órgãos. No tecido celular subcutâneo, diminui o tecido adiposo nos membros e aumenta no tronco (Jacob Filho e Souza, 2000).

Os prejuízos mais comuns das funções motoras do idoso são a redução nos movimentos, força muscular, força máxima e coordenação. Muito comuns na prática clínica, a atrofia e declínio da força muscular e dependência física ainda não têm causas e mecanismos totalmente conhecidos (Thompson, 1994).

As alterações fisiológicas no sistema cardiopulmonar decorrentes do envelhecimento na população idosa são grandes. Há um aumento na pressão sangüínea, que pode chegar a uma média de 96 a 110 mmHg em idosos normais a até $130 \mathrm{mmHg}$ em sujeitos com aterosclerose. Estas alterações acometem principalmente a pressão sistólica. O débito cardíaco decresce aproximadamente $0,7 \%$ a cada ano após os 20 anos de idade. Para se ter uma idéia do tamanho do impacto, basta comparar que o coração bombeia aproximadamente cinco litros de sangue por minuto aos 20 anos e apenas 3,5 litros aos 75 anos. A reserva cardíaca diminui, o que faz com o que o indivíduo perca progressivamente sua capacidade de responder ao 
estresse físico e psicológico. Também há redução no catabolismo lipídico, o que leva a acúmulo desta substância no organismo, predispondo a arterioesclerose (Payton e Poland, 1983).

A força muscular geral é mantida em níveis satisfatórios até os 50 anos. Nas próximas duas décadas, há uma queda de 15\% (Brennan, 2002). Paralelamente às intensas modificações físicas decorrentes do envelhecimento, após os 60 anos a massa corporal diminui, mesmo com o incremento do volume de gordura (Santana et al., 2001). Não se sabe o quanto a atividade física regular pode alterar a densidade do corpo, embora programas de treinamento a longo prazo pareçam mais eficientes (McArdle et al., 1996). Existe consenso sobre a influência da composição corporal no desempenho físico e pulmonar, sendo recomendado seu controle durante estudos que envolvam exercícios e o sistema pulmonar. 


\section{FUNÇÃO RESPIRATÓRIA}

A função respiratória é essencial ao ser humano. Um arcabouço morfofisiológico regula as trocas gasosas, através de uma intrincada rede bioquímica. Como todo o organismo, o sistema respiratório é afetado pelas conseqüências do envelhecimento fisiológico, podendo também sofrer perturbações patológicas. É impossível impedir com absoluta garantia o aparecimento destas perturbações. Entretanto, não é utópico dizer que ao se fortalecer todo o sistema respiratório diminuem-se as chances de que estas perturbações se instalem ou que sejam mais precoce e satisfatoriamente solucionadas.

\subsection{Morfofisiologia do sistema respiratório}

A principal função do sistema pulmonar é prover um meio de troca gasosa entre o ambiente e o corpo. Além disso, o sistema respiratório é importante na regulação do equilíbrio ácido-básico durante o exercício. O sistema respiratório conta com estruturas anatômicas como o nariz, cavidade nasal, faringe, traquéia, árvore brônquica e pulmões (Powers e Howley, 2000). Vértebras torácicas, discos intervertebrais, costelas, cartilagens costais e esterno formam o tórax, estrutura esquelética que protege órgãos vitais - como coração e pulmões - e alguns órgãos abdominais (Gardner et al., 1986).

O sistema pulmonar é constituído por um grupo de passagens que filtram o ar e o transportam aos pulmões, onde a troca gasosa ocorre no interior dos alvéolos. O ar entra na traquéia a partir da faringe, que recebe ar das cavidades oral e nasais. Em

geral, os humanos respiram pelo nariz até que a ventilação aumente a 
aproximadamente 20-30 litros por minuto, quando a boca passa a ser a principal via de passagem de ar. A troca gasosa nos pulmões ocorre através de cerca de 300 milhões de pequenos alvéolos. Estima-se que a área de superficial total disponível para a difusão num pulmão humano seja de 60-80 m² (Powers e Howley, 2000).

Os pulmões são envolvidos por um conjunto de membranas denominada pleura. A pleura visceral adere à superfície externa do pulmão, enquanto a parietal reveste a parede torácica e o diafragma. Essas pleuras são separadas por uma fina camada de líquido que atua como lubrificante, permitindo o deslizamento de uma pleura sobre a outra. A pressão na cavidade pleural (intrapleural) é inferior à atmosférica e se torna ainda mais baixa durante a inspiração, fazendo com o que o ar insufle os pulmões (Powers e Howley, 2000).

As propriedades elásticas do pulmão derivam de dois fatores: forças teciduais e de revestimento. Não há evidência de que o material que reveste o pulmão seja alterado com a idade. Entretanto, acredita-se que o tecido conectivo pulmonar sofre alteração com o passar dos anos e que qualquer redução na força de retração elástica no revestimento pulmonar seja secundário às mudanças teciduais e sua influência nas dimensões alveolares. A composição do tecido pulmonar é complexa, mas é predominantemente formada por elementos fibrosos. As fibras elásticas são mais importantes quando o pulmão está suportando volumes menores. Nos volumes mais altos, as fibras colágenas atuariam com sua inextensibilidade para frear amplitudes extremas que pudessem causar danos (Turner et al., 1968).

A ventilação é o movimento do ar do ambiente para os pulmões. Ocorre pela diferença de pressão entre as duas extremidades (Powers e Howley, 2000). Durante a respiração ao repouso, os músculos primários responsáveis pela inspiração são o diafragma e os intercostais externos. 
O diafragma é responsável por $2 / 3$ do volume corrente na posição sentada e em pé e 3/4 na posição supina (Shaffer et al., 1981). É constituído por duas partes de origem embrionária e ações distintas na caixa torácica. Deste modo, podem ser considerados músculos distintos, unidos a uma inserção comum - o centro tendíneo. Ambas partes se contraem empurrando as vísceras abdominais para baixo e para frente, causando aumento na pressão abdominal e deslocamento do conteúdo abdominal para baixo. A parte costal também expande a caixa torácica inferior, elevando as costelas para fora (Powers e Howley, 2000; Azeredo, 2002). Na respiração corrente normal, o diafragma move-se cerca de um centímetro, mais ou menos. Em inspiração e expiração forçadas, pode ocorrer uma excursão total de até $10 \mathrm{~cm}$ (McArdle et al., 1996). Estas ações reduzem a pressão intrapleural, o que provoca a expansão pulmonar. Esta expansão reduz a pressão intrapulmonar abaixo da pressão atmosférica, permitindo o fluxo de ar para o interior dos pulmões. Durante o exercício, a inspiração é auxiliada por músculos acessórios da inspiração (intercostais externos, escalenos, peitorais menores e esternocleidomastoídeos) (Powers e Howley, 2000).

O diafragma humano tem propriedades semelhantes ao músculo sóleo (contração lenta e resistência à fadiga), mas com propriedades intermediárias em relação a fibras rápidas e lentas. O diafragma possui ainda uma melhor capacidade oxidativa e habilidade de aumentar o fluxo sangüíneo em caso de sobrecarga ou exercício, quando comparado aos músculos dos membros (McKenzie e Gandevia, 1986).

Mudanças na pressão intramuscular local podem alterar a perfusão da musculatura inspiratória e influenciar a "endurance". Durante uma contração isométrica máxima, a circulação sangüínea dos membros é ocluída, efeito que não ocorre no 
diafragma por alterações na pressão pleural e abdominal (McKenzie e Gandevia, 1986).

Os músculos intercostais têm importante papel estabilizador da caixa torácica, prevenindo movimentos paradoxais e a distorção durante a inspiração diafragmática. Os escalenos agem elevando e expandindo a caixa torácica. São considerados motores primários quando estabilizam a caixa torácica superior, evitando movimentos paradoxais nessa região durante a inspiração. O esternocleidomastoídeo é acessório da respiração a volumes elevados ou quando há demanda ventilatória aumentada, como durante o exercício. Leva a deslocamento cranial do esterno e expansão da caixa torácica superior (Azeredo, 2002).

Entretanto, alguns autores provaram que estão ativos também em certas manobras inspiratórias. Além dos escalenos e esternocleidomastoídeos, outros músculos acessórios podem atuar na respiração vigorosa, como músculos da articulação do ombro e peitorais (Shaffer et al., 1981).

Os músculos respiratórios são músculos esqueléticos, semelhantes a outros músculos esqueléticos do organismo (Shaffer et al., 1981; Kim, 1984; Pardy et al., 1988). Constituem uma mistura de fibras tipo I, lla e Ilb. O diafragma contém $50 \%$ de fibras tipo I e 50\% tipo II. Durante o repouso, o trabalho é desenvolvido predominantemente por fibras tipo I. Aos esforços, são recrutadas as fibras tipo II (Pardy et al., 1988).

A expiração ao repouso é um processo passivo. Os pulmões e a parede torácica são elásticos e tendem a retornar à posição de equilíbrio após se expandirem na inspiração (Shaffer et al., 1981; Powers e Howley, 2000). Quando a respiração tornase vigorosa, como no exercício ou patologia respiratória, a expiração deixa de ser passiva. Os músculos intercostais internos e o reto abdominal contraem-se, aumentando a pressão intra-abdominal e pleural. O diafragma é empurrado para cima 
e as costelas são puxadas para baixo e para dentro, auxiliando a redução do volume pulmonar durante a expiração (Shaffer et al., 1981; Powers e Howley, 2000; Azeredo, 2002).

Kim (1984) cita que dentre os músculos respiratórios, os inspiratórios são considerados os mais importantes em termos de papel, fadigabilidade e treinamento. São ativados em todos os ciclos, não somente em casos de exercício e tosse, como os expiratórios. Todavia, tal posicionamento é controverso.

Azeredo (2002) cita que os músculos expiratórios podem também facilitar a inspiração devido a sua atividade tônica em ortostatismo, prevenindo o encurtamento do diafragma durante a inspiração e melhorando suas características na curva de comprimento-tensão. O autor coloca também que os músculos abdominais exercem importante papel nos músculos inspiratórios, apresentando atividade eletromiográfica tônica independente da fase de respiração em indivíduos normais na posição ortostática. Cálculos sugerem que, com diferentes cargas de resistência, 10 a 20\% do trabalho inspiratório são transferidas aos músculos expiratórios (Abbrecht et al., 1991).

Existem estudos realizados exclusivamente para comprovar a importância da musculatura expiratória na eficiência inspiratória. Abbrecht et al. (1991) expõem que durante o exercício extenuante há contração da musculatura expiratória, o que reduz o volume residual e permite que o diafragma opere em um comprimento mais vantajoso durante a inspiração. O recrutamento do músculo abdominal para aumentar a ventilação pode adiar ou prevenir o início da fadiga muscular inspiratória. 0 recrutamento da musculatura abdominal e conseqüente redução do volume residual pode ocorrer durante um treino com resistência ao fluxo inspiratório. Além disso, o recrutamento da musculatura expiratória pode auxiliar os músculos inspiratórios a aumentar sua força. 
Embora existam controvérsias, o sistema pulmonar geralmente não é considerado um fator limitante do exercício submáximo prolongado. A insuficiência muscular respiratória pode ocorrer em certas patologias, mas não se acredita que a fadiga da musculatura respiratória limite a capacidade de exercício de indivíduos saudáveis ao nível do mar (Powers e Howley, 2000).

O fluxo de ar através das vias áreas depende da resistência das mesmas. Esta resistência depende enormemente do calibre desta via, de modo que uma redução de $50 \%$ no calibre acarreta em um aumento de dezesseis vezes na resistência ao fluxo (Powers e Howley, 2000).

Os valores normais de função pulmonar e sua amplitude são calculados de acordo com sua idade, altura e peso. Também é relacionada ao tabagismo. Alguns autores colocam que há relação até mesmo com religião e raça (Roberts et al., 1991).

\subsection{Influência do peso corporal na função respiratória}

Aceito hoje como padrão de medida internacional e recomendado pela Organização Mundial de Saúde como indicador do estado nutricional (WHO, 1995), o índice de massa corpórea serve para identificar, da melhor maneira possível, o grau de obesidade de uma pessoa. Sua forma de cálculo é a divisão do peso (em kg) do indivíduo por sua altura ao quadrado (em m²). De uma maneira generalizada, o índice de massa corpórea estabelece padrões ideais de peso corporal, sendo considerado normal um quociente entre 18,5 e $24,99 \mathrm{~kg} / \mathrm{m}^{2}$, com pequenas variações para o sexo masculino ou feminino.

Sujeitos mal nutridos freqüentemente apresentam fraqueza de musculatura respiratória e músculos mais susceptíveis a fadiga, além de depressão do sistema 
imunológico, com risco aumentado de infecções. A obesidade leva a aumento no volume residual e redução na capacidade residual funcional (Pryor e Webber, 2002).

\subsection{Influência do envelhecimento na função respiratória}

A função pulmonar declina lentamente durante toda a vida adulta, mesmo em indivíduos saudáveis (Grimby, 1988; Griffith et al., 2001). Diversos fatores correlacionam-se com o declínio da função pulmonar, dentre eles o tabagismo moderado a intenso, exposições ocupacionais, hipersensibilidade de vias aéreas e desnutrição. Fatores que afetam o tamanho do pulmão também estão associados a uma redução discreta na função pulmonar, como altura, peso, tamanho da cintura e raça. Também foram associados com esta redução alguns marcadores de doença clínica - como tabagismo, hipertensão arterial sistólica e bronquite crônica - e patologias do coração ou pulmão, como pneumonia, asma, enfisema e insuficiência cardíaca congestiva. Homens idosos saudáveis têm perda na função pulmonar em uma taxa mais rápida (em termos absolutos) quando comparados com as mulheres idosas saudáveis (Griffith et al., 2001).

Todas as estruturas relacionadas à respiração alteram-se com o envelhecimento (Papaléo, 2002). Acredita-se que o declínio do sistema cardiorespiratório inicie-se aos 20 anos (Payton e Poland, 1983). Estudos transversais revelam que o declínio da função pulmonar acelera após os 70 anos (Griffith et al., 2001).

O envelhecimento altera toda a estrutura pulmonar. Os alvéolos sofrem discreta redução em sua superfície total. Os septos interalveolares rompem-se, fazendo que haja fusão alveolar (Jacob Filho e Souza, 2000; Papaléo, 2002). A área funcional do sistema respiratório disponível para trocas gasosas reduz-se $0,27 \mathrm{~m}^{2}$ ao ano (Payton e Poland, 1983). 
As paredes das vias aéreas tornam-se menos resistentes, predispondo ao colabamento expiratório. Há dilatação dos bronquíolos respiratórios, ductos e sacos alveolares, levando ao errôneo termo "enfisema senil" (Papaléo, 2002).

Um estudo realizado por Ware e colaboradores (1990) mostrou que há perda de cerca de $3 \mathrm{~cm}$ na altura dos 25 aos 75 anos. A altura é uma das variáveis usadas em estimar a função de pulmão e conseqüentemente as mudanças na altura relacionadas com a idade podem afetar significativamente a função pulmonar (Santana et al., 2001).

Devido às modificações nos mecanismos reguladores da respiração, sejam eles quimioceptores, centros de controle do sistema nervoso central e músculos efetores, verifica-se redução da resposta ventilatória às variações das pressões parciais de oxigênio e de gás carbônico no sangue (Jacob Filho e Souza, 2000; Papaléo, 2002).

Com o envelhecimento, desaparecem as articulações sinoviais entre o esterno e cartilagens costais. Elementos ósseos e cartilaginosos se fundem. Nos jovens, as cartilagens costais são constituídas por condrócitos e matriz uniforme, com fibras colágenas finas e proteoglicanas. Muitos condrócitos degeneram e as fibras colágenas se espessam, aumenta o depósito de cálcio e a cartilagem fica mais rígida. $\mathrm{O}$ manúbrio e o corpo do esterno são unidos por fibrocartilagem. Com a idade, esta fibrocartilagem pode desaparecer, unindo as duas partes ósseas (Jacob Filho e Souza, 2000; Papaléo, 2002).

A mobilidade da caixa torácica na respiração depende diretamente destas articulações. O envelhecimento reduz a complacência da caixa torácica, com conseqüente redução nas forças de tração da parede torácica. Todos estes fatores contribuem para a redução nas pressões inspiratória e expiratória máximas (Jacob Filho e Souza, 2000; Papaléo, 2002).

O idoso utiliza $70 \%$ da elasticidade total de sua parede torácica, enquanto um jovem utiliza apenas $40 \%$ do seu máximo (Turner et al., 1968). A redução na 
elasticidade, somada às modificações na morfologia torácica, que determinam a configuração do tórax senil ou "em barril", e a hipotrofia dos músculos esqueléticos acessórios da respiração, reduzem a capacidade de expansão da caixa torácica (Grimby, 1988; Papaléo, 2002).

O envelhecimento está associado ao declínio na complacência pulmonar e elasticidade pulmonar, com redução na eficiência e desempenho ventilatório (Turner et al., 1968; Neder, et al., 2003). Grande parte das alterações funcionais que ocorrem no aparelho respiratório são dependentes da redução na elasticidade pulmonar, que resulta em menor recolhimento expiratório (Grimby, 1988; Papaléo, 2002) e facilita o incremento do volume residual (Papaléo, 2002).

A redução na elasticidade pulmonar pode ser justificada pelo decréscimo na eficiência da elastina tecidual e complacência da parede torácica Payton e Poland, 1983; Papaléo, 2002). O aumento progressivo na elastina pulmonar decorrente do envelhecimento tem sido descrita por diversos autores, o que é exatamente o oposto do esperado quando se tem uma redução na pressão de recolhimento elástico. Entretanto, observa-se que a fórmula da elastina é alterada quimicamente com a idade, de modo que ela torna-se mais resistente a elastase (Turner et al., 1968). O sistema elástico é o componente do tecido conectivo responsável pela sua elasticidade. Distribui-se mais seletivamente que o colágeno, presente em maior quantidade nos tecidos e órgãos que sofrem tração e extensão, como pele, parede arterial e pulmões. Com o envelhecimento, ocorrem alterações nas fibras elásticas maduras. Observa-se aumento em sua quantidade, alteração na composição de seus aminoácidos, fragmentação e irregularidades de forma, além de depósitos de cálcio. Tais alterações determinam mudanças nas características funcionais das mesmas, ocasionando redução da elasticidade dos tecidos que as contêm (Papaléo, 2002). 
Na respiração espontânea, a complacência pulmonar aumenta com a idade. A complacência da parede torácica, ao contrário, diminui. Aos 20 anos, os sujeitos têm seus pulmões com menor complacência que a da parede torácica. Aos 60 anos, ocorre o contrário. Esta redução na complacência da parede torácica é maior que o aumento na complacência pulmonar, o que faz com que o sistema respiratório do idoso tenha uma menor potência (Turner et al., 1968).

A redução na pressão de recolhimento elástico do pulmão ocorre juntamente com a redução de todos os volumes pulmonares. A parede torácica não mostra alterações dos 20 aos 60 anos em volumes próximos da capacidade residual funcional. Em volumes abaixo disso, a tendência de recolhimento elástico da parede torácica aumenta com a idade, enquanto em volumes superiores, essa tendência diminui com a idade (Turner et al., 1968).

Um estudo realizado por Turner et al., em 1968, comprovou, através da mensuração da pressão esofágica, que há redução na pressão de recolhimento elástico dos 20 aos 60 anos. Também concluiu que há aumento na capacidade residual funcional e na capacidade pulmonar total em decorrência da idade. Acreditase que isso se deva quase que totalmente a alterações na elasticidade pulmonar decorrente do envelhecimento. Observaram que, em pessoas idosas, a complacência pulmonar aumenta, enquanto as forças de tração da parede torácica diminuem.

O volume residual, volume que resta nos pulmões após uma expiração profunda, tende a aumentar com a idade (McClaran et al., 1995; McArdle et al., 1996). Pickies e Vandervoort (1998) citam que o volume residual aumenta cerca de $30 \%$, levando a enrijecimento progressivo do tecido elástico dos pulmões e parede torácica e diminuindo o retorno passivo na expiração. $O$ volume de reserva inspiratória e o volume de reserva expiratória se tornam proporcionalmente menores (McClaran et al., 1995; McArdle et al., 1996). A perda na reserva inspiratória e o aumento no volume 
residual são atribuídos a uma redução nos componentes elásticos do tecido pulmonar, observada com o envelhecimento (McArdle et al., 1996).

Payton e Poland (1983) citam que o envelhecimento leva a alterações na ventilação voluntária máxima, trocas gasosas e pressão sangüínea. A ventilação voluntária máxima é o parâmetro que decresce mais acentuadamente, cerca de $40 \%$ entre 20 e 80 anos. A extração do oxigênio do sangue para os tecidos baixa de quatro para 1,5 litros por minuto dos 20 aos 75 anos (Timo laria, 1996). O aparelho respiratório tem uma perda de 50\% na ventilação voluntária máxima dos 25 aos 85 anos em decorrência do processo de envelhecimento. Isto resulta em aumento da resistência das vias aéreas e reduz a capacidade vital em 40\% (Payton e Poland, 1983).

A capacidade vital e o $\mathrm{VEF}_{1}$ (volume expiratório forçado no primeiro segundo) diminuem linearmente com a idade (Pickies e Vandervoort, 1998). Timo laria (1996) afirmou que há perda significativa da capacidade vital já aos 40 anos. Acredita-se que este declínio seja semelhante em homens e mulheres, embora as mulheres apresentem uma capacidade vital menor em relação à idade e altura (Ashley et al., 1975).

O envelhecimento leva a uma redução na $V F_{1}$ que pode predispor a dispnéia durante o exercício, também relacionada ao tabagismo. Com o declínio da função respiratória, a percepção de dispnéia pode limitar ainda mais o exercício (Grimby, 1988). A cada 10 anos, percebe-se uma queda de 9 a $27 \%$ no $\operatorname{VEF}_{1}$, dependendo da idade e sexo (Ashley et al., 1975).

Um estudo realizado por McClaran et al. (1995) seguiu 18 sujeitos entre 67 e 73 anos, saudáveis, por seis anos. No período, não houve alteração na capacidade pulmonar total, capacidade residual funcional e capacidade de difusão. A capacidade vital, $\mathrm{VEF}_{1}$ e taxa máxima de volatização decresceram. O volume residual aumentou 
de 11 a 13\%. No exercício submáximo, a limitação ao fluxo expiratório aumentou. No exercício máximo, houve significante hipoxemia arterial.

O envelhecimento torna a coluna vertebral menos flexível como um todo (Battíe et al., 1987; Caromano e Candeloro, 2001), em conseqüência das alterações nos discos intervertebrais e deformidades nas vértebras. Os movimentos da coluna cervical e da cintura escapular são os mais atingidos (Batti'e et al., 1987). No idoso, o núcleo pulposo dos discos intervertebrais perde água e proteoglicanas. As fibras colágenas deste núcleo aumentam em número e espessura, ao contrário do anel fibroso, no qual elas ficam mais delgadas. Com isso, a espessura do disco se reduz, acentuando as curvas da coluna e contribuindo para o aumento da cifose, principalmente a torácica (Jacob Filho e Souza, 2000), aumento antero-posterior do tórax e redução da mobilidade torácica (Bates e Hanson, 1998).

O aumento na cifose torácica faz com que uma eventual sobrecarga leve a uma solicitação exagerada musculatura respiratória, principalmente esternocleidomastoídeos, peitorais maiores e trapézios. O aumento na cifose faz com que se reduza a ativação dos músculos primários da respiração, que se encontram em franca desvantagem biomecânica ou com perda de força muscular em decorrência do envelhecimento (Hilmann, 1982). Mellin (1987) comprovou também a relação entre a cifose e lordose com a mobilidade no plano sagital e frontal.

Com o envelhecimento, uma maior quantidade de colágeno é sintetizada, surgem ligações cruzadas na molécula e há maior resistência à ação da colagenase. Em conseqüência disto, aumenta-se a rigidez dos tecidos e há maior dificuldade de difusão dos nutrientes dos capilares para as células e dos metabólitos das células para os capilares, o que ocasiona deterioração progressiva da função celular (Papaléo, 2002). 
Moll e Wright (1973) comprovaram que a idade reduz significativamente a mobilidade de tórax e coluna de sujeitos com espondilite anquilosante. Madureira e Lima (1998) expõe um decréscimo de $20 \%$ na amplitude de movimento, no teste de sentar e alcançar, entre as idades de 25 e 65 anos. A taxa de maior deterioração ocorre a partir do 65 anos.

Em conseqüência destas observações, observa-se em idosos uma insuficiência restritiva, obstrutiva ou difusional. No entanto, estas deficiências tornam-se evidentes apenas em condições de esforço ou quando o idoso apresenta um processo patológico pulmonar, que vai somar-se às alterações determinadas pelo envelhecimento (Papaléo, 2002).

Parece haver ainda uma relação inversa entre a idade e velocidade de "clearance" mucociliar, com redução no reflexo da tosse e aumento na possibilidade de aspiração, o que torna a pneumonia mais freqüente nos idosos (Jacob Filho e Souza, 2000).

\subsubsection{Envelhecimento e músculos estriados esqueléticos}

Em relação à perda de massa, os órgãos internos mais afetados pelo envelhecimento são os rins e o fígado, mas os músculos são os que sofrem maior prejuízo ponderal com o passar do tempo (Jacob Filho e Souza, 2000). O peso e a área de secção dos músculos diminuem, demonstrando perda de massa muscular. Thompson (1994) relata declínio de 18\% entre a segunda e a sétima década de vida. As fibras musculares podem sofrer degeneração e/ou hipertrofia, talvez por compensação. As fibras que mais sofrem redução em volume são as de contração rápida. São substituídas por tecido conjuntivo, aumentando assim o colágeno intersticial (Jacob Filho e Souza, 2000). 
Os músculos esqueléticos têm grande plasticidade e alteram sua biomecânica, arranjo estrutural e funções contráteis em resposta a alterações na mecânica respiratória, alterações no padrão de uso, estado nutricional e crescimento e desenvolvimento (Tolep e Kelsen, 1993). Deste modo, a redução na força muscular geral em idosos pode ocorrer em decorrência de inatividade, dieta inadequada e de baixo valor nutritivo, comorbidade e do próprio processo biológico de envelhecimento (Busby-Whitehead, 2001).

Evidências sugerem que a massa muscular decresça 3 a 6\% a cada década após os 60 anos (Dipietro e Dziura, 2000). A força isométrica máxima sofre redução com o envelhecer, variando entre os diferentes grupos musculares (Thompson, 1994).

Os efeitos de uma depleção nutricional nos músculos respiratórios foram descritos por diversos estudos em ratos. Dependendo da extensão e duração da restrição calórica, o peso do diafragma cai proporcionalmente ao peso corporal. A força contrátil também decai, mas a força gerada não segue a mesma proporção, com queda menos acentuada. Sujeitos com $71 \%$ do peso corporal esperado apresentam força muscular respiratória a 40\% do predito (Rochester, 1986).

Há muitos anos o envelhecimento do músculo esquelético em geral é objeto de estudo. Porém, somente nos últimos anos é que se atentou para o fato de que a musculatura respiratória também é afetada pelo envelhecimento (Tolep e Kelsen, 1993).

Observa-se redução nos valores de $\mathrm{PI}_{\text {máx }}$ (pressão inspiratória máxima) e $\mathrm{PE}_{\text {máx }}$ (pressão expiratória máxima) a partir dos 50 anos de idade. Da diferença destas pressões depende o gradiente pressórico que determina a eficiência da tosse. Deste modo, entende-se que o processo fisiológico do envelhecimento pode ser responsável pela ocorrência de fenômenos patológicos, como a retenção de secreção brônquica e sua conseqüente infecção (Jacob Filho e Souza, 2000). 
As alterações na estrutura do músculo decorrentes do envelhecimento atingem seu pico aos 70 anos, embora de maneira muito mais qualitativa do que quantitativa (Grimby, 1988). A força de contração máxima da musculatura esquelética reduz-se com a idade, o que contribui significativamente para a deficiência da função neuromuscular (Arabadjis et al., 1990). Entretanto, as causas dessa perda de força de contração e os tipos de fibras mais afetados são muito controversas.

Arabadjis et al. (1990) acreditam que essa redução se deva a uma perda de massa muscular e a perda rápida de fibras glicolíticas.

Payton e Poland (1983) citam que não há decréscimo na capacidade de gerar tensionamento nas fibras dos músculos em decorrência do envelhecimento. A função muscular é reduzida pelo decréscimo no número de fibras e na atividade da junção mioneural. Uma menor quantidade de alongamento é necessário para produzir a tensão máxima de tração. Assim, a redução na capacidade de gerar força provavelmente deve ocorrer pelo processo de destreinamento comum no envelhecimento.

Grimby (1988) acredita que a redução na massa muscular decorrente da idade é devido a perda de unidades motoras, de modo que a força muscular e o poder aeróbico decaem proporcionalmente. Cita ainda que a idade faz com que muitas funções relacionadas ao sistema locomotor sejam deterioradas e parte da redução na função muscular pode ser devido à inatividade.

Thompson (1994) coloca que a atrofia muscular varia de acordo com o indivíduo e é diferente em diferentes músculos. Deve-se a um decréscimo no número de fibras ou tamanho das mesmas, ou ambos. Entretanto, o mesmo autor coloca que a redução no número de fibras não apresenta evidências suficientes de que se deva a um fenômeno do envelhecimento, admitindo as controvérsias em relação ao assunto. Enquanto alguns autores provam não haver alterações patológicas nos músculos, 
\{Grimby et al. (1984) apud Arabadjis et al. (1990)\}, outros demonstram perda seletiva de fibras tipo II (Lexell et al. (1983) ${ }^{\star \star}$ apud Arabadjis et al. (1990); Thompson, 1994) e outros, perda e aumento no tamanho de fibras tipo I \{Sato et al. (1984) ${ }^{* * *}$ apud Arabadjis et al. (1990)\}. Estudos citam ainda aumento no número de fibras tipo I e a transformação de fibras tipo II em I (Thompson, 1994). Grimby (1988) cita que há redução nas fibras de contração rápida (tipo II) no quadríceps, mas não em outros músculos, provavelmente devido a diferenças no padrão de atividade e unidade de recrutamento motor.

Thompson (1994) sugere que a perda de massa muscular que ocorre com o envelhecimento não se deve a perda preferencial de algum tipo de fibra. Entretanto, como os músculos demonstram plasticidade diferente para cada tipo de fibra com o treinamento, é possível que isso sugira que a distribuição do tipo de fibras em idosos deva-se, em parte, a hereditariedade e atividade. $O$ autor acredita que resultados conflitantes sobre o efeito da idade na distribuição das fibras se deva a diferentes níveis de atividade entre os músculos estudados e diferenças metodológicas.

Os músculos inspiratórios de indivíduos saudáveis têm alta resistência a fadiga induzida pela repetição de esforços estáticos máximos. Foi observado que os músculos inspiratórios de indivíduos jovens têm maior resistência à fadiga induzida por contrações estáticas máximas repetidas quando comparados aos músculos expiratórios ou outros músculos esqueléticos (McKenzie e Gandevia, 1986).

\footnotetext{
" Grimby G, Aniansson A, Zetterberg C, Saltin B. Is there a chance in relative muscle fiber composition with age?. Clin Physiol. 1984;4:189-94.

** Lexell J, Hernriksson-Larsén K, Winblad B, Sjostrom M. Distribution of different fiber types in human skeletal muscles: effects of aging studied in whole muscle cross sections.Muscle \& Nerve.1984;6:588-95.

"Sato T, Akatsuka H, Kito K, Tokoro Y, Tauchi H, Kato K. Age changes in size and number of muscle fibers in human mirror pectoral muscle. Mechanisms of Ageing and Development. 1984;28:99-109.
} 
Um músculo é dito fraco quando sua força contrátil em resposta a um nível de estímulo é reduzida pela alteração no estado funcional básico das células musculares. A fraqueza se caracteriza por prejuízo na contração não decorrente de trabalho extenuante. Um músculo fraco gera força abaixo do normal no início do movimento. Com o decorrer do movimento, ele pode ser ainda enfraquecido pela fadiga. Assim, um músculo fraco é predisposto a fadiga (Rochester, 1986).

O enfraquecimento da musculatura respiratória leva a incapacidade do músculo de gerar tensão, produzindo pressões e movimentos anormais durante a respiração. A diminuição na força respiratória pode levar a redução cinésica bilateral da parede torácica, complacência alveolar e volume pulmonar, alteração das pressões pleurais, hipoventilação e colapso alveolar (Azeredo, 2002).

\subsection{Força muscular respiratória}

A força muscular respiratória é definida como a pressão mínima e máxima mensurada ao nível da boca, atribuída a um esforço muscular necessário para produzir a mudança de pressão (Leith e Bradley, 1976; Shaffer et al., 1981).

Durante a inspiração forçada, o fluxo máximo a ser atingido a cada volume depende em grande parte de esforço empreendido pelos músculos inspiratórios. A expiração forçada é esforço-dependente somente no início da mesma. A partir de então, esforços maiores não conduzem a fluxos proporcionais, podendo até ser acompanhados de pequena redução de fluxo devido à compressão dinâmica das vias aéreas, favorecendo um gasto aumentado de energia para a respiração e prejudicando a ventilação (Azeredo, 2002).

O desempenho dos músculos respiratórios não tem recebido a devida atenção em muitas patologias pulmonares. Entretanto, nas doenças do interstício do pulmão, 
por exemplo, os músculos estão trabalhando cronicamente contra cargas elásticas extras, o que gera uma tendência de que se desenvolva adaptações ou fadiga crônica (Pardy et al., 1988).

A fraqueza da musculatura expiratória prejudica a efetividade da tosse (Rochester, 1986; Nomori et al., 1994). Estudos utilizando voluntários normais mostram que quando a $\mathrm{PE}_{\text {máx }}$ cai abaixo de $30 \%$ do normal, há redução de $15 \%$ na taxa de fluxo da tosse. O fluxo supramáximo inicial, que representa a expulsão do ar das vias aéreas de grosso calibre é perdido. Isto sugere que a fraqueza da musculatura expiratória abole a compressão dinâmica de vias aéreas de grosso calibre, prevenindo a redução na área de secção transversa que ocorre com a tosse normal. Como resultado, a velocidade corrente do ar não é nem próxima do pico, o que provavelmente limita a efetividade de expulsão da tosse (Rochester, 1986).

Deste modo, a fraqueza da musculatura expiratória interfere no "clearance" brônquico e predispõe a retenção de secreções e desenvolvimento de infecções bronco-pulmonares (Olgiati et al., 1989). A atelectasia e a pneumonia são causadas principalmente pela redução na habilidade de expectoração, constituindo-se das causas mais comuns de complicações pós-operatórias (Nomori et al., 1994). Azeredo (2002) cita que sujeitos idosos, em sua maioria, são incapazes de gerar a força inspiratória necessária para realizar respiração profunda e, conseqüentemente, para tossir.

A fadiga muscular ocorre quando a taxa de consumo de energia é maior que a taxa de energia dada ao músculo. A depleção nas reservas de energia interna do músculo leva a falência da geração de força, ao início da fadiga. A fadiga dos músculos diafragma e intercostais é um problema clínico em potencial, pois tem como destino final a falência respiratória (Shaffer et al., 1981; Rochester, 1986; Olgiati et al., 1989; Azeredo, 2002; Pryor e Webber, 2002), seja ela crônica ou aguda. 
Em relação a falência respiratória hipercápnica, observa-se que a retenção de dióxido de carbono ocorria quando a capacidade vital era menor do que a metade do predito (Rochester, 1986).

A fadiga muscular respiratória também pode levar a dispnéia (Pryor e Webber, 2002), limitação na capacidade de exercício (Azeredo, 2002) e é uma das maiores causas não anestésicas de indicação de suporte ventilatório mecânico. A fraqueza muscular respiratória severa pode conduzir ainda a dificuldades fonatórias (Olgiati et al., 1989).

Os fatores que podem limitar o desempenho no exercício são complexos. Em indivíduos normais, o sistema cardiovascular e possivelmente os músculos dos membros a limitam. Em sujeitos com DPOC, aspectos ventilatórios ainda podem influenciar. Entretanto, as trocas gasosas e mecânica ventilatória anormais, hipertensão pulmonar e fadiga muscular respiratória também podem limitar o exercício. Deste modo, uma melhora no desempenho no exercício dada por um programa que melhore a força dos músculos não pode ser esperada. Estudos a este respeito são muito contraditórios, em todos os tipos de sujeitos (Pardy et al., 1988; Lacasse et al., 1997).

A fraqueza muscular respiratória sem ligação com patologia pulmonar produz um padrão ventilatório restritivo, caracterizado por redução no volume corrente, VEF ventilação voluntária máxima e capacidade pulmonar total e um aumento no volume residual. O decréscimo no volume corrente e ventilação voluntária máxima e aumento no volume residual são proporcionais a severidade da fraqueza (Rochester, 1986).

A fadiga diafragmática ocorre quando o índice de pressão-tempo atinge um nível crítico. Na respiração espontânea, o componente dominante do índice de pressãotempo é a taxa de pressão requerida para respirar pela pressão inspiratória estática máxima. Conseqüentemente, quando há um aumento na pressão respiratória, como 
por patologias obstrutivas e restritivas, é mais provável que haja fadiga, pois os músculos estão fracos (Rochester, 1986).

\subsubsection{Avaliação da força muscular respiratória}

O desempenho muscular é bem avaliado através da sua força, "endurance" e habilidade em resistir a fadiga (Shaffer et al., 1981). Leith e Bradley (1976) definem "endurance" como a capacidade de sustentar altos níveis de ventilação por períodos relativamente longos.

$\mathrm{Na}$ avaliação pulmonar, é importante detectar as alterações decorrentes da perda de força dos músculos respiratórios e alterações na mobilidade de tórax, resultante de encurtamento, fraqueza muscular e perda da tração elástica pulmonar (Black e Hyatt, 1969).

A avaliação da força dos músculos respiratórios tem vasta aplicação. Permite o diagnóstico de insuficiência respiratória por falência muscular, possibilita o diagnóstico precoce de fraqueza dos músculos respiratórios, auxiliando os profissionais da saúde

a estabelecer protocolos de treinamento físico geral e em particular da musculatura respiratória (Azeredo, 2002). Também é útil na avaliação do desmame de ventilação mecânica, e para predizer a avaliação de cirurgia de transplante cardíaco em sujeitos com insuficiência cardíaca congestiva (Harik-Khan et al., 1998).

A mensuração das pressões máximas também pode ser útil para quantificar a fraqueza da musculatura respiratória. Em contraste com as medidas de volume pulmonar e testes dinâmicos - como avaliação da capacidade máxima respiratória que podem ser alteradas por muitas doenças intrapulmonares, a determinação das pressões máximas $\left(\mathrm{PI}_{\text {máx }}\right.$ e $\left.P E_{\text {máx }}\right)$ é um método específico para estimar a força da musculatura respiratória (Black e Hyatt, 1969). A utilização da prova de função 
pulmonar e a cirtometria torácica podem fornecer dados complementares (Jardim, 1985).

Um dos testes mais indicados para avaliação da força muscular respiratória é a mensuração das pressões respiratórias máximas. Trata-se de índices da força do diafragma e dos músculos abdominais e intercostais, considerados melhores que a capacidade vital forçada e $\mathrm{VEF}_{1}$, ambos mensurados através de espirometria (Santana et al., 2001). A mensuração da $\mathrm{PI}_{\operatorname{máx}}$ é um procedimento clínico fácil, rápido e não invasivo para determinar o índice de força muscular inspiratória em indivíduos saudáveis e em sujeitos com patologias pulmonares ou neuromusculares (Black e Hyatt, 1969; Harik-Khan et al., 1998), podendo ser utilizadas na avaliação de intervenções terapêuticas (Black e Hyatt, 1969).

As pressões respiratórias máximas diminuem com idade (Santana et al., 2001). Estima-se que um indivíduo de 60 anos necessita despender 20\% mais força num determinado nível de ventilação do que um indivíduo de 20 anos (Turner et al., 1968). Alterações na função pulmonar dadas pela idade sugerem que isso seja uma conseqüência clínica do sarcopenia comum da idade (Santana et al., 2001).

Black e Hyatt (1969) desenvolveram um instrumento simplificado para determinação das pressões respiratórias máximas. A partir desse primeiro modelo, outros foram aperfeiçoados (Black e Hyatt, 1974; Camelo et al., 1985). A pressão gerada é resultante da combinação das forças exercidas pelo recolhimento elástico pulmonar e musculatura respiratória. Recomenda-se, para avaliações nos laboratórios de provas funcionais pulmonares e em trabalhos de campo, que se utilizem manovacuômetros que permitam mensurações na faixa de -160 a +200 $\mathrm{cmH}_{2} \mathrm{O}$ (Souza, 2002).

Recomenda-se que o indivíduo esteja na posição sentada, com o tronco em um ângulo de $90^{\circ}$ com as coxas. O posicionamento altera a prova de força muscular 
respiratória, de modo que as provas em decúbito dorsal têm resultados menores que em pé ou sentado (Souza, 2002).

Souza (2002) cita que não se altera o resultado das avaliações de acordo com a hora do dia, e a ordem em que foram realizados os teste de $\mathrm{PI}_{\text {máx }}$ e $\mathrm{PE}_{\text {máx }}$. Recomenda-se que sejam obtidas três manobras aceitáveis, com um repouso de 30 a 40 segundos entre cada duas manobras.

Embora de fácil mensuração, os valores de $\mathrm{PI}_{\operatorname{máx}}$ obtidos dependem de uma série de fatores. A mensuração da $\mathrm{PI}_{\operatorname{máx}}$ é fortemente dependente do avaliador e da motivação do sujeito (Hautmann et al., 2000; Souza, 2002). O coeficiente de variação dos sujeitos varia entre 7 a $10 \%$. $\mathrm{A} \mathrm{PI}_{\text {máx }}$ depende ainda da idade, sendo claramente desproporcional em pessoas acima dos 60 anos de idade. Depende também de altura, peso, índice de massa corpórea e tabagismo (redução de 15\%). O limite de normalidade está em cerca de 59 (para mulheres) a 60\% (para homens) do valor médio predito (Hautmann et al., 2000). Os resultados dependem também da compreensão das manobras, volume pulmonar em que foram realizadas as mensurações e do correspondente valor da pressão de retração elástica do sistema respiratório, que resulta da soma das pressões de retração elásticas dos pulmões e caixa torácica. Por todos estes fatores, acredita-se que o valor encontrado para o teste superestima o valor real em cerca de $30 \%$, tanto na $\mathrm{Pl}_{\text {máx }}$ quanto na $\mathrm{PE}_{\text {máx }}$ (Souza, 2002).

Quando o volume é a capacidade residual funcional, a pressão de retração elástica do sistema respiratório é nula, de modo que quando o tórax está na capacidade pulmonar total ou volume residual, o sistema tende a retrair ou expandirse, respectivamente. Assim, o valor obtido na avaliação da $P E_{\text {máx }}$ depende da pressão dos músculos expiratórios e da retração elástica do sistema respiratório. O mesmo ocorre na $\mathrm{PI}_{\text {máx }}$ (Souza, 2002). 
O efeito dos volumes pulmonares sobre a pressão estática máxima já foi bem descrito. Os maiores valores para $\mathrm{PE}_{\text {máx }}$ foram obtidos com um volume pulmonar acima de $70 \%$ da capacidade pulmonar total. Os maiores valores para a $\mathrm{PI}_{\text {máx }}$ eram encontrados com o pulmão a volumes menores que 40 a $50 \%$ da capacidade pulmonar total (Black e Hyatt, 1969).

A PImáx pode ser mensurada a partir de uma expiração forçada, quando o volume de gás contido nos pulmões é o volume residual, ou a partir de uma expiração normal (a partir da capacidade residual funcional). $A \mathrm{PE}_{\text {máx }}$ também pode ser mensurada a partir de uma inspiração forçada (capacidade pulmonar total) (Azeredo, 2002; Souza, 2002) ou de uma expiração normal (Souza, 2002). O diafragma é capaz de gerar maior força quando se encontra alongado entre cinco e 10\% acima do repouso, o que ocorre ao final da expiração máxima. O mesmo ocorre com os músculos expiratórios, cujas pressões máximas são obtidas em níveis próximos à inspiração máxima, ou seja, ao nível da capacidade pulmonar total (Azeredo, 2002).

Alguns estudos relatam padrões de normalidade para a $\mathrm{Pl}_{\text {máx }}$ Um estudo realizado por Black e Hyatt (1969) analisou a $\mathrm{Pl}_{\text {máx }}$ e $\mathrm{PE}_{\text {máx }}$ de 120 indivíduos, com o auxílio de um manovacuômetro. Os 120 indivíduos eram numericamente semelhantes em relação ao sexo e foram subdivididos em seis grupos de acordo com a faixa etária (entre 20 - 30 anos, $30-40,40$ - 50, 60 - 70 e acima de 70 anos). Os sujeitos não apresentavam queixas relacionadas ao sistema respiratório ou qualquer anormalidade torácica. Entretanto, não foram descartados os tabagistas. $A \mathrm{PE}_{\text {máx }}$ foi mensurada a partir da capacidade pulmonar total (após inspiração forçada) e a $\mathrm{Pl}_{\text {máx }}$, a partir do volume residual (após expiração forçada). As pressões obtidas deveriam ser mantidas por no mínimo um segundo. Para testar a reprodutibilidade dos resultados, cinco sujeitos repetiram o mesmo procedimento por três dias consecutivos. Não houve diferença significativa entre os resultados obtidos. A mensuração das pressões 
máximas pode ser mais bem reproduzida a partir dos volumes escolhidos para este estudo, pois já foi mostrado que as mudanças na pressão máxima para uma dada mudança de volume é menor nestes volumes quando comparado a capacidade pulmonar total. Os valores obtidos pelas mulheres na $\mathrm{Pl}_{\text {máx }}$ e $\mathrm{PE}_{\text {máx }}$ foram de aproximadamente 65 a $70 \%$ dos valores obtidos pelos homens, conforme predito por outros estudos. Não houve redução estatisticamente significativa na $\mathrm{Pl}_{\text {máx }}$ e $P E_{\text {máx }}$ em indivíduos até 55 anos. Após os 55 anos, a $\mathrm{PE}_{\operatorname{máx}}$ em homens e mulheres e a $\mathrm{PI}_{\operatorname{máx}}$ em mulheres reduziu-se estatisticamente com a idade (Black e Hyatt, 1969).

$\mathrm{A} \mathrm{PI}_{\text {máx }}$ e $\mathrm{PE}_{\text {máx }}$ estão reduzidas na presença de fraqueza ou fadiga muscular. Shaffer et al. (1981) citam que a falência respiratória hipercápnica estão associadas à força menor que $30 \%$ do predito. Azeredo (2002) define padrões de normalidade para adultos jovens. Espera-se um valor entre -90 a $-120 \mathrm{cmH}_{2} \mathrm{O}$ para a $\mathrm{Pl}_{\text {máx }} \mathrm{e}+100$ a +150 para a $\mathrm{PE}_{\text {máx }}$. Entretanto, em relação a $\mathrm{Pl}_{\text {máx }}$, Harik-Khan et al. (1998) citam que os valores dos homens são por volta de $30 \%$ maiores que os das mulheres (101 e 72 $\mathrm{cmH}_{2} \mathrm{O}$, respectivamente), e nestas o declínio na $\mathrm{PI}_{\text {máx }}$ com a idade é mais acentuada.

Azeredo (2002) estabelece ainda valores de $\mathrm{P}_{\text {máx }}$ considerados normais a adultos jovens para classificar sua musculatura respiratória em fraca, fadigada ou em falência. Estes valores estão descritos na Tabela 1. O quadro de fadiga traduz-se clinicamente por enfraquecimento muscular por diversas razões, que faz com que o músculo não seja capaz de gerar tensão suficiente para promover adequada ventilação alveolar, assegurando as trocas gasosas. A falência pode ocorrer quando o consumo de energia pelos músculos é maior do que o suprimento de energia fornecido pelo sangue. 
Tabela 1 - Caracterização de quadro clínico de acordo com valores da pressão inspiratória máxima

\begin{tabular}{lc}
\hline QUADRO CLÍNICO & $\mathrm{PI}_{\text {máx }}{ }^{(1)}$ \\
\hline Fraqueza muscular respiratória & $-70 \mathrm{a}-45$ \\
Fadiga muscular respiratória & $-40 \mathrm{a}-25$ \\
Falência muscular respiratória & $<-20$ \\
\hline FONTE: Azeredo (2002) & \\
${ }^{(1)}$ Valores em $\mathrm{cmH}_{2} \mathrm{O}$
\end{tabular}

Vale lembrar que os valores acima são referência para adultos jovens e a partir dos 20 anos de idade ocorre um decréscimo anual de $0,5 \mathrm{cmH}_{2} \mathrm{O}$ por ano em ambos sexos (Azeredo, 2002).

Utilizando também concentrações de gases, Pardy et al. (1988) diferenciam fraqueza de fadiga respiratória. A fraqueza é sugerida por uma redução na força e elevação crônica na $\mathrm{PaCO}_{2}$ (pressão parcial de dióxido de carbono no sangue arterial). A fadiga é sugerida por uma redução abrupta na força muscular respiratória, aumento na $\mathrm{PaCO}_{2}$ ou desenvolvimento agudo de movimentos paradoxais na parede abdominal.

Hautmann et al. (2000) citam que a $\mathrm{Pl}_{\text {máx }}$ apresenta uma variabilidade marcante entre os sujeitos semelhantes. Uma explicação suficiente não está disponível, embora esta diferença provavelmente seja devido às diferentes musculaturas dos indivíduos. O mesmo autor cita que os estudos com pressões da boca não são diretamente comparáveis. Relata uma grande diferença na $\mathrm{Pl}_{\text {máx }}$ nos diversos estudos. Diferenças na distribuição etária das coortes, métodos e equipamentos podem explicar estas variações (Hautmann et al., 2000). Vale lembrar que o treinamento pode conduzir a "bias" de interpretação e alterar os resultados de testes repetidos com o mesmo indivíduo (Black e Hyatt, 1969). 


\subsubsection{Treino de força muscular respiratória}

Diversos autores já descreveram os efeitos deletérios da redução na força muscular respiratória, conforme descrito anteriormente. Deste modo, novos estudos são constantemente conduzidos, objetivando verificar os efeitos de treinos de força e "endurance" da musculatura respiratória em diferentes populações e variáveis, como desempenho no exercício, níveis de dispnéia e outros itens.

Grande parte dos estudos relacionados ao treino muscular respiratório envolve sujeitos com patologias respiratórias crônicas, particularmente a DPOC.

Um estudo clássico foi realizado em 1976 por Leith e Bradley. Os autores analisaram a força e "endurance" respiratória de voluntários jovens, antes e depois de um programa de treinamento dos músculos respiratórios. Os sujeitos eram todos saudáveis, mas dois eram tabagistas. Os 12 sujeitos foram divididos em três grupos. $\mathrm{O}$ primeiro grupo realizou treino de fortalecimento muscular respiratório, o segundo treino de "endurance" respiratória e o último atuou como controle. O grupo de fortalecimento realizou manobras estáticas de inspiração e expiração máxima 20\% acima do volume corrente, mantidas por três a cinco segundos, contra obstrução aérea, por aproximadamente 30 minutos por dia. O grupo que treino "endurance" realizou exercícios de hiperventilação até a exaustão, três a cinco vezes de 45 a 60 minutos por dia. O grupo controle não sofreu intervenção. Os sujeitos realizaram os exercícios cinco dias por semana, por cinco semanas. O grupo que realizou treino de força obteve uma melhora de $55 \%$ na $\mathrm{Pl}_{\text {máx }}$ e $\mathrm{PE}_{\text {máx }}$ e de apenas $4 \%$ na capacidade vital e capacidade pulmonar total. No grupo dois, inicialmente os sujeitos eram capazes de resistir 15 minutos hiperventilando a $81 \%$ da sua ventilação voluntária máxima. Após o treino, esse valor aumentou para $96 \%$. Também houve melhora de $14 \%$ na ventilação 
voluntária máxima. Os autores alertaram para os efeitos do aprendizado em ambos grupos.

Winer et al. (1992) selecionaram 36 indivíduos com DPOC, divididos em três grupos. O primeiro grupo foi submetido a treino de musculatura inspiratória, realizado nos primeiros 15 minutos de cada sessão. Foi utilizado "threshold" para que os indivíduos respirassem com uma resistência igual a $15 \%$ da sua $\mathrm{Pl}_{\text {máx }}$ na primeira semana. A resistência era aumentada $5 \%$ a cada sessão, até que se alcançasse $60 \%$ do valor máximo, ao final do primeiro mês. Esta resistência era mantida até o terceiro mês. A resistência era então novamente aumentada até mais de $80 \%$ da $\mathrm{Pl}_{\text {máx}}$. Os sujeitos do segundo grupo também utilizavam "threshold", mas sem resistência alguma. Ambos grupos sofreram intervenção de um protocolo de exercícios constituído de 20 minutos de bicicleta ergométrica, 10 minutos de remo estático e 15 minutos de exercícios de fortalecimento geral. O grupo $\mathrm{C}$ atuou como controle, não sofrendo intervenção alguma. O programa teve seis meses de duração. O primeiro grupo apresentou aumento significativo na força muscular inspiratória e ainda mais significativo na "endurance" dos músculos respiratórios. Ambos grupos apresentaram melhora na distância percorrida em 12 minutos, mas o primeiro grupo obteve melhora mais pronunciada.

Sarmiento et al. (2002) selecionaram quatorze sujeitos com DPOC, divididos em dois grupos para receber ou não treinamento inspiratório com "threshold". Os treinos foram realizados 30 minutos por dia, cinco dias por semana, por cinco semanas

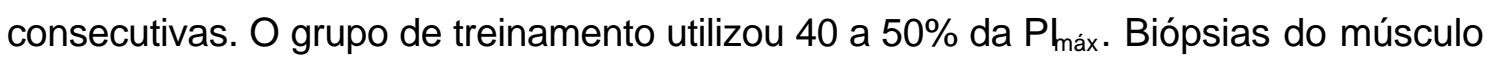
intercostal externo e vasto lateral foram realizadas antes e depois do treinamento. No grupo treinado foram observadas alterações na força e "endurance" nos músculos inspiratórios. O exercício aumentou a proporção de fibras tipo I e o tamanho das fibras 
tipo II, mostrando que o treino inspiratório específico induz a melhora funcional e mudanças adaptativas na estrutura do músculo intercostal externo.

Um estudo realizado por Patessio e colaboradores em 1989 investigou os efeitos de um treino de resistência inspiratória sobre a sensação de dispnéia em sujeitos com DPOC. Nove sujeitos saudáveis do sexo masculino e 18 sujeitos com DPOC foram selecionados. Tiveram mensuradas a sua $\mathrm{PI}_{\text {máx }}$, "endurance" dos músculos inspiratórios e sensação de dispnéia. Foram divididos em dois grupos. O primeiro foi submetido a treino de resistência respiratória e o segundo atuou como placebo. No final do treinamento, a $\mathrm{Pl}_{\text {máx }}$ foi melhor no grupo tratado. $\mathrm{O}$ treinamento também foi responsável por uma redução na sensação de dispnéia através de um aumento na força e "endurance" respiratória.

Scherer et al. (2000) realizaram treino de "endurance" em sujeitos com DPOC e limitação ventilatória. Trinta sujeitos foram divididos em dois grupos. Um deles realizou treinamento de "endurance" com hiperpnéia isocápnica e o segundo utilizou um equipamento placebo (grupo controle). Ambos grupos treinaram duas vezes por dia, por 15 minutos, cinco dias por semana, por oito semanas. O treinamento induziu a mudanças significativas na ventilação sustentada, "endurance" dos músculos inspiratórios (observado pelo aumento na carga inspiratória do "threshold"), $\mathrm{PE}_{\text {máx }}$, distância percorrida em seis minutos e nos escores de componentes físicos, quando comparados ao grupo controle. Não evidenciou-se melhora significativa na $\mathrm{P}$ háx neste estudo.

Um estudo realizado por Goldstein e colaboradores (1989) selecionou 12 sujeitos com DPOC estáveis e severos. Foram randomizados em dois grupos: intervenção e controle. O grupo de estudo foi submetido a um programa utilizando "threshold", por quatro semanas, duas vezes por dia, cinco dias por semana. Eles iniciavam com uma carga que pudessem suportar por 10 minutos e eram encorajados a aumentar a 
duração do treinamento a cada sessão, até que atingissem 20 minutos, quando a carga era aumentada. Os controles realizaram o treinamento com um equipamento parecido, porém, sem carga. Não houve diferença na função pulmonar, tolerância ao exercício ou força muscular inspiratória entre o grupo controle e estudo. Entretanto, o grupo de estudo apresentou melhora significativa na "endurance" da musculatura inspiratória.

Sturdy et al. (2003) conduziram um estudo com nove sujeitos com DPOC, menores de 75 anos. Foram avaliadas a força muscular inspiratória (mensurada através da $\mathrm{PI}_{\text {máx }}$ ) e "endurance" (mensurada através da máxima pressão gerada contra uma carga de "threshold" progressivamente aumentada). Posteriormente, submeteuse os sujeitos a 60 minutos de exercícios gerais de "endurance", principalmente voltados aos grandes grupos musculares dos membros inferiores. Imediatamente após cada sessão de exercícios gerais, eram ministrados dois minutos de treino inspiratório seguido de um minuto de descanso, até que se completassem 20 minutos. Ao final do tratamento, detectou-se melhora significativa na $\mathrm{Pl}_{\text {máx }}(32 \pm 27 \%, \mathrm{p}<0.05)$ e "endurance" da musculatura inspiratória.

Harver et al. (1989) avaliaram 19 sujeitos com DPOC severa ou moderada. Foram divididos em dois grupos. Ambos grupos foram submetidos a treino inspiratório de 15 minutos duas vezes por dia, utilizando um instrumento que possibilitava "feedback" visual a cada ciclo respiratório a respeito da intensidade do exercício. Os sujeitos do grupo experimental treinaram em seis níveis de intensidade crescente de resistência inspiratória. O grupo controle foi submetido a um treino com resistência constante. Não houve diferença estatisticamente significativa entre os grupos em relação a $\mathrm{Pl}_{\text {máx }}$. Entretanto, os sujeitos do grupo de intervenção mostram aumento significativo na força dos músculos inspiratórios, além de redução na dispnéia após oito semanas de treinamento. 
Um estudo realizado com nove sujeitos com DPOC entre 40 e 70 anos foi realizado por Larson e Kim (1984). Tinha como objetivo determinar os efeitos do treino com incentivador inspiratório na $\mathrm{P}_{\text {máx }}$, desempenho no exercício, condição clínica e atividades de vida diária. A força muscular inspiratória foi avaliada através da $\mathrm{PI}_{\text {máx }}$. Os sujeitos foram submetidos a um mês de treino muscular inspiratório com um incentivador construído a partir de um espirômetro volume-dependente. A força muscular inspiratória obteve aumento estatisticamente significativo.

Lacasse et al. (1997) realizaram um estudo que analisou 22 ensaios clínicos aleatorizados a respeito de exercícios gerais, exercícios respiratórios, educação e apoio psicossocial em sujeitos com DPOC. Destes, sete estudos diziam respeito a programas de exercícios respiratórios adicionados a programas de exercícios convencionais. Concluíram que o treino muscular inspiratório e outros exercícios respiratórios, quando realizados junto a um programa de exercícios, tem resultados muito contraditórios.

Um estudo realizado por Sampaio e colaboradores, em 2002, comparou a força muscular respiratória de sujeitos asmáticos submetidos a exercício respiratório e treinamento físico. Trinta e sete asmáticos foram distribuídos em três grupos. $\mathrm{O}$ primeiro foi submetido a treino respiratório e treino físico. O segundo, somente a treino respiratório. O terceiro grupo atuou como controle. O treino respiratório foi realizado com "threshold", dez minutos por dia, com carga de $40 \%$ da $\mathrm{Pl}_{\text {máx }}$ (obtida em avaliação diária). O treino físico consistia de 30 minutos de esteira rolante. As intervenções eram realizadas três vezes por semanas, durante seis semanas consecutivas, com duração de uma hora cada sessão. Os grupos que receberam tratamento obtiveram melhora na $\mathrm{PI}_{\text {máx }}\left(51,2 \%\right.$ para o primeiro grupo e $34,5 \%$ para o segundo grupo) e $\mathrm{PE}_{\text {máx }}(54,9$ e $39,7 \%$, respectivamente). Trinta dias após o término do treinamento, não foram constatadas mudanças significativas nos resultados encontrados. 
O treino muscular respiratório utilizando incentivadores mecânicos também é realizado com diversas outras amostras, envolvendo sujeitos normais, atletas, patologias cardíacas e neurológicas e sujeitos pós-operados.

McEntire et al. (2003) selecionaram 15 indivíduos normais, divididos em dois grupos. Ambos grupos realizaram treino de ciclismo a $70 \%$ da $\mathrm{VO}_{2 m a ́ x}$, por seis semanas. O primeiro foi submetido a treino muscular respiratório com aparato que oferecia resistência de $15 \mathrm{cmH}_{2} \mathrm{O}$. O segundo atuou como controle e realizou apenas os exercícios de ciclismo. Não houve alteração estatisticamente significativa na $\mathrm{Pl}_{\text {máx }}$ entre os grupos.

Um estudo realizado por Valle et al. (2002) investigou os efeitos do treinamento e destreinamento da força muscular respiratória em 20 soldados, divididos em grupo experimental e controle. O grupo experimental realizou treino de força muscular respiratória com manovacuômetro três vezes por semana, com duração de 40 minutos cada sessão, durante oito semanas. O grupo controle foi submetido a treinamento militar. Avaliando-se a força muscular respiratória em três diferentes momentos, observou-se alterações estatisticamente significativas, que mantiveram-se após quatro meses de treinamento.

Volianitis et al. (2001) selecionaram 14 remadoras profissionais, com média de idade de aproximadamente 24 anos. Foram submetidas a teste ergométrico, avaliação das pressões respiratórias máximas e randomizadas em dois grupos. O grupo intervenção foi submetido a 11 semanas de treinamento muscular inspiratório, que consistia em realizar 30 inspirações forçadas, duas vezes por dia, utilizando "threshold" com resistência de $50 \%$ da $\mathrm{PI}_{\text {máx }}$. A força muscular inspiratória melhorou $22 \%$ no grupo intervenção, contra $6 \%$ de melhora do grupo placebo. Constataram também aumento no tempo de resistência inspiratória a fadiga. 
Romer et al. (2002) realizaram um estudo para verificar os efeitos do treino muscular inspiratório na fadiga de ciclistas profissionais submetidos a percursos simulados de 20 e $40 \mathrm{~km}$ de bicicleta. Selecionaram 16 ciclistas profissionais, todos do sexo masculino e não-tabagistas, e os randomizaram em dois grupos - experimental e placebo. O treino inspiratório constava de 30 esforços inspiratórios a $50 \%$ da $\mathrm{Pl}_{\text {máx }}$, duas vezes por dia, por seis semanas, utilizando "threshold". O grupo placebo utilizou $15 \%$ da $\mathrm{Pl}_{\text {máx }}$. Os sujeitos foram submetidos a percursos de 20 e $40 \mathrm{~km}$ de ciclismo, pré e pós a realização do programa de treinamento inspiratório. Foram avaliadas as funções estáticas e dinâmicas da musculatura inspiratória em 16 tempos (pré cada um dos dois percursos e zero, dois, 10 e 30 minutos após o término dos mesmos). Concluíram que o treino muscular inspiratório foi capaz de atenuar a fadiga inspiratória encontrada em ciclistas após ambos percursos de ciclismo - 20 e 40 km.

Um estudo realizado por Martínez et al. (2001) selecionou 20 sujeitos com insuficiência cardíaca crônica, divididos em dois grupos. O primeiro realizou exercícios inspiratórios com "threshold" a $30 \%$ da $\mathrm{Pl}_{\text {máx. }} \mathrm{O}$ segundo, utilizou $10 \%$ da $\mathrm{P}_{\text {máx. }} \mathrm{O}$ treinamento era composto por duas sessões de 15 minutos, seis dias por semana, durante seis meses. Ambos grupos apresentaram melhora estatisticamente significativa na dispnéia, $\mathrm{VO}_{2 m a ́ x}$, carga máxima sustentada e $\mathrm{Pl}_{\text {máx }}$. Somente o grupo que treinou a $30 \%$ da $\mathrm{PI}_{\text {máx }}$ apresentou melhora na distância percorrida em seis minutos.

Um estudo realizado por Olgiati e colaboradores, em 1989, verificou os efeitos do treino respiratório em sujeitos com esclerose múltipla. Foram estudados oito sujeitos com esclerose múltipla estável, com média de idade de 53 anos. Os sujeitos apresentavam fraqueza muscular respiratória prévia (média de 64\% do predito para a $\mathrm{PI}_{\text {máx }}$ e $41 \%$ da $\left.P E_{\text {máx }}\right)$. O exercício respiratório foi realizado com o sujeito instruído a respirar contra uma resistência externa. O tipo resistência (inspiratória ou expiratória) 
era escolhida de acordo com a $\mathrm{PI}_{\text {máx }}$ e $\mathrm{PE}_{\text {máx }}$ dos sujeitos, que deveriam ser menores que $70 \%$ do predito. Os sujeitos eram atendidos duas vezes por dia, cinco dias por semana, por $4 \pm 1$ semana. Houve um aumento de $31 \%$ na $P l_{\text {máx }}$ e $31 \%$ na $P E_{\text {máx }}$ e $21 \%$ na ventilação voluntária máxima. Concluiu-se que o treino muscular respiratório foi capaz de melhorar a força muscular respiratória e capacidade ventilatória, constituindo-se de um método adicional de reabilitação em sujeitos com esclerose múltipla, nos quais a fraqueza muscular respiratória contribui para a intolerância ao exercício, dificuldades na tosse e fonação e até uma eventual falência respiratória.

Um estudo realizado por Azeredo (2002) monitorou a $\mathrm{Pl}_{\text {máx }}$ de 15 indivíduos com doença restritiva pulmonar por 45 dias consecutivos que utilizaram um incentivador respiratório a volume. Realizaram o treinamento três vezes ao dia. Ao final de 45 dias, o volume aumentou em média 12 a 15\%, valores estatisticamente não significativos. Cita que o treinamento muscular pode estender-se por meses até que surjam respostas significativas a terapia.

Um estudo realizado por Nomori e colaboradores, em 1994, buscou verificar os efeitos do exercício respiratório no pré-operatório de sujeitos submetidos a cirurgia torácica. Acompanhou 50 sujeitos com idades entre 24 e 73 anos. O protocolo consistia de respiração diafragmática profunda com $2 \mathrm{~kg}$ de peso sobre o abdome, tosse eficaz com contração potente da musculatura abdominal (três vezes por dia, por dez minutos), treino com um aparato que resistia a expiração com carga de $15 \mathrm{cmH}_{2} \mathrm{O}$ ("Increased Dead Space and Expiratory Pressure") quatro vezes por dia, por dez minutos cada sessão. O treino era realizado em todo o tempo de internação précirurgia (7 a 21 dias, média de 14). Além de mensuração da $\mathrm{PI}_{\text {máx }}$ e $P E_{\text {máx }}$, também foi determinada a capacidade vital, capacidade vital forçada e $\mathrm{VEF}_{1}$ através de teste espirométrico. Os testes eram realizados na admissão ao programa e um dia antes da cirurgia. Encontrou-se aumento tanto na força inspiratória quanto expiratória. Os oito 
sujeitos que apresentaram complicações pós-operatórias tiveram uma $\mathrm{Pl}_{\text {máx }}$ e $\mathrm{PE}_{\text {máx }}$ significativamente menor que os sujeitos que não apresentaram complicações. Nenhum dos sujeitos com complicações havia obtido grande melhora com o treino préoperatório. Os seis sujeitos que obtiveram melhores resultados nos treinos não apresentaram complicações pulmonares pós-operatórias.

Um estudo realizado por Azeredo (2002) analisou os efeitos da sustentação máxima da inspiração no ganho de força muscular respiratória. Esta técnica foi desenvolvida nos Estados Unidos e utiliza um aparato denominado inspirômetro incentivador. Referem ganho de aproximadamente $8 \%$ na $\mathrm{Pl}_{\text {máx }}$ em uma semana de treinamento utilizando a inspirometria de incentivo. Concluiu que quando aplicada com padrão de respiração lenta, a técnica parece gerar um bom desempenho nas relações tensão/comprimento e força/velocidade. Entretanto, o autor cita que isto não significa que a técnica seja suficiente para aumentar a força dos músculos respiratórios, pois não há evidências estatisticamente significativas. Deste modo, a variação pressórica e sua instabilidade parecem demonstrar que a inspirometria de incentivo não é uma técnica para fortalecer os músculos respiratórios, e sim para melhorar seu desempenho em algumas situações clínicas. O autor indica ainda o uso do "threshold" como método mais eficaz de fortalecimento.

Observa-se uma não uniformidade nos resultados dos estudos acima descritos. Diversos trabalhos obtiveram resultados contraditórios, principalmente no que se refere aos efeitos do treino respiratório no desempenho durante o exercício.

\subsection{Expansibilidade torácica}

A expansibilidade torácica é definida como o movimento observado no tórax durante uma incursão inspiratória e expiratória. Depende da capacidade dos músculos 
respiratórios em gerar pressão negativa intrapleural eficiente e da integridade da caixa torácica. A fraqueza muscular respiratória leva a incapacidade do músculo de gerar tensão, ocasionando redução na expansibilidade torácica (Azeredo, 2002).

A noção de distensibilidade do tórax está diretamente ligada a elasticidade dos elementos anatômicos do tórax e dos pulmões. A elasticidade total do tórax pode ser considerada dependente da elasticidade da parede torácica e em menor proporção, da elasticidade dos pulmões (Kapandji, 1990).

Conforme descrito nos capítulos anteriores, o envelhecimento exerce efeito considerável nos órgãos envolvidos com a respiração (Papaléo, 2002; Griffith et al., 2001; Santana et al., 2001). Alterações na morfofisiologia, complacência e elasticidade do pulmão e caixa torácica decorrentes do processo normal de envelhecimento são responsáveis por modificações na expansibilidade de caixa torácica.

Acredita-se que a expansibilidade torácica seja influenciada por diversos fatores, dentre eles os movimentos da coluna vertebral. Moll e Wright (1973) estudaram a relação entre expansão torácica e flexibilidade em sujeitos com espondilite anquilosante. Demonstraram relação da expansão torácica com os movimentos de flexão lateral e extensão, todos estatisticamente significativos em indivíduos com esta patologia. Entretanto, esta relação não foi estatisticamente significativa para sujeitos normais.

Diversos estudos comprovam haver relação significativa entre expansão torácica e função pulmonar em pacientes com espondilite anquilosante (Feltelius et al., 1986; Seçkin et al., 2000; Vanderschueren et al., 1989). Vanderschueren et al. (1989) cita que quando havia uma redução pronunciada na expansibilidade torácica, a capacidade vital apresentava apenas $62 \%$ do seu valor predito.

Um estudo realizado por Fisher et al. (1990) estabeleceu relações entre expansibilidade torácica, função pulmonar e tolerância ao exercício, também em 
indivíduos com espondilite anquilosante. Foram estudados 33 sujeitos, com média de idade de aproximadamente 47 anos, a maioria tabagista (67\%). Dezesseis deles praticavam atividade física regularmente. Tiveram avaliadas sua condição clínica, mobilidade espinal (expansibilidade torácica, flexão e extensão lombar pelo método de Schober), função pulmonar (espirometria) e condição aeróbica (testes de esforço). Concluiu-se que a redução na capacidade vital está associada com redução na expansibilidade torácica. Entretanto, não encontrou associação com a tolerância ao exercício nestes sujeitos. Os resultados sugeriram que uma pequena quantidade de exercícios continuamente pode manter uma satisfatória capacidade de exercício, apesar da restrição das amplitudes espinhal e torácica.

Miller et al. (2002) estudaram os efeitos da restrição da parede torácica na função cardiorespiratória de repouso e durante o exercício em indivíduos saudáveis. Objetivou-se estimar as interações cardiorespiratórias observadas em condições clínicas que levam a alterações restritivas ao pulmão e caixa torácica. Através de restrição mecânica externa ao tórax e abdômen, observou-se que a capacidade vital reduziu-se em 35\%. Observou-se que a restrição à expansão torácica reduziu significativamente o volume de ejeção cardíaco durante o exercício. O aumento compensatório na freqüência cardíaca não preveniu a redução no débito cardíaco. 0 consumo de oxigênio $\left(\mathrm{VO}_{2}\right)$ não se alterou, provavelmente através do aumento na extração e redistribuição no fluxo sangüíneo via ativação simpática. 


\subsubsection{Avaliação da expansibilidade torácica}

O avaliação da expansibilidade torácica objetiva mensurar a limitação da mobilidade das articulações esternocostais, costotransversas e costovertebrais (Meirelles e Kitadai, 1998).

Viitanen et al. (1995) citam que a avaliação da expansibilidade torácica já está bem descrita pela literatura. Diversos autores (Moll e Wright, 1973; Fisher et al., 1990; Pyle et al., 1991; Burgos et al., 1993; Viitanen et al., 1995; Heikkila et al., 2000; Seçkin et al., 2000) mensuraram a expansibilidade torácica de seus trabalhos através de um padrão estabelecido por Moll e Wright (1972). Estes autores solicitaram uma inspiração e uma expiração máxima, mensurando a distâncias na expansão torácica, ao nível do quarto espaço intercostal. Realizam-se três medidas consecutivas, conservando a melhor delas. Os sujeitos permaneceram em pé, com as mãos atrás da cabeça. Moll e Write (1972) definem que homens e mulheres de 15 a 24 anos devem ter expansibilidade entre 3,01 e 2,31, respectivamente. Citam ainda que a expansibilidade torácica é maior em homens que mulheres.

Cipriano (1999) descreve um teste simples para avaliação da expansibilidade torácica. Com o indivíduo na posição sentada, colocar uma fita métrica ao nível dos mamilos. Instruir ao sujeito que expire e registrar a medida. Logo após, solicitar inspiração profunda e fazer novo registro. O resultado advém da subtração da maior e menor medida alcançada pelo sujeito. A expansão torácica esperada em um homem adulto normal é de cerca de $5 \mathrm{~cm}$. Espera-se um valor de $2,5 \mathrm{~cm}$ ou mais em indivíduos do sexo feminino.

A avaliação da expansibilidade torácica através da cirtometria foi considerado por Heikkila et al. (2000) como um dos métodos mais sensíveis para se avaliar a eficiência de programas de curto prazo de fisioterapia em sujeitos com espondiloartropatias. 
Apesar disso, a reprodutibilidade deste teste foi considerada pobre, principalmente se realizado sem padronização cuidadosa. Ressalta-se a necessidade de padronização do teste para o que o mesmo se torne confiável.

Entretanto, Pyle et al. (1991) relataram em seu estudo que devido a uma variabilidade de mensuração, considera-se a avaliação da expansão torácica de caráter duvidoso dentro de uma rotina de avaliação.

Não existe grande quantidade de estudos definindo padrões de normalidade para a expansibilidade torácica com sujeitos normais. A maioria destes trabalhos é relacionado a indivíduos com patologias crônicas restritivas, principalmente a espondilite anquilosante.

Burgos et al. (1993) avaliaram a expansibilidade torácica de 157 adolescentes saudáveis e 20 com espondilite anquilosante, com idades entre 11 e 15 anos. A média da expansibilidade do grupo saudável foi de $5,6 \mathrm{~cm}$ (5,9 para homens e 4,8 para mulheres). De todas as variáveis analisadas (idade, altura, peso, sexo e fase da patologia), somente a idade esteve correlacionada com expansão torácica. Combinando os resultados encontrados de seu estudo com o de outros trabalhos, Burgos et al. (1993) concluíram que a expansibilidade aumenta dos 11 aos 34 anos, quando começa a decair lentamente até cerca de $2,5 \mathrm{~cm}$ em indivíduos maiores de 74 anos. Os valores distribuem-se de maneira uniforme em homens e mulheres, sendo que os primeiros apresentam valores maiores.

Os critérios de Nova York de classificação da espondilite anquilosante definem uma expansibilidade normal como aquela que alcança 2,5 cm (Burgos et al., 1993). Entretanto, Moll e Write (1972) citam que a expansibilidade torácica mensurada de três diferentes maneiras é inespecífica para estes indivíduos, não auxiliando no diagnóstico da espondilite anquilosante. Colocam que apenas 39 a $55 \%$ dos homens e mulheres estavam nos intervalos de normalidade. 
Apesar dos poucos relatos encontrados do uso do teste de cirtometria para avaliação da expansibilidade torácica, acredita-se que o mesmo seja de grande valia para a pesquisa e também prática clínica, já que é barato e de fácil realização. Entretanto, deve-se atentar para os cuidados que impedem que o sujeito avaliado realize compensações e conseqüentemente invalide os resultados do teste.

\subsection{Flexibilidade de tronco e pélvis}

A flexibilidade pode ser definida como a máxima amplitude fisiológica passiva de um dado movimento articular. É considerada um dos componentes da aptidão e desempenho físico, sendo relevante para a execução de movimentos simples ou complexos, desempenho desportivo, manutenção da saúde e preservação da qualidade de vida (Araújo, 2000).

Um certo grau de flexibilidade parece ser fundamental para a saúde. Todavia, não são claramente definidos os níveis ótimos de flexibilidade, bem como sua variação em função da idade, gênero, raça e padrão de atividade física regular. Níveis extremamente altos de flexibilidade nem sempre são associados a padrões ótimos de saúde, podendo, inclusive, ser comuns em indivíduos acometidos de certas anormalidades ou enfermidades (Araújo, 2000).

A flexibilidade tende a ser específica para um dado movimento e para uma dada articulação (Araújo, 2000). É alterada com a idade, o que dificulta determinar exatamente o que é uma redução fisiológica, normal da idade, ou causada por limitações patológicas. Para confundir ainda mais estas relações, observa-se uma grande variação na flexibilidade em indivíduos de uma mesma idade (Einkauf et al., 1987). 
A flexibilidade pode ser decomposta em dois componentes: estático e dinâmico. O componente estático refere-se à amplitude máxima de um movimento. O dinâmico refere-se à resistência ou rigidez oferecida ao movimento, dentre de uma determinada amplitude, sendo quantificada para fins de pesquisa através do torque (Araújo, 2000). Assim, o bom funcionamento dos componentes estáticos e dinâmicos depende de um emaranhado de complexas estruturas anatômicas e fisiológicas.

Variações na flexibilidade normal são encontradas freqüentemente, diferindo em homens e mulheres. Entretanto, estas relações são controversas em diversos estudos. Sturrock et al. (1973) apud Einkauf et al. (1987) encontram que homens têm maior mobilidade na extensão, enquanto mulheres apresentam maiores graus de flexão. Entretanto, Moll e Wright (1976) $)^{\star *}$ apud Einkauf et al. (1987) concluíram que a mobilidade de flexão e extensão é maior em homens, enquanto a flexão lateral apresenta maiores valores em mulheres. Moll e Wright (1972) comprovaram, em sujeitos com espondilite anquilosante, que a flexibilidade anterior é maior em homens do que em mulheres.

Os efeitos do envelhecimento sobre as estruturas morfofisiológicas relacionadas com a flexibilidade são bem conhecidos e foram descritos nos capítulos anteriores. Mellin (1987) comprovou em seu estudo que a idade apresentou maior correlação com a flexibilidade do que a altura. O peso apresentou correlação negativa com as medidas de mobilidade, exceto a flexão lateral. Batti'e et al. (1987) comprovaram que idade, sexo e peso afetam a amplitude de movimento.

Muita atenção tem sido dedicada à relação entre flexibilidade da coluna lombar e homeostasia da região dorsal (Batti'e et al. 1987). Mellin (1987) selecionou 476

\footnotetext{
* Sturrock RD, Wojtulewski JA, Hart FD. Spondylometry in a normal population and in ankylosing spondylitis. Rheumatology and Rehabilitation, 1973;12:135-42.

"Moll JMH, Wright V. Measurement of spinal movement. In: Jayson M. The lumbar spine and back pain. New York: Grune \& Stratton Inc; 1976. p.93-111.
} 
sujeitos com idades entre 35 e 55 anos e que relatavam lombalgia crônica. Correlacionou-se a mobilidade espinal à idade, altura, peso, lordose e cifose. A lombalgia esteve mais relacionada com a mobilidade tóraco-lombar do que com a lombar. Também esteve mais relacionada à flexão lateral com rotação do que flexão anterior e extensão.

Apesar de uma das variáveis avaliadas e analisadas por este trabalho tratar-se da flexibilidade anterior do tronco e pélvis, o protocolo de exercícios respiratórios proposto não tem objetivos específicos a este fim. Com isto, objetiva-se verificar se a flexibilidade anterior do tronco e pélvis pode ser influenciada por um programa de exercícios voltados a melhorar a amplitude de movimento da caixa torácica e força muscular respiratória.

Acredita-se que o programa proposto possa influenciar tal variável, uma vez que se tratam de exercícios que influenciam toda a biomecânica da caixa torácica e coluna vertebral. Além disso, o protocolo desenvolvido em meio aquático será influenciado ainda pelos efeitos térmicos e mecânicos da água.

\subsubsection{Avaliação da flexibilidade}

A avaliação da amplitude de movimento articular é tradicionalmente realizada através da goniometria (medida dos ângulos da amplitude de movimentos articulares). Os testes para determinar a mobilidade global enfatizam os movimentos de flexão e extensão da coluna vertebral. A avaliação precisa da mobilidade da coluna vertebral só pode ser realizada através de radiografias da coluna (Kapandji, 1980).

Araújo (2000) propôs um sistema de classificação de testes de flexibilidade. Os métodos de avaliação da mobilidade articular estática podem ser classificados em lineares, angulares ou adimensionais. Os métodos lineares caracterizam-se por utilizar 
a escala métrica para avaliar, indiretamente, a mobilidade articular, normalmente através de movimentos compostos, isto é, movimentos que envolvem mais de uma articulação. Os métodos angulares avaliam a amplitude de movimento de diversas articulações com o auxílio de goniômetros, inclinômetros ou flexômetros. Os métodos adimensionais são aqueles que não possuem unidades convencionais de quantificação, tal como ângulos ou centímetros, atribuindo valores numéricos ou pontos a determinados graus de amplitude de movimentos articulares. Também se pode dicotomizar a resposta em sim ou não.

Apesar de haver vários métodos para mensuração da flexibilidade, a escolha de uma medida acurada e clinicamente viável é difícil, e praticamente todos os métodos têm suas desvantagens (Einkauf et al., 1987).

Vários estudos tentam desenvolver um bom método para avaliação da mobilidade espinal. Um estudo realizado por Fitzgerald et al. (1983) apud Einkauf et al. (1987) utilizou a goniometria para mensurar a flexão lateral e a extensão. Tal método foi escolhido pois a goniometria se mostrou uma ferramenta confiável e conveniente para mensuração da amplitude de movimento de membros superiores e inferiores. $\mathrm{O}$ autor conseguiu boa reprodutibilidade entre os diferentes avaliadores. Entretanto, os autores observaram e concluíram que a goniometria não apresenta boa acurácia nos estudos envolvendo a coluna vertebral, apesar de clinicamente acessível (Einkauf et al., 1987).

Kendall et al. (1995) descreveram um teste para mensurar a flexibilidade da coluna vertebral e comprimento dos isquiotibiais. O indivíduo senta-se com joelhos estendidos e pés em ângulo reto. Recomenda-se que o sujeito tente alcançar a ponta dos dígitos na base do hálux, ou além, indo o mais distante que a amplitude de comprimento muscular permitir. Tanto a coluna quanto os isquiotibiais se alongarão ao

\footnotetext{
"Fitzgerald GK, Wynveen KJ, Rheault W. Objective assessment with establishment of normal values for lumbar spinal range of motion. Physical Therapy. 1983;63:1776-81.
} 
máximo. Os isquiotibiais com comprimento normal permitem que a pelve flexione em direção à coxa até que o ângulo entre o sacro e a mesa seja de aproximadamente $80^{\circ}$. A flexão da coluna lombar permite um aumento na convexidade posterior, visualizado como uma curvatura homogênea e contínua dessa área. Se a flexibilidade da coluna e o comprimento dos isquiotibiais estiverem normais, um adulto médio é capaz de tocar as pontas dos dígitos nos artelhos na inclinação anterior com os joelhos estendidos. Kendall et al. (1995) descreveram ainda quatro diferentes posicionamentos do indivíduo obtidos na realização do teste, de acordo com o comprimento de sua musculatura posterior (Figuras $1-4)$.

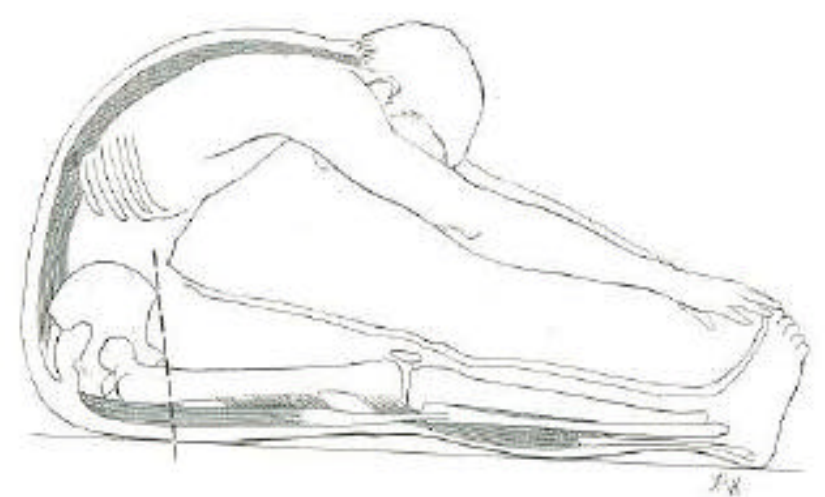

FONTE: Kendall et al. (1995)

Figura 1. Comprimento normal dos músculos da coluna, isquiotibiais e músculos gastrocnêmio-sóleo

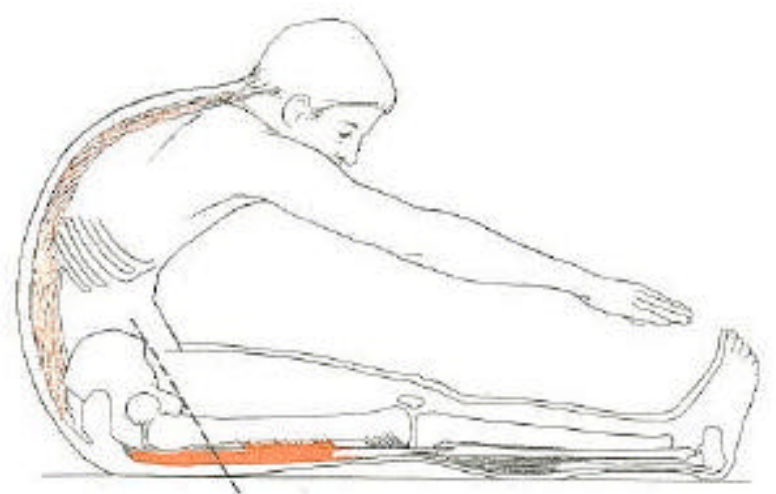

FONTE: Kendall et al. (1995)

Figura 2. Comprimento excessivo dos músculos da coluna, isquiotibiais curtos, comprimento normal de gastrocnêmio-sóleo 


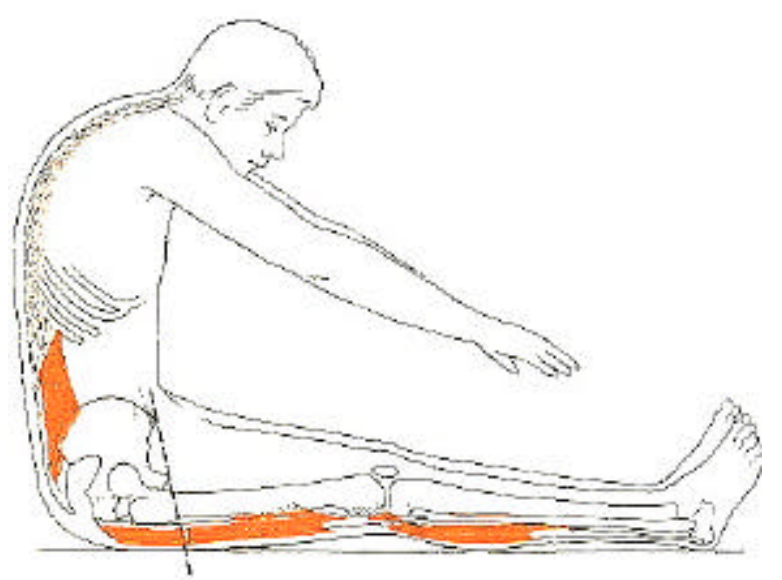

FONTE: Kendall et al. (1995)

Figura 3. Comprimento excessivo dos músculos superiores da coluna, leve encurtamento dos músculos na coluna média e inferior e no gastrocnêmio-sóleo. Isquiotibiais com comprimento normal

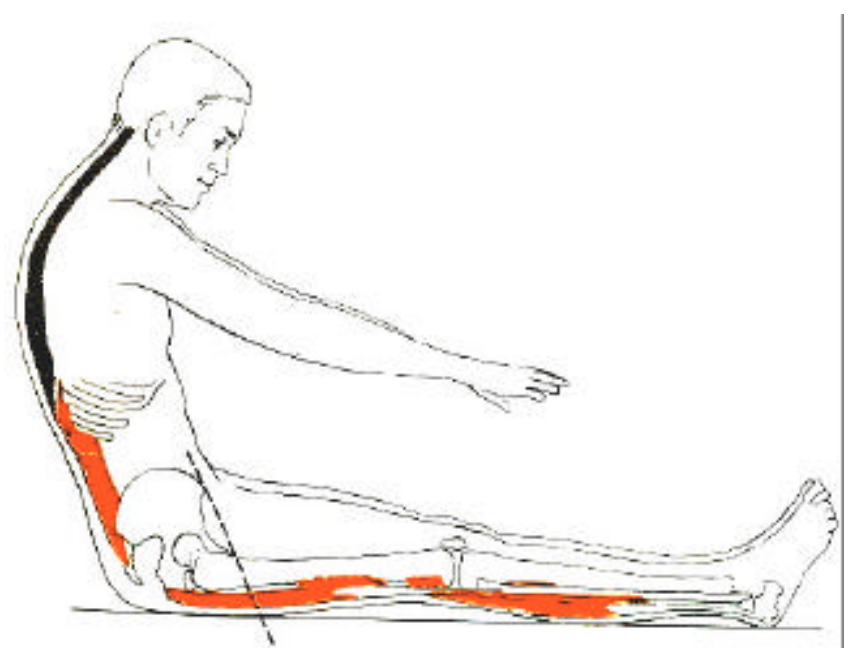

FONTE: Kendall et al. (1995)

Figura 4. Comprimento normal dos músculos da coluna superior, músculos da coluna inferior, isquiotibiais e gastrocnêmio-sóleo curtos

Kapandji (1980) descreve o teste dedo-chão como uma medida simplificada da amplitude global da flexão da coluna vertebral. Consiste em mensurar a distância entre o terceiro dedo e o chão, durante flexão anterior do tronco. O autor coloca que o teste pode ser alterado por variações no posicionamento da pelve e joelhos, além da situação de relaxamento da coluna cervical e membros superiores durante a realização do mesmo. O controle dessas variáveis torna o teste demorado, desconfortável e cansativo para idosos. Perret et al. (2001) colocam ainda que o teste 
de flexão anterior do tronco mensura a mobilidade antero-posterior total (pélvica e espinal).

Perret et al. (2001) elaboraram um estudo para verificar os critérios de validade, confiabilidade e reprodutibilidade do teste. Para validar o teste, comparou-se os resultados do teste dedo-chão com duas radiografias em inclinação anterior, realizados no intervalo de uma hora. Para testar a confiabilidade, consideram que deveria haver quatro testes de sucesso no intervalo de uma hora. Duas avaliações foram realizadas por dois investigadores cegos para verificar a reprodutibilidade interobservadores. Os critérios de reprodutibilidade compararam o dedo-chão com o teste de Schober antes e depois de cinco semanas de reabilitação intensiva. Devido a excelentes índices de validade, confiabilidade e reprodutibilidade, concluiu-se que o teste dedo-chão pode ser utilizado na pesquisa e prática clínica. O teste dedo-chão é considerado mais relevante que o teste de Schober após um programa de reabilitação intensiva, pois os indivíduos freqüentemente apresentam melhoram na flexão lombar e pélvica conjuntamente.

Entretanto, Pyle et al. (1991) demonstraram que o teste dedo-chão consiste de uma medida inválida para avaliação exclusiva da flexibilidade espinal de sujeitos com espondilite anquilosante, já que é influenciado por diversos fatores e estruturas, difíceis de se interpretar. Originalmente um teste para os eretores espinhais e extensibilidade dos isquiotibiais, a distância dedo-chão no plano sagital é influenciada pela flexão do quadril e mobilidade dos tecidos moles da região posterior da coxa. Por isso, não pode ser considerado um meio exclusivo de avaliação da flexibilidade espinal.

Viitanen et al. (1995) classificaram os testes de avaliação de flexibilidade e mobilidade em dois tipos. O primeiro tipo é sensível a ensaios clínicos e o segundo engloba testes utilizados em intervenções de longo prazo. O teste dedo-chão foi 
classificado como uma medida de avaliação sensível a ensaios clínicos, programas de curto prazo.

Pyle et al. (1991) avaliaram a distância dedo-chão com o auxílio de uma régua, mensurando de maneira direta a distância do terceiro dedo ao chão. Atualmente, se utiliza a documentação fotográfica do teste, para posterior avaliação. Esse recurso já foi utilizado com sucesso em avaliações antropométricas (RIEHL, 1988).

Para viabilizar a coleta de distâncias e ângulos através de fotografias, foi proposta a utilização de referências anatômicas, marcadas na pele com adesivos. A distância do terceiro dedo ao chão foi substituída pela distância entre o processo ulnar e o chão (distância punho-chão), uma vez que este tem melhor definição visual na fotografia. A utilização desse método também gera material permanente e permite comparação de pré e pós-testes de forma mais fidedigna ('Caromano et al., 1995; Nonaka et al., 1999; Caromano; Mendes, 2000).

O teste dedo-chão já está bem descrito e padronizado (Viitanen et al., 1995). É considerado por Heikkila et al. (2000) como um dos métodos mais sensíveis para se avaliar a eficiência de programas de curto prazo de fisioterapia em indivíduos com espondiloartropatias. Tal conclusão foi obtida a partir de um estudo que avaliou 13 diferentes testes de mobilidade, com o intuito de se determinar as ferramentas mais sensíveis para se avaliar os efeitos de programas terapêuticos de curto prazo na mobilidade de coluna e tórax em indivíduos com espondiloartropatias.

\footnotetext{
${ }^{1}$ Caromano FA, Ostermayer E, Taniguchi C, Nonaka I, Farias MR. (Faculdade de Medicina da Universidade de São Paulo). Flexibility and posture in elders using analyzed photographic method. (Apresentado no I Congresso Pan-Americano de Gerontologia; 1995; São Paulo, SP).
} 


\section{EXERCÍCIOS RESPIRATÓRIOS TERAPÊUTICOS}

A cinesioterapia, terapia por exercícios, tem seus primeiros relatos relacionados à função respiratória na década de 70 , sobretudo com exercícios que motivam a fase expiratória, como soprar luvas, canudos ou transferir líquidos de um frasco para outro (Azeredo, 2002).

A importância da respiração tem relatos antigos, associado ou não à alguma forma de exercício. Cita-se que o exercício respiratório é responsável por redução na ansiedade e mudança na atitude perante a vida (Lacasse et al., 1997). Algumas técnicas, como a ioga, centralizam seus exercícios na importância vital do exercício. Um estudo proposto por Tandon (1978) apud Lacasse et al. (1997) comparou os efeitos da fisioterapia pulmonar simples com exercícios respiratórios baseados na ioga. O programa foi aplicado três vezes por semana, por nove meses. O grupo que realizou exercícios de ioga apresentou melhora na capacidade máxima de exercício cerca de $43 \%$ maior. Os sujeitos referiram também melhora na dispnéia e tolerância ao exercício geral.

Um programa de exercícios voltados a melhorar a função respiratória consiste basicamente de uma série de movimentos corporais, particularmente envolvendo tronco e membros superiores, combinados com padrões ventilatórios específicos. Neste trabalho, foram solicitadas inspirações e expirações profundas lentas, concomitantes a exercícios de tronco e membros superiores. Tal atitude aumenta os movimentos torácicos de um ciclo normal e solicita maior esforço muscular. A inspiração profunda pode produzir uma eficiente expansão pulmonar, que impede o aparecimento de "shunt" intrapulmonar e atelectasia (Azeredo, 2002). Estudando a 
técnica de sustentação máxima da inspiração, o autor observou que as inspirações lentas produziam um resultado muscular melhor. Justifica que a relação entre força e velocidade mostra que quanto mais rápido o músculo se encurta durante a contração, menor a força contrátil que ele é capaz de gerar.

Azeredo (2002) cita diversas modalidades de padrões respiratórios a serem adotados em programas de cinesioterapia respiratória. Dentre eles, podem ser citados o padrão ventilatório ao nível da capacidade residual funcional, que favorece a ventilação das zonas basais, diminuindo a hipoventilação alveolar e as secreções brônquicas. Ela consiste em uma expiração oral tranqüila até o nível de repouso expiratório, seguida de uma inspiração até o nível de volume corrente ou volume de reserva inspiratória.

Estudos anatômicos garantem que os músculos respiratórios são músculos esqueléticos, de modo que suas respostas ao treinamento são similares aos dos músculos esqueléticos (Shaffer et al., 1981; Kim, 1984; Pardy et al., 1988), com melhora na força e resistência ("endurance") e estando sujeitos a deficiências e alterações por déficit nutritivo e fadiga muscular respiratória (Sampaio et al., 2002). Um estudo realizado por Belman e Gaesser (1988) comprovou que os músculos respiratórios de idosos na sétima e oitava década de vida são treináveis, com ganhos semelhantes aos obtidos com indivíduos jovens.

Deste modo, o tipo e ritmo ventilatório utilizados determinam os tipos de benefícios alcançados. A força é treinada mediante treino específico da musculatura respiratória (treino utilizando as forças estáticas máximas). A melhora na resistência pode ser alcançada por treinamento específico (por meio de carga inspiratória limite e

\footnotetext{
"Tandon MK. Adjunct treatment with yoga in chronic severe airways obstruction.
} Thorax.1978;33:514-7. 
carga inspiratória resistida) ou não específico (Shaffer et al., 1981; Pardy et al., 1988; Winer et al., 1992; Azeredo, 2002).

No treinamento por carga inspiratória limite, o sujeito é obrigado a gerar uma pressão limite predeterminada a cada respiração para abrir a válvula e permitir o fluxo aéreo (Azeredo, 2002). A resposta a este treinamento pode ser um aumento na resistência máxima tolerável em um período específico de tempo ou aumento no tempo em que uma determinada carga é tolerada (Pardy et al., 1988).

Apesar dos benefícios desta modalidade, Olgiati et al. (1989) afirmam que o excesso de resistência externa ocasiona sobrecarga e pode levar a falência miocárdica. Em casos de fraqueza severa, os músculos fadigados estão trabalhando contra uma complacência reduzida dos pulmões e caixa torácica e provavelmente estão próximos do seu limiar de fadiga. Assim, a resistência inspiratória pode ser potencialmente danosa e não é recomendada (Smith et al., 1988). É difícil manter treino com cargas pesadas por períodos prolongados, principalmente por causa da dependência de energia anaeróbica, acúmulo de lactato e conseqüente fadiga (Sturdy et al., 2003).

O treinamento por carga inspiratória resistida é voltado a melhorar a "endurance" dos músculos ventilatórios, utilizando a hiperpnéia isocápnica voluntária. Este método tem sido pouco estudado em razão da complexidade do sistema requerido (Azeredo, 2002). Nele, o indivíduo mantém altos níveis de ventilação em aparelhos com orifícios cada vez menores, sustentando as condições isocápnicas por no mínimo 15 minutos (Pardy et al., 1988).

Mostrou-se recentemente que a "endurance" do diafragma é prejudicada durante esforços máximos que elevam a pressão abdominal comparado com esforços inspiratórios que causam pequenos ou nulos aumentos na pressão abdominal. Estes 
achados sugerem que a pressão pleural e abdominal são fatores que influenciam o desempenho máximo (McKenzie e Gandevia, 1986).

O treinamento não específico envolve exercícios gerais, não voltados especificamente ao sistema respiratório. Entretanto, indivíduos que apresentam um elevado grau de limitação ao exercício podem não obter treinamento respiratório quando submetidos ao exercício comum, em função da pequena reserva respiratória. Neste caso, a ventilação máxima do exercício está próxima ou excede a ventilação voluntária máxima. Estes sujeitos toleram pouco o trabalho realizado com os membros superiores porque necessitam utilizar os músculos requeridos nessas extremidades como músculos respiratórios (Azeredo, 2002).

Pryor e Webber (2002) citam que o exercício intensivo dos membros superiores pode levar a incremento na força e resistência da musculatura respiratória. Coloca que esta modalidade é provavelmente o mais benéfico método para melhorar a força e a resistência dos músculos respiratórios para sujeitos que são capazes de sustentar altos níveis de ventilação, pois, dessa maneira, adquirem um treinamento efetivo dos músculos respiratórios. De maneira semelhante, FRITH (2002) cita que o exercício geral ou específico do membro superior (músculos peitorais) melhora a função ventilatória, talvez com a mesma amplitude do que a melhora dada pelo treino muscular ventilatório.

Os exercícios gerais, exercícios de membros superiores e o treinamento muscular respiratório podem melhorar a tolerância à dispnéia, aumentar a força muscular respiratória e melhorar a qualidade de vida (Lacasse et al., 1997; Pryor e Webber, 2002). Um programa de cinesioterapia associado a um controle postural efetivo e a administração de oxigênio podem reverter quadros de hipoxemia leve e moderada (Azeredo, 2002). 
Kim (1984) cita que o exercício respiratório não melhora a dificuldade expiratória de indivíduos com enfisema pulmonar. Em contrapartida, melhora a função inspiratória, já que seu treino melhora a efetividade da ventilação, reduz o trabalho respiratório e melhora a oxigenação tecidual.

O treino de fortalecimento da musculatura ventilatória tem mostrado aumento nas pressões isométricas geradas pelos músculos inspiratórios e expiratórios Shaffer et al., 1981). Pode ser recomendado para sujeitos com fraqueza muscular respiratória, exceto quando a fadiga muscular respiratória é causa de fraqueza ou a fraqueza é severa (Pardy et al., 1988).

O treinamento da força dos músculos respiratórios pode vencer cargas mecânicas impostas, como a redução da complacência e o aumento da resistência de via aérea. O treinamento de "endurance" pode ser útil para atrasar ou prevenir a fadiga muscular (Azeredo, 2002). É indicado para sujeitos com redução de força, indivíduos portadores de doença neuromuscular, alterações da parede torácica e atrofia dos músculos respiratórios por várias causas - como uso prolongado de ventilação mecânica ou corticosteróides (Azeredo, 2002).

O fortalecimento muscular respiratório em indivíduos sedentários, atletas e pneumopatas tem sido objeto de interesse de diversos pesquisadores, preocupados com as alterações ocorridas no organismo destes sujeitos, sobretudo com o enfraquecimento da musculatura respiratória. Apesar disso, existem dados bastante diversificados na literatura, inclusive controversos, e diferentes pontos de vista sobre os resultados do fortalecimento muscular respiratório (Sampaio et al., 2002).

Mahler e Belman (1988) dizem acreditar que o treino muscular respiratório deve ser um componente de todas as terapias para indivíduos com DPOC sintomáticos. Justifica sua posição em três fatos. Primeiro, a dispnéia é associada com o desempenho muscular. Segundo, a força ou "endurance" estão reduzidas em muitos 
sujeitos com DPOC. Terceiro, ao se aumentar a força ou "endurance", pode-se reduzir potencialmente a sensação de falta de ar.

Diversos estudos foram realizados objetivando verificar os efeitos de um programa de fortalecimento muscular respiratório específico, principalmente em relação à tolerância ao exercício. Entretanto, os resultados são muito contraditórios (Pardy et al., 1988; Winer et al., 1992; Lacasse et al., 1997; Sampaio et al., 2002).

A grande maioria dos estudos utilizando fortalecimento muscular respiratório é realizados em indivíduos com DPOC. Os trabalhos chegam a conclusões interessantes. Lareau et al. (1999) citam que o treino da musculatura respiratória reduz a dispnéia, limitação ao exercício e hipercapnia nestes sujeitos. Vale et al. (1993) apud Sampaio et al. (2002) relataram melhora na capacidade de realizar exercícios físicos e na qualidade de vida de sujeitos com DPOC quando submetidos a um programa de seis semanas de fortalecimento respiratório.

Entretanto, Lacasse et al. (1997) relatam novamente resultados contraditórios ao analisar 22 estudos que utilizaram o treino muscular respiratório adicionados a programas de exercícios em indivíduos com DPOC.

Azeredo (2002) cita que padrão respiratório adotado durante o treinamento específico em sujeitos com DPOC é muito diferente do exigido no esforço, utilizando freqüências respiratórias e taxas de fluxo altas. Este fato poderia levar a uma ausência de real melhora de "endurance" dos músculos respiratórios após treinamento.

Acredita-se que a dificuldade em determinar o melhor regime de treinamento, número pequeno de sujeitos em cada estudo, falta de supervisão do padrão respiratório adequado e padrões diferentes adotados entre os exercícios globais e os

\footnotetext{
* Vale F, Readon JD, Zuwallack RL. The long-term benefits of outpatient pulmonary rehabilitation on exercise endurance and quality of life. Chest.1983;103:42-5.
} 
específicos para a musculatura respiratória podem justificar os efeitos variáveis em resposta ao treinamento (Azeredo, 2002).

Apesar dos diversos benefícios, Sonne (1994) cita as respostas negativas ao exercício respiratório resistido. Uma resistência muito intensa pode levar a uma redução no volume corrente, aumento na taxa respiratória e retenção de dióxido de carbono. Um exercício bem tolerado pode tornar-se intolerável se aplicado por tempo prolongado e uma carga bem tolerada no repouso pode tornar-se dificilmente tolerável durante o exercício.

A maioria dos estudos relacionada ao treinamento muscular respiratório é dirigidos à musculatura inspiratória. A respeitos do exercício expiratório, Kim (1984) cita que ele não melhora a dificuldade expiratória de sujeitos com enfisema pulmonar. Em contrapartida, melhora a função inspiratória, já que seu treino melhora a efetividade da ventilação, reduz o trabalho respiratório e melhora a oxigenação tecidual (Kim, 1984). Entretanto, um estudo realizado por Kurabayashi et al. (2000), também com sujeitos enfisematosos, demonstrou que exercícios expiratórios realizados com a boca e nariz imerso (contra a resistência da pressão hidrostática) produziram um aumento significativo no $\mathrm{VEF}_{1}$, pico de fluxo expiratório e $\mathrm{PaO}_{2}$ (pressão parcial de oxigênio no sangue arterial) e redução na $\mathrm{PaCO}_{2}$.

Observa-se que o fortalecimento muscular respiratório é tema de diversos trabalhos já realizados e idealizados em todo o mundo. Entretanto, poucos utilizam a cinesioterapia com tais fins. Grande parte das referências utiliza aparatos que causam resistência mecânica ao fluxo inspiratório e expiratório e estuda sujeitos com DPOC. 


\subsection{Influência da imersão e exercício na função respiratória}

"Na água, a alma encontra a liberdade que o corpo perdeu". A frase do mentor de um dos mais divulgados métodos de reabilitação em hidroterapia traduz o fator integrante e motivante que a água exerce sobre as pessoas que a ela confiam seus corpos e almas. Derivada das palavras gregas "hydor" (água) e "therapeia" (cura) (Campion, 2000), a água tem relatos de uso terapêutico e recreativo, cujas datam confundem-se com a história da civilização.

A água é, certamente, um meio diferenciado e bastante apropriado para desenvolver atividades com indivíduos idosos. Permite o atendimento de grupos e facilita a recreação e socialização. O treino do domínio da água, como com

movimentos básicos de natação, associados a melhoras funcionais, melhoram a autoestima e autoconfiança do indivíduo imerso (Caromano e Candeloro, 2001).

Grande parte dos benefícios da hidroterapia justificam-se pelos efeitos físicos da água no corpo imerso, que resultam nas propriedades fisiológicas e terapêuticas do tratamento em piscina terapêutica. Os benefícios também derivam dos efeitos do exercício, que variam com a duração do tratamento e exercício, tipo, progressão e intensidade do exercício, temperatura da água, postura, movimentos associados dos membros superiores e também com a patologia do indivíduo (Bates e Hanson, 1998).

\subsubsection{Efeitos físicos e fisiológicos da água}

As propriedades mecânicas da água levam em consideração a densidade do corpo imerso, relação entre sua massa e volume. Comparando a densidade do corpo imerso com a da água, é possível determinar se um corpo flutua ou submerge. No caso do organismo humano, a densidade relativa varia com a composição corporal, de 
maneira que pessoas com maior quantidade de gordura flutuam com maior facilidade (Skinner e Thomson, 1985).

A flutuação, força de empuxo no sentido oposto à gravidade, confere aos corpos imersos um efeito de sustentação, permitindo que os mesmos sejam submetidos a diferentes sensações e movimentos, além de marcha e ortostatismo precoces. Ao anular a força da gravidade, a flutuação ainda contrapõe-se ao acúmulo venoso de sangue nos membros inferiores, auxiliando na redução de edemas e aprimorando o tráfego venolinfático (Skinner e Thomson, 1985; Becker, 2000).

Todos os corpos imersos também estão submetidos a pressão hidrostática. A pressão hidrostática é definida como a força exercida por unidade de área, em que a força de convenção atua supostamente de modo perpendicular à área de superfície, e é exercida igualmente sobre toda a área da superfície de um corpo imerso em repouso, a uma dada profundidade (Lei de Pascal) (Caromano e Nowotny, 2002). A pressão hidrostática aumenta com a densidade e profundidade (Becker, 2000; Fuentes e Santos, 2002).

A viscosidade, ou resistência do fluido, é causada pela fricção entre suas moléculas, que tendem a aderir-se a superfície do corpo que se move através dele, causando resistência ao seu movimento (Skinner e Thomson, 1985).

Os efeitos térmicos da água são peculiares, de modo que permitem grande troca de calor com o corpo imerso. Tal troca ocorre de duas maneiras: condução e convecção. A primeira ocorre pelo movimento normal de energia que ocorre do corpo mais quente para o mais frio. A convecção é a perda causada pelo movimento da água contra o corpo, que ocorre mesmo em temperaturas idênticas (Skinner e Thomson, 1985). A troca de calor entre o meio e o corpo imerso é regulada pelo calor específico, que avalia o tempo necessário para determinado corpo esquentar ou esfriar. Assim, quanto maior o calor específico, maior a facilidade para que haja 
alterações de temperatura. O calor específico da água é muito maior que o do ar, de modo que a perda e ganho de calor se dão de maneira muito mais fácil (Skinner e Thomson, 1985).

A simples imersão em repouso já confere ao organismo imerso grandes alterações, principalmente cardiovasculares. As alterações neste sistema ocorrem em contato de qualquer magnitude com a água, como o simples molhar da face ou imersão completa. Esse contato com a água leva a instalação do reflexo de mergulho, que consiste em bradicardia, vasoconstricção periférica e aumento no suprimento sangüíneo para órgãos vitais. A esse reflexo atribui-se o papel de tentar conservar calor do organismo, além de manter regular a pressão arterial. A resposta fisiológica de bradicardia à imersão advém de diversos mecanismos, quase todos devido a hipervolemia central advinda da vasoconstricção induzida pelo frio e pelo desvio de sangue dos membros inferiores, induzidos pela flutuação e pressão hidrostática da água (Skinner e Thomson, 1985; Bates e Hanson, 1998; Becker e Cole, 2000; Bookspan, 2000). O aumento no retorno venoso, base para a grande maioria das alterações fisiológicas da imersão (Bates e Hanson, 1998), ocorre quando o nível da água está acima do processo xifóide (Becker e Cole, 2000; Bookspan, 2000).

Conforme dito, a água exerce pressão sobre todos os corpos imersos. Estima-se que esta pressão seja de $1,0 \mathrm{mmHg} / 1,36 \mathrm{~cm}$ de profundidade. Assim, um corpo imerso a uma profundidade de 1,2m está sujeito a uma força igual a $88,9 \mathrm{mmHg}$, que é ligeiramente maior que a pressão arterial diastólica - podendo auxiliar na resolução de edemas (Caromano e Nowotny, 2002). A pressão transmural nos grandes vasos aumenta de 3,0 mmHg a $5 \mathrm{mmHg}$ para 12 a $15 \mathrm{mmHg}$ (Caromano et al., 2003). A pressão hidrostática afeta todo o sistema venoso, cavidades corporais e músculos, de tal forma que pode ocorrer uma redução no perímetro torácico com o indivíduo na posição vertical de um a $3,5 \mathrm{~cm}$ e redução no perímetro abdominal de 2,5 a $6,5 \mathrm{~cm}$, 
bem como alterações metabólicas por redução no $\mathrm{VO}_{2}$, o que se traduz em relaxamento muscular e redução no tônus (Fuentes e Santos, 2002). Caromano et al. (2003) citam que a circunferência torácica reduz-se 10\% em relação ao valor de terra. O centro diafragmático desloca-se cranialmente (Rosales e Represas, 2002; Caromano et al., 2003), a pressão intratorácica aumenta de $0,4 \mathrm{mmHg}$ para 3,4 mmHg. A média da pressão atuando sobre a parede torácica, durante a imersão até o pescoço, no final de uma expiração espontânea, é de $21 \mathrm{cmH}_{2} \mathrm{O}$. A pressão da parede abdominal, com imersão em água até imediatamente abaixo do diafragma, é de 12 $\mathrm{cmH}_{2} \mathrm{O}$ (Caromano et al., 2003). A imersão ao nível do pescoço aumenta a pressão abdominal sobre o diafragma de seis para $12 \mathrm{cmH}_{2} \mathrm{O}$ (Kurabayashi et al., 1997).

Estas alterações de pressão influenciam diretamente os volumes e capacidades pulmonares.

A capacidade vital sofre uma redução de $6 \%$ e $9 \%$, variando de acordo com o estudo (Caromano et al., 2003). Bréchat et al. (1999) referem queda de 10\% na capacidade vital em imersão em repouso, ao nível do processo xifóide. O volume de reserva expiratória reduz-se $66 \%$. Com imersão ao nível cervical, o volume de reserva expiratória altera-se de 1,86 para 0,56, em média (Caromano et al., 2003). Bréchat et al. (1999) encontraram uma tendência marcante de redução na capacidade vital e $\operatorname{VEF}_{1}(p=0,06)$ quando o indivíduo é submergido ao nível do processo xifóide. No repouso, o volume corrente e freqüência respiratória parecem não sofrer alterações com a imersão em repouso (Bookspan, 2000). A pressão hidrostática altera marcadamente o espaço morto das vias aéreas superiores, reduzindo aproximadamente 50\% do espaço total (Kurabayashi et al., 1997).

As alterações na ventilação culminam em aumento no trabalho respiratório de $60 \%$ (Bookspan, 2000) a 65\% (Caromano et al., 2003). A imersão é ligada a um aumento na carga respiratória por dois motivos. O primeiro deve-se exatamente a esta 
hipervolemia central relatada no parágrafo anterior, que se traduz em um maior volume sangüíneo inunda o tecido pulmonar e a complacência pulmonar reduzida requer um maior esforço ventilatório. O segundo fator se deve a pressão hidrostática. Enquanto a pressão nas vias áreas permanece a mesma da atmosfera, a pressão da água sobre o abdome e tórax é mais alta, a qual empurra o diafragma no sentido cranial, aumenta a pressão transtorácica e reduz a capacidade residual funcional e a capacidade vital (Bréchat et al., 1999; Becker e Cole, 2000).

\subsubsection{Imersão, exercício e função respiratória}

Os efeitos de um programa de exercícios aquáticos são amplamente estudados. Alguns trabalhos relatam os efeitos da imersão e exercício aquático na função respiratória, bem como seus benefícios e riscos potenciais.

Acredita-se que os efeitos do exercício físico na ventilação são semelhantes ao exercício realizado em terra. Pode haver um aumento na freqüência respiratória em decorrência do aumento na demanda de oxigênio e produção de dióxido de carbono (Cureton, 2000).

Bréchat et al. (1999) comprovaram que o exercício em água demanda uma maior necessidade ventilatória e proporciona um maior gasto energético quando comparado ao mesmo exercício realizado em terra. Entretanto, sabe-se que para exercícios em solo, a taxa de gasto de energia depende da intensidade do exercício (velocidade de movimento e desenvolvimento de força), peso corporal e habilidade na execução de atividade. Na água, a força de flutuação reduz consideravelmente o peso do corpo, mas a viscosidade é maior que no ar e há também um maior gasto para manutenção da temperatura corporal. Deste modo, comparando-se os exercícios realizados em 
terra e na água, o gasto de energia pode ser maior, igual ou menor, dependendo da atividade, profundidade da água e velocidade de execução (Cureton, 2000).

Fuentes e Santos (2002) citam que o exercício aquático pode levar a reeducação respiratória, já que a pressão hidrostática fortalece a musculatura inspiratória.

Já divulgados que os exercícios respiratórios aquáticos são úteis em indivíduos com DPOC, devido aos efeitos da pressão hidrostática em adição aos efeitos dos exercícios respiratórios convencionais realizados sob a pressão atmosférica. Acreditase que a expiração através da pressão da água eleva a pressão subdiafragmática peritoneal, resultando em carga contra a contração do diafragma durante a inspiração e a assistência para elevar o diafragma durante a expiração. Além disso, o aumento no retorno venoso e débito cardíaco levam a uma melhora nas trocas gasosas (Kurabayashi et al., 2000).

Bréchat et al. (1999) estudaram os efeitos da imersão sobre variáveis relacionadas ao sistema respiratório. Comparou dois grupos de nove sujeitos que realizaram exercícios de ciclismo por 30 minutos. O primeiro grupo realizou os exercícios imersos até o nível do processo xifóide, com água a $33{ }^{\circ} \mathrm{C}$. O segundo realizou o exercício em ambiente terrestre. Ambos grupos realizaram exercícios a $60 \%$ do $\mathrm{VO}_{2 \text { máx }}$ e mesma carga ergométrica. Não houve diferença no volume minuto de ventilação, volume corrente, freqüência respiratória, volume inspiratório nos exercícios realizados em água e em terra. Entretanto, utilizando uma mesma carga ergométrica, o volume minuto de ventilação, volume corrente, freqüência respiratória, tempo inspiratório e nível de lactato plasmático foram significativamente maiores em água. A potência do exercício alcançada na em indivíduos saudáveis imersos no nível do processo xifóide foi somente $60 \%$ do alcançado em terra. Para alcançar o mesmo trabalho ergométrico em água do que em terra, foi necessário aproximadamente $130 \%$ do $\mathrm{VO}_{2}$ utilizado em terra. Concluiu que o exercício em água leva a uma maior 
necessidade ventilatória e proporciona um maior gasto energético quando comparado ao mesmo exercício realizado em terra.

Kurabayashi et al. (1997) realizaram um estudo com indivíduos com asma, submetidos a oito minutos de natação. Observou que a redução no VEF 1 é menor que após ciclismo ou corrida terrestre.

Perk et al. (1996) selecionaram 20 sujeitos com DPOC estável e os dividiram em dois grupos. O primeiro realizou exercícios aquáticos submáximos para membros superiores por 15 minutos em piscina a $32{ }^{\circ} \mathrm{C}$ e o segundo seguiu o mesmo protocolo em terra. Foram avaliadas a pressão sistólica e diastólica, capacidade vital, pico de fluxo expiratório, $V E F_{1}$, freqüência cardíaca, freqüência respiratória e saturação de oxigênio durante o repouso e protocolo de exercícios. No repouso, as pressões sistólica e diastólica, capacidade vital, $V_{E F}$ e pico de fluxo expiratório foram menores na água do que em terra (14 mmHg, $6 \mathrm{mmHg}, 12 \%, 14 \%$ e 18\%, respectivamente). Durante o exercício, houve uma sensação de aumento no trabalho respiratório em alguns períodos do treinamento. Entretanto, não houve necessidade de interromper o tratamento por sintoma qualquer em nenhum momento. O exercício aquático mais extenuante resultou em menor queda na saturação de oxigênio comparado com o exercício em terra. Apesar das restrições pulmonares observadas na imersão em repouso, todos os sujeitos desenvolveram o treino melhor no ambiente aquático, sem dessaturação clinicamente relevante, arritmias ou desconfortos. Os autores sugeriram que a adaptação cardiorespiratória durante o treinamento físico em água compensou completamente a restrição de volume pulmonar dado pela pressão hidrostática.

A natação e o mergulho podem induzir o desenvolvimento de volumes pulmonares estáticos acima dos normais. Nestes desportos, os músculos inspiratórios são fortalecidos, pois trabalham contra a resistência adicional do peso da água que comprime o tórax. Isto pode explicar as capacidades vitais relativamente grandes 
relatadas para mergulhadores sem equipamento especial e nadadores competitivos (McArdle et al., 1996).

Um exercício em piscina pode aumentar especificamente a carga aos músculos respiratórios e reduzir o espaço morto, com deterioração mínima da função respiratória. Tudo isso resulta em melhora nas trocas sangüíneas gasosas e função respiratória a longo prazo, além de reduzir a sintomatologia clínica logo após o exercício (Kurabayashi et al., 1997).

Similarmente a outras modalidades de exercício físico, o protocolo de cinesioterapia respiratória proposto pode alterar a composição corporal, com perda de peso ou ainda sua manutenção, com redução da massa gordurosa e aumento da massa magra. O sistema respiratório é alterado por modificações no peso corporal. Assim, é importante que tais alterações sejam monitoras com o objetivo de se impedir que correlações errôneas sejam estabelecidas. 


\section{CASUÍSTICA E MÉTODOS}

\subsection{Tipo de Estudo}

Trata-se de um ensaio clínico randomizado, que comparou dois protocolos de cinesioterapia respiratória, realizados em dois ambientes diferentes - aquático e terrestre.

\subsection{Local}

O estudo foi realizado na Clínica de Fisioterapia da Universidade Estadual do Oeste do Paraná - "Campus" Cascavel e no Laboratório de Reatividade Comportamental da Faculdade de Medicina da Universidade de São Paulo.

Para o protocolo terrestre foi utilizada uma sala de dimensões $11,5 \times 11,5 \mathrm{~m}$. Para o protocolo aquático, foi utilizada uma piscina aquecida a $32 \pm 2^{\circ} \mathrm{C}$, de dimensões 11,8 x 7,75m e 1,05m de profundidade. O grupo controle utilizou sala com dimensões de 7 $\mathrm{x} 11,5 \mathrm{~m}$.

\subsection{Participantes}

Foram selecionados 81 idosos com idade entre 60 e 65 anos. O cálculo da amostra foi realizado desejando $90 \%$ de poder estatístico para detectar a diferença de $40 \%$ do grupo intervenção e assumindo um $\alpha$ de $5 \%$ e intervalo de confiança de $95 \%$. Utilizou-se a fórmula proposta por Pocock, em 1983. 
Os voluntários foram selecionados através de cadastros realizados por instituições religiosas ou unidades básicas de saúde. O convite foi realizado via ligação telefônica e/ou visita residencial, na qual esclareceu-se os objetivos básicos do trabalho. Os interessados foram orientados a comparecer ao local de execução do trabalho para que fossem submetidos ao "Protocolo de Entrevista Geral". Este protocolo (descrito no Anexo A) foi realizado com o objetivo de se verificar o enquadramento do voluntário nos critérios de inclusão e exclusão, posteriormente citados.

Os voluntários foram selecionados segundo critérios específicos. Deveriam ser socialmente ativos, mas não praticar qualquer tipo de atividade física mais de uma vez por semana. Deveriam não ter fumado nos últimos dez anos, não apresentar disfunções de origem respiratória, músculoesquelética, neuromotora ou cardiovascular, nem doença crônica ou queixas impeditivas das atividades físicas a serem treinadas. Foram excluídos os indivíduos que apresentassem alterações que dificultassem ou impedissem a relação do sujeito com a imersão, como hidrofobia, úlceras ou outras alterações dérmicas. Foi considerada ainda a disponibilidade de tempo, meios de transporte, aceitação da rotina de treinamento - que previa um mínimo de faltas de $20 \%$, além de intenção de completar o treinamento e fornecimento do consentimento informado.

Todas as intercorrências clínicas (como oscilações na pressão arterial, cefaléias, vertigens e náuseas) ocorridas durante a realização dos exercícios propostos foram anotadas, com o objetivo de que se pudesse estudar a exclusão do voluntário caso estas intercorrências representassem um perigo para a saúde do voluntário ou pudesse interferir no resultado do estudo. A exclusão seria executada caso o voluntário apresentasse sintomas que o impedissem de realizar as atividades em mais de um cinco das dez primeiras sessões, ou a qualquer 
momento, a critério do voluntário ou clínico por ele responsável. Não houve nenhum caso de exclusão por este motivo.

Os voluntários também foram regularmente questionados a respeito de possíveis alterações dérmicas, possivelmente decorrentes do uso da piscina. Dentre as alterações mais comumente encontradas estão os pruridos e eritemas. Também poderiam ser detectadas alterações decorrentes de processos patológicos, como manchas decorrentes de contaminações por micoses fúngicas e bacterianas. Neste caso, o voluntário seria encaminhado a avaliação clínica. Se realmente diagnosticada tal alteração, seria verificado o tempo necessário de afastamento do sujeito do ambiente aquático. Se este ultrapassasse dez dias, o mesmo seria imediatamente excluído do trabalho. Também não houve intercorrências neste sentido.

\subsection{Procedimentos}

\subsubsection{Entrada e aleatorização}

Após verificar o perfeito enquadramento do sujeito nos critérios de inclusão através da análise detalhada do "Protocolo de Entrevista Geral" (Anexo A), os sujeitos foram convidados a ler e assinar o termo de consentimento livre e esclarecido (Apêndice). Previamente, em um escritório central, foram criados 81 envelopes selados, opacos, idênticos e numerados. Os sujeitos deram entrada seqüencial no estudo. Através do sorteio dos envelopes previamente preparados, os 81 sujeitos foram randomizados em três grupos, conforme descrito abaixo: 
- $\quad$ Grupo $1\left(\mathrm{G}_{1}\right)$ - 27 sujeitos, que foram submetidos a um protocolo de exercícios respiratórios no meio aquático (Quadro 1).

- $\quad$ Grupo $2\left(\mathrm{G}_{2}\right)$ - 27 sujeitos, que foram submetidos a um protocolo de exercícios respiratórios no meio terrestre (Quadro 1).

- Grupo $3\left(\mathrm{G}_{3}\right)$ - 27 sujeitos, que não sofreram intervenção de exercícios, atuando como controle. Este grupo foi submetido a atividades diferentes de exercícios, tais como palestras relacionadas à saúde (Quadro 2).

Antes que os 81 sujeitos que se enquadrassem nos critérios de inclusão e exclusão aceitassem participar do estudo, foram contatados 397 sujeitos.

Durante o desenvolvimento dos protocolos, oito sujeitos do $\mathrm{G}_{1}$ foram excluídos do estudo (quatro por excesso de faltas, um integrou outro programa de atividade física enquanto participava do estudo e três desistiram alegando falta de tempo e/ou dificuldade em conciliar os horários de atendimento com suas atividades diárias). Dos integrantes restantes (total de 19), 17 eram mulheres e dois eram homens, com média de idade de 61,95 anos.

No $G_{2}$, oito sujeitos foram excluídos do estudo. Destes, um foi a óbito por infecção urinária após a avaliação inicial, não chegando a participar necessariamente do programa. Dois foram excluídos por excesso de faltas. Cinco desistiram, sendo que destes dois relataram falta de tempo para participar do programa, um revelou dificuldades financeiras em relação ao transporte até o local de atendimento e dois não revelaram as causas de sua desistência. Dos 19 sujeitos que completaram o tratamento, 17 eram mulheres e dois homens, com média de idade de 62,47 anos.

No $G_{B}$, seis sujeitos desistiram das atividades propostas. Destes, dois relataram dificuldades em acompanhar os horários propostos e os quatro restantes não justificaram sua desistência. Este grupo concluiu suas atividades com um total de 21 
sujeitos (18 mulheres e três homens), com média de idade de 62,04 anos. Estes dados estão expostos na Tabela 2.

Tabela 2 - Descrição da amostra

\begin{tabular}{|c|c|c|c|c|c|c|c|c|c|c|}
\hline GRUPO & MÉDIA DE IDADE & & & & & JEI & $\overline{O S}$ & & & \\
\hline & & & Inicia & & & sis & nte & & Fin & \\
\hline & Sexo & $\mathrm{F}$ & $M$ & Total & $\mathrm{F}$ & $M$ & Total & $\mathrm{F}$ & $M$ & Tota \\
\hline $\mathrm{G}_{1}$ & 61,95 & 24 & 3 & 27 & 8 & 0 & 8 & 17 & 2 & 19 \\
\hline $\mathrm{G}_{2}$ & 62,47 & 22 & 5 & 27 & 5 & 3 & 8 & 17 & 2 & 19 \\
\hline $\mathrm{G}_{3}$ & 62,02 & 21 & 6 & 27 & 2 & 4 & 6 & 18 & 3 & 21 \\
\hline TOTAL & 62,15 & 67 & 14 & 81 & 15 & 7 & 22 & 52 & 7 & 59 \\
\hline
\end{tabular}

\subsubsection{Avaliação}

Os 81 voluntários selecionados foram submetidos a uma avaliação funcional respiratória (pré-teste). Foram realizados um conjunto de quatro testes, todos no período da manhã e por examinadores extensivamente treinados. Os exames avaliaram as principais disfunções concorrentes no processo de alteração da biomecânica respiratória durante o envelhecimento: expansibilidade torácica, flexibilidade de coluna e pelve e força muscular respiratória.

Também foi mensurado o índice de composição corporal. Tal medida foi tomada para controlar possíveis alterações significativas no peso corporal, o que afetaria a função respiratória e impediria a determinação exata dos efeitos do exercício sobre os sujeitos. Após a realização do programa de exercícios (pós-teste), os indivíduos não poderiam ter seu índice de composição corporal alterado em mais de 5\%, com pena de exclusão do estudo. 
5.4.2.1 Avaliação objetiva da expansibilidade torácica (cirtometria dirigida)

O participante foi sentado em um banco, sem apoio para os braços nem para as costas, com os ombros relaxados, as mãos apoiadas no colo e os pés apoiados no chão. Uma fita métrica foi acoplada ao tórax na altura das axilas. Foi orientado ao voluntário que respirasse tranqüilamente até que houvesse acomodação da respiração, observada pela manutenção da medida da expansibilidade. Em seguida, foi requisitada uma série de três inspirações forçadas, cada uma seguida de uma expiração forçada, com intervalo de quinze segundos entre cada respiração (inspiração e expiração forçadas). O mesmo procedimento foi repetido com a fita ao nível do processo xifóide (Figura 5). Entre as mudanças de posição da cinta foi dado um intervalo de três minutos, com o objetivo de garantir que o sujeito não entrasse em fadiga durante o processo. Os participantes foram estimulados verbalmente para alcançarem seus limites máximos durante a realização dos testes.

Foi requisitado ao sujeito, após orientação, que não executasse movimentação do tronco, cabeça, ombros ou realizasse força nos membros superiores. Com este controle, pretendeu-se impedir movimentos compensatórios do tórax durante a inspiração e expiração forçadas.

Para efeito de estudo, foi selecionado o maior valor encontrado para a diferença entre a amplitude do tórax durante a inspiração forçada e a expiração forçada, para cada um dos níveis.

Previamente à realização do teste, ofereceu-se a possibilidade de demonstrações e tentativas livres. 


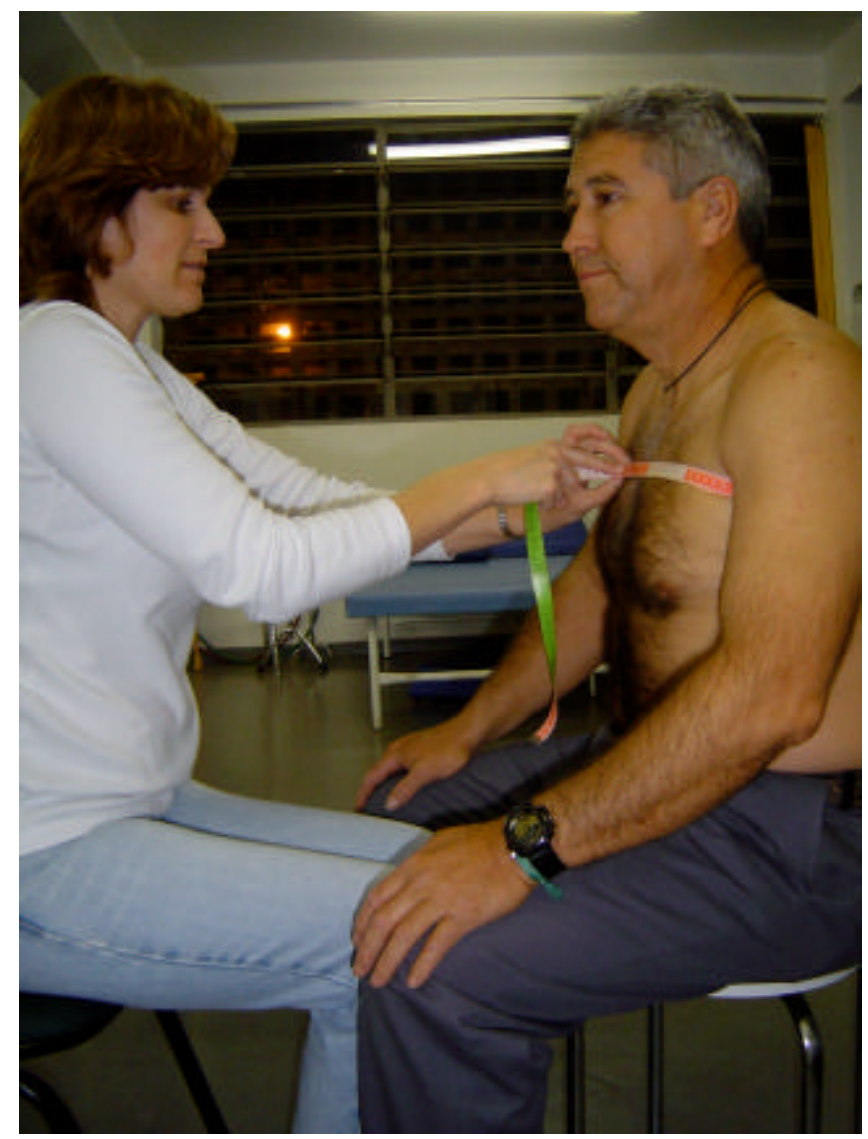

Figura 5. Avaliação da expansibilidade torácica

5.4.2.2 Avaliação objetiva da flexibilidade de coluna e pelve e conformação do tórax por meio do teste dedo-chão modificado

O teste dedo-chão foi modificado em uma série de fatores para facilitar o sucesso do mesmo dentro do presente estudo. Primeiramente o teste foi modificado para a posição sentada, pois se verificou que a população estudada encontraria dificuldade para manter o equilíbrio diante de todas as exigências do teste, descritas abaixo, como os joelhos estendidos, cabeça e ombro relaxados e tornozelos dorsifletidos. O teste também sofreu modificações que incluíram a realização do teste fotografado, conforme descrito abaixo, visando melhorar a confiabilidade do teste. 
A avaliação da flexibilidade foi realizada por estudo fotográfico padronizado dos indivíduos realizando o teste simples de distância dedo-chão (modificado para punhochão) na posição sentada. Tal procedimento fornece a medida direta da distância punho-chão durante a flexão anterior do tronco, bem como informações sobre a conformação do tórax e mobilidade espinal e da pelve. O teste simples da distância dedo-chão já teve sua validade comprovada por Perret et al. (2001), sendo indicada na prática clínica.

O sujeito foi sentado em uma maca rígida, com os joelhos, cotovelos e dígitos totalmente estendidos, não sendo permitida sua flexão ou hiperextensão nem deslocamento posterior de pelve. O indivíduo foi instruído a manter os pés unidos e a cabeça e ombros relaxados. Os tornozelos foram mantidos em posição neutra para flexão dorsal e plantar, através da colocação de um artefato rígido na extremidade distal da maca (Figura 6). O artefato tinha a altura de $20 \mathrm{~cm}$. Foi solicitado ao indivíduo que realizasse flexão anterior do tronco, levando o dígito médio de encontro ao topo do artefato posicionado na extremidade distal da maca.

Todos os participantes tiveram fotografadas sua vista lateral direita. Os indivíduos tiveram o processo estilóide da ulna direita marcado com um adesivo branco circular, para facilitar a identificação deste ponto nas fotografias. Durante a foto, foi colocado lateralmente ao sujeito um bastão de $30 \mathrm{~cm}$, que mais tarde possibilitou a mensuração das medidas reais (Figura 7).

A máquina fotográfica (Marca "Sony", Modelo P-31, 2.0 "Mega Pixels") foi colocada sobre um tripé, posicionada a dois metros de distância do sujeito. A altura foi regulada para cada sujeito de forma que o centro da foto coincidia com o joelho da pessoa fotografada.

Considerando que, na literatura, os resultados do teste correspondente referemse à distância do terceiro dedo ao chão - cuja medida normal é zero, isto é, o dedo 
toca o solo - e que a mão tem em média $20 \mathrm{~cm}$ de comprimento, os resultados aqui obtidos estarão defasados aproximadamente $20 \mathrm{~cm}$.

Foi utilizado o "software Corel Draw" para medir a distância punho-chão, entre o processo estilóide da ulna e o artefato rígido posicionado na extremidade distal da maca. Para calcular a distância real, a partir da foto, efetua-se uma regra de três, considerando duas medidas conhecidas: a medida real e a fotografada do bastão posicionado lateralmente ao sujeito durante a foto e a medida fotografada da distância punho-chão; o resultado da proporção foi a medida real da distância punho-chão.

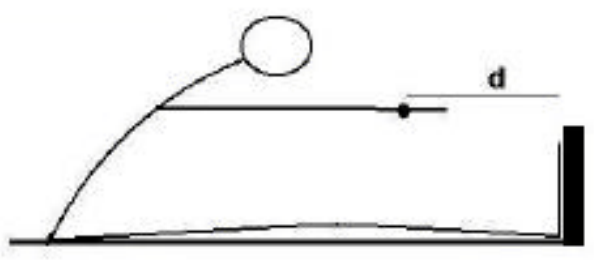

Figura 6. Mensuração da distância "d", entre a placa vertical e o processo estilóide da ulna

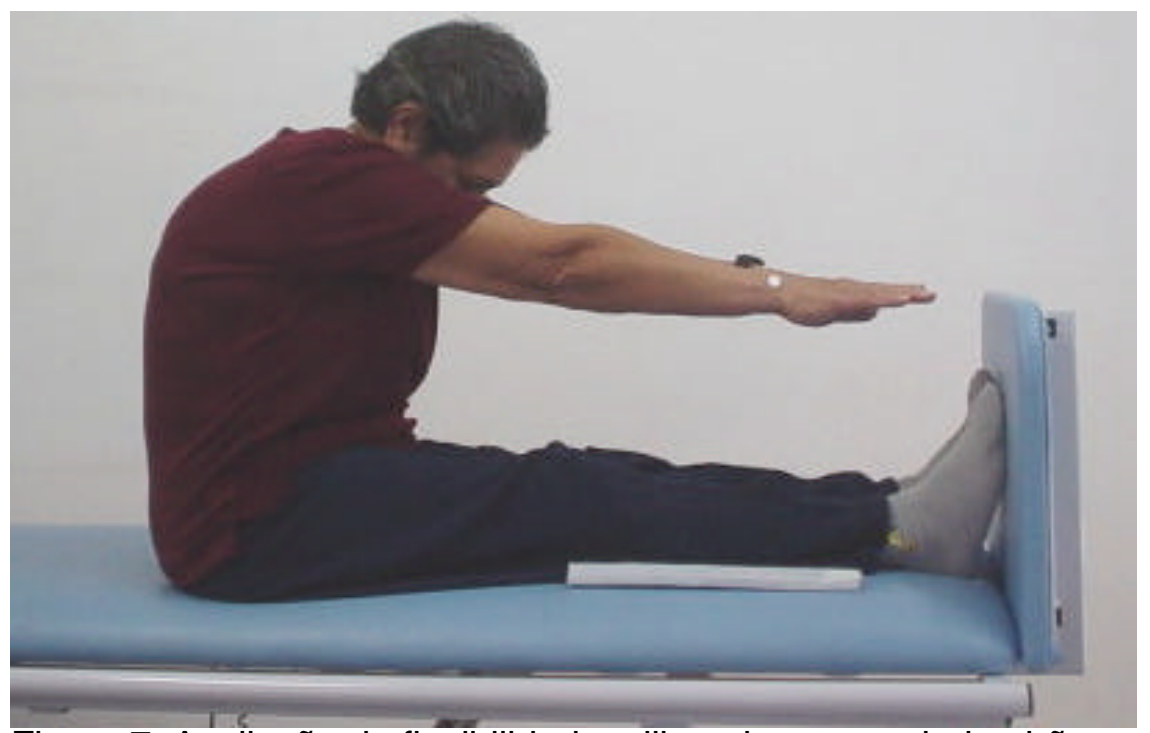

Figura 7. Avaliação da flexibilidade utilizando o teste dedo-chão modificado 
5.4.2.3 Avaliação das pressões respiratórias máximas ( $\mathrm{PI}$ e $P E_{\operatorname{máx}}$ )

O terceiro teste buscava mensurar as pressões respiratórias máximas, inspiratória $\left(\mathrm{Pl}_{\text {máx }}\right)$ e expiratória $\left(\mathrm{PE}_{\text {máx }}\right)$. Foi utilizado um manovacuômetro da marca "Gerar" (Figura 8), com escala variando de zero a $150 \mathrm{mmH}_{2} \mathrm{O}$ positivos (para medidas de pressões expiratórias máximas, $\left.P E_{\text {máx }}\right)$ e de zero a $150 \mathrm{mmH}_{2} \mathrm{O}$ negativos (para medidas de pressões inspiratórias máximas, $\mathrm{PI}_{\text {máx }}$ ). O mesmo era calibrado antes dos procedimentos.

Os participantes foram posicionados sentados eretos, sem recostar-se na cadeira, com os pés apoiados no chão e com uma clipe de obstrução nasal. Foram registradas as medidas de $\mathrm{PI}_{\text {máx }}$ e $\mathrm{PE}_{\text {máx }}$, após uma expiração e inspiração normais respectivamente, como sugerido por Sorlie et al. (1989).

O próprio participante foi orientado a segurar firmemente o conector bucal do aparelho, pressionando-o contra os lábios. As manobras foram repetidas por três vezes, com intervalo de dois minutos entre cada uma, tendo sido utilizada, para fins de estudo, a melhor das três medidas. Os participantes foram estimulados verbalmente para efetuarem o maior esforço possível por três segundos. Previamente à realização das manobras, forneceu-se aos participantes uma explicação detalhada sobre a técnica, acompanhada de demonstrações e tentativas livres (Figura 9). 


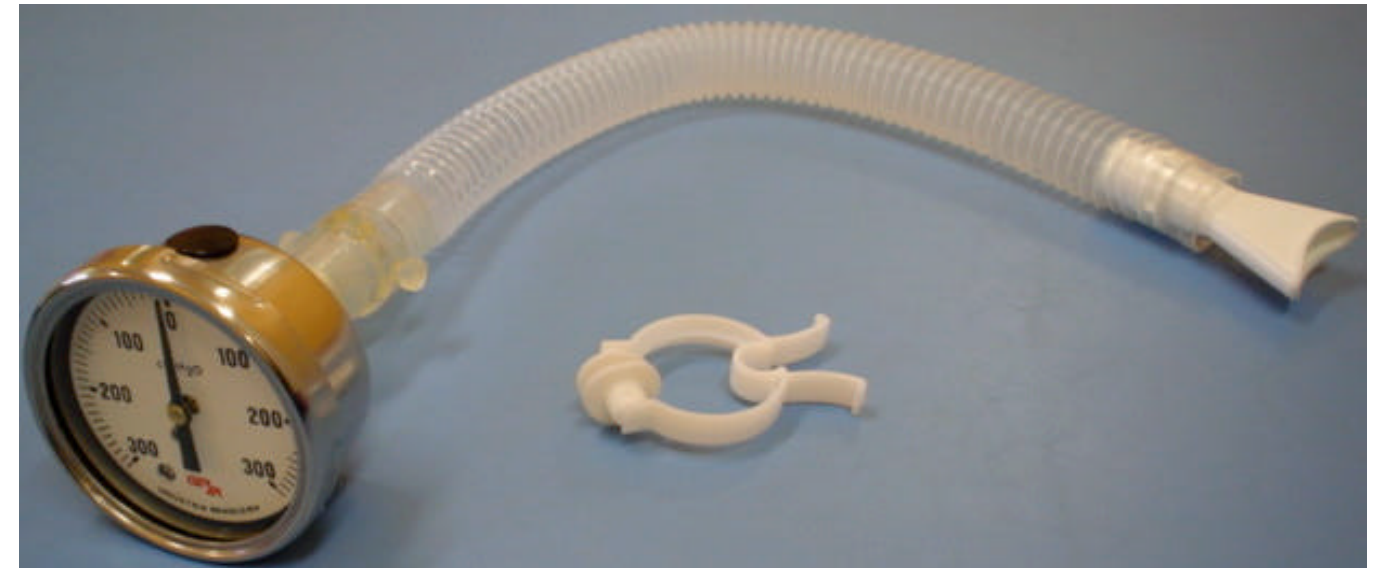

Figura 8. Manovacuômetro utilizado para mensuração das pressões respiratórias máximas

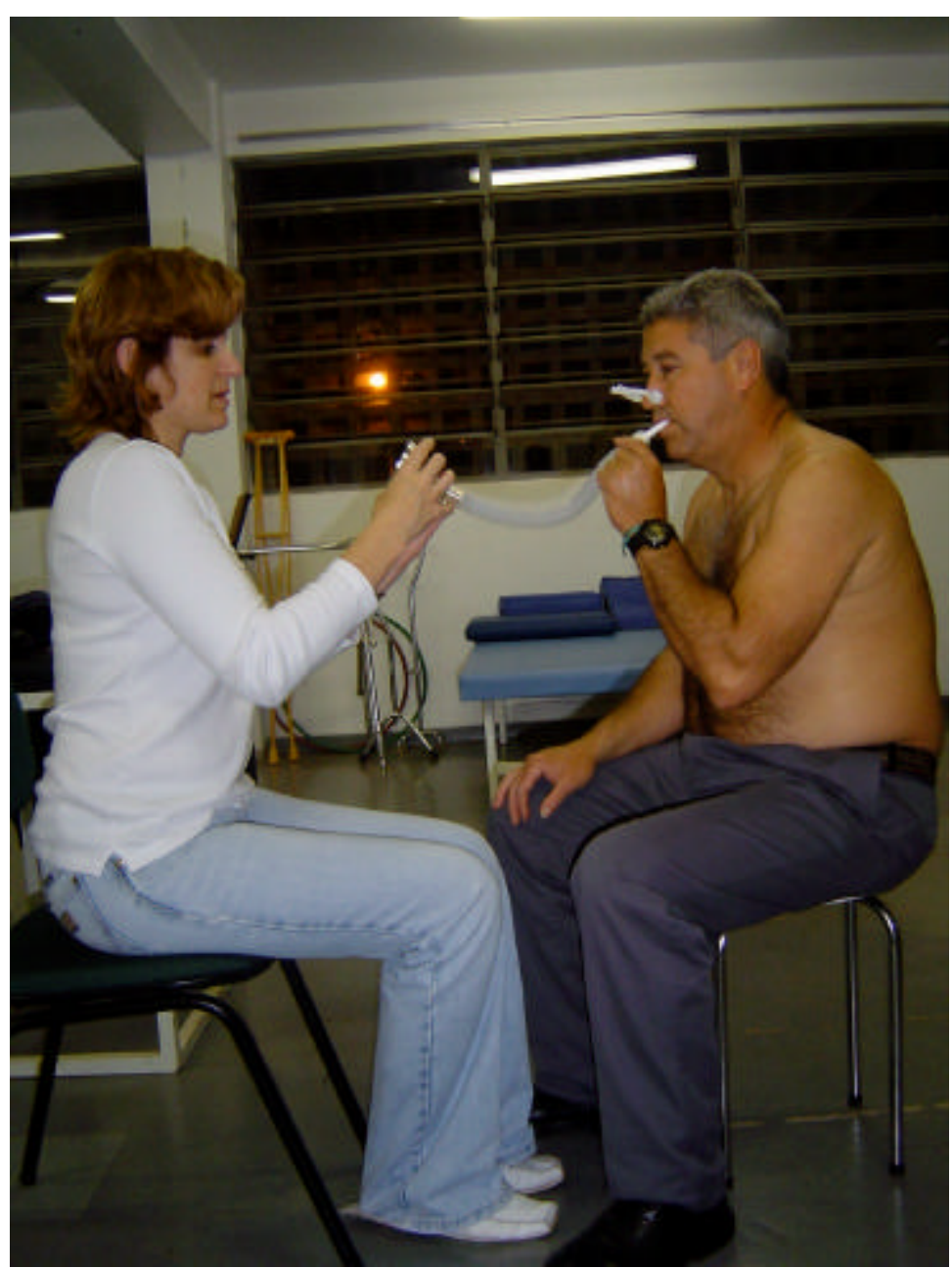

Figura 9. Avaliação das pressões respiratórias máximas 


\subsubsection{Avaliação da composição corporal}

Foi solicitado ao indivíduo que se posicionasse em pé, ereto, o mais despido possível e descalço, sobre uma balança portátil. Foi anotado o peso do indivíduo em quilogramas.

Posteriormente foi solicitado ao mesmo que se posicionasse em pé, encostado em uma parede branca, para que tivesse mensurada sua altura em metros com o auxílio de uma fita métrica.

O cálculo do índice de massa corpórea foi realizado diretamente pela divisão do peso (em kg) do indivíduo por sua altura ao quadrado (em m²).

Ao término dos protocolos de cinesioterapia respiratória, os participantes foram novamente submetidos à avaliação funcional respiratória (teste pós-imediato), utilizando para tal o mesmo protocolo do pré-teste. Os resultados foram posteriormente comparados com o do próprio sujeito e entre os grupos. O protocolo de reavaliação foi aplicado no período da manhã, bem como no pré-teste, com um intervalo mínimo de 24 horas e máximo de cinco dias após o término do protocolo de exercícios. Ao término do estudo, os sujeitos foram informados dos resultados por eles obtidos.

Todos os procedimentos foram realizados com o auxílio de pesquisadores treinados, sendo todos acadêmicos do segundo, terceiro e quarto anos do curso de fisioterapia da Universidade Estadual do Oeste do Paraná.

\subsection{Intervenções}

O protocolo de cinesioterapia respiratória (Quadro 1) foi elaborado e adaptado aos dois meios - aquático e terrestre - com objetivos idênticos. Foram aplicados 
durante dez semanas consecutivas, três vezes por semana, com duração de uma hora cada sessão.

Quadro 1 - Protocolo de cinesioterapia respiratória aplicado aos grupos água e solo

O protocolo de exercícios era composto por nove itens descrito abaixo:

Aquecimento inicial - marcha em círculos com mudanças de sentido esporádicas.

Exercício ativo/resistido de adução-abdução horizontal da articulação do ombro

Exercício ativo/resistido de flexão-extensão da articulação do ombro.

Exercício ativo/resistido de flexão anterior associada à rotação do tronco.

Exercício ativo/resistido de flexão lateral de tronco.

Exercício ativo/resistido de rotação lateral de tronco.

Exercício ativo em cadeia cinética fechada para membros superiores.

Exercício ativo de elevação dos membros superiores acima da cabeça.

Relaxamento final - inspiração e expiração profunda, sem o acompanhamento de outros movimentos.

O grupo controle também compareceu ao local dos atendimentos, uma vez por semana. Os sujeitos deste grupo foram submetidos a atividades diferentes de exercícios, tais como palestras sobre temas gerais e atividades recreativas diversas, todas descritas em protocolo (Quadro 2). Tal atitude teve como intenção igualar os dois grupos de intervenção com o grupo controle, visto que os primeiros poderiam ser beneficiados por efeitos psicológicos decorrentes do simples deslocamento de suas residências e convívio social proporcionado pelos exercícios. Acredita-se que tais fatores podem influenciar e ou superestimar os efeitos decorrentes dos exercícios 
propriamente ditos. Ao término das atividades, os sujeitos do grupo controle eram convidados a realizar atividades semelhantes aos dos grupos de intervenção, $G_{1}$ e $G_{2}$, sem fins de pesquisa.

Quadro 2 - Protocolo de atividades aplicadas ao grupo controle

Palestras sobre temas gerais de saúde:
Hipertensão arterial
Osteoporose
Diabetes melitus
Lombalgia
Depressão
Farmacologia, uso de medicamentos
Aspectos relacionados ao exercício físico - benefícios, cuidados, intensidade e
outras recomendações para prática segura
Fisiologia de alguns dos diversos sistemas do corpo humano.
Jogos
Bingos
Festas com a presença de alguns familiares

Os exercícios de ambos protocolos tiveram como objetivos principais melhorar o controle voluntário da respiração, aumentar a força muscular respiratória, melhorar a expansibilidade, mobilidade e flexibilidade de todo o tronco, com ênfase no tórax e cintura escapular. Os exercícios foram realizados com intensidade progressiva, de acordo com a melhora na habilidade do indivíduo. Seguiram também uma seqüência 
lógica de aquecimento, condicionamento, fortalecimento e resfriamento. O grupo que realizou os exercícios em meio também foi orientado a permanecer sempre com ombro coberto pela água (Figura 10).

Durante todos os exercícios propostos eram solicitadas inspirações e expirações profundas. As inspirações eram solicitadas sempre que o movimento envolvesse aumento da amplitude da caixa torácica, como, por exemplo, ao abduzir ou fletir a articulação do ombro. Foi fornecido incentivo verbal durante a realização de todas as atividades propostas.

Os exercícios eram realizados em grupo, mas com atenção individual para cada participante. Ambos grupos utilizaram recursos para a motivação dos exercícios, como halteres, bolas, arcos e bastões diversos (Figura 11).

Os protocolos de exercícios foram elaborados baseado em informações da literatura, de modo que atingissem limiares que os tornassem eficientes, sem, contudo, envolver esforço demasiado dos voluntários. Considerando a idade da população envolvida e a dificuldade de monitorar o esforço ideal de cada indivíduo, poderiam ocorrer efeitos colaterais da hiperventilação, como vertigens, sudorese e estocolmos. Em casos extremos, até mesmo desmaios e cefaléias. 


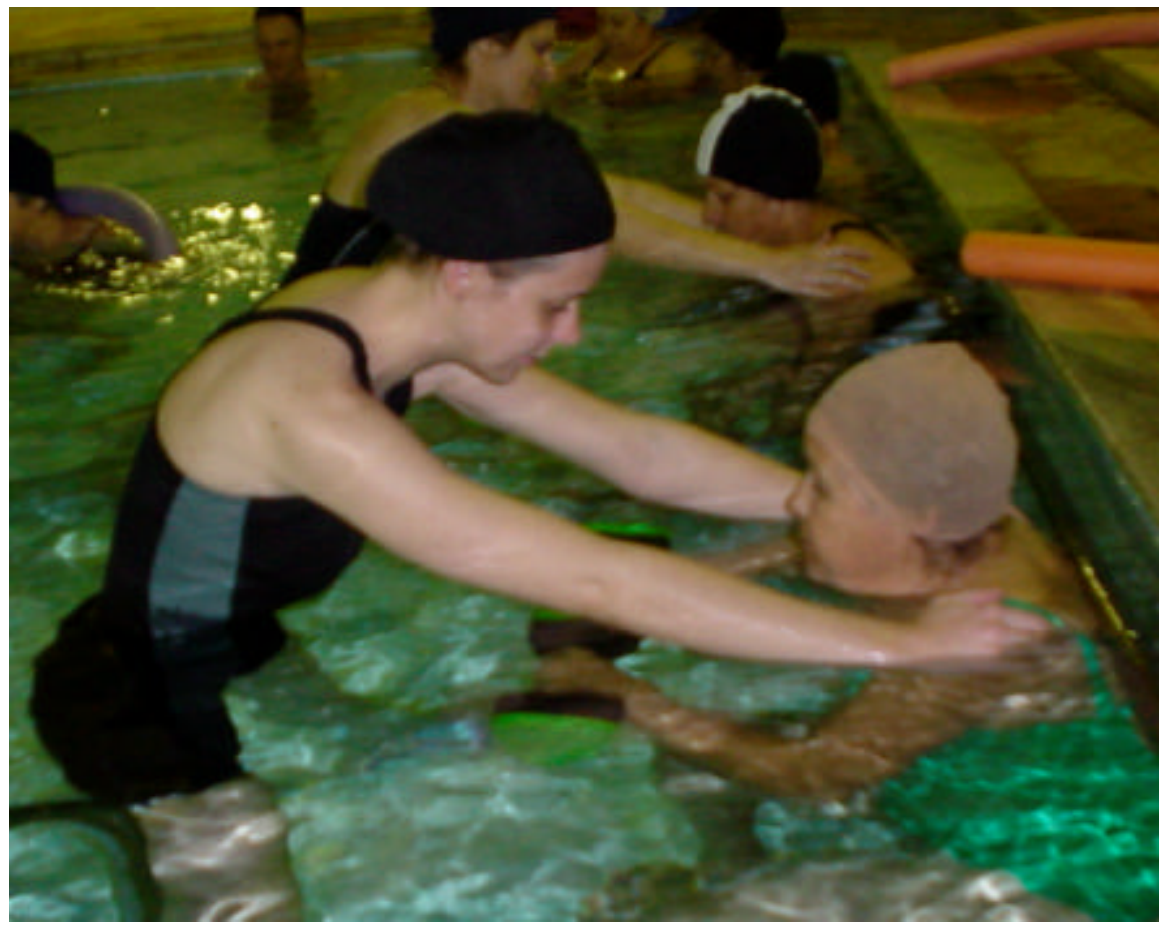

Figura 10. Realização do protocolo aquático, com ombros constantemente submersos

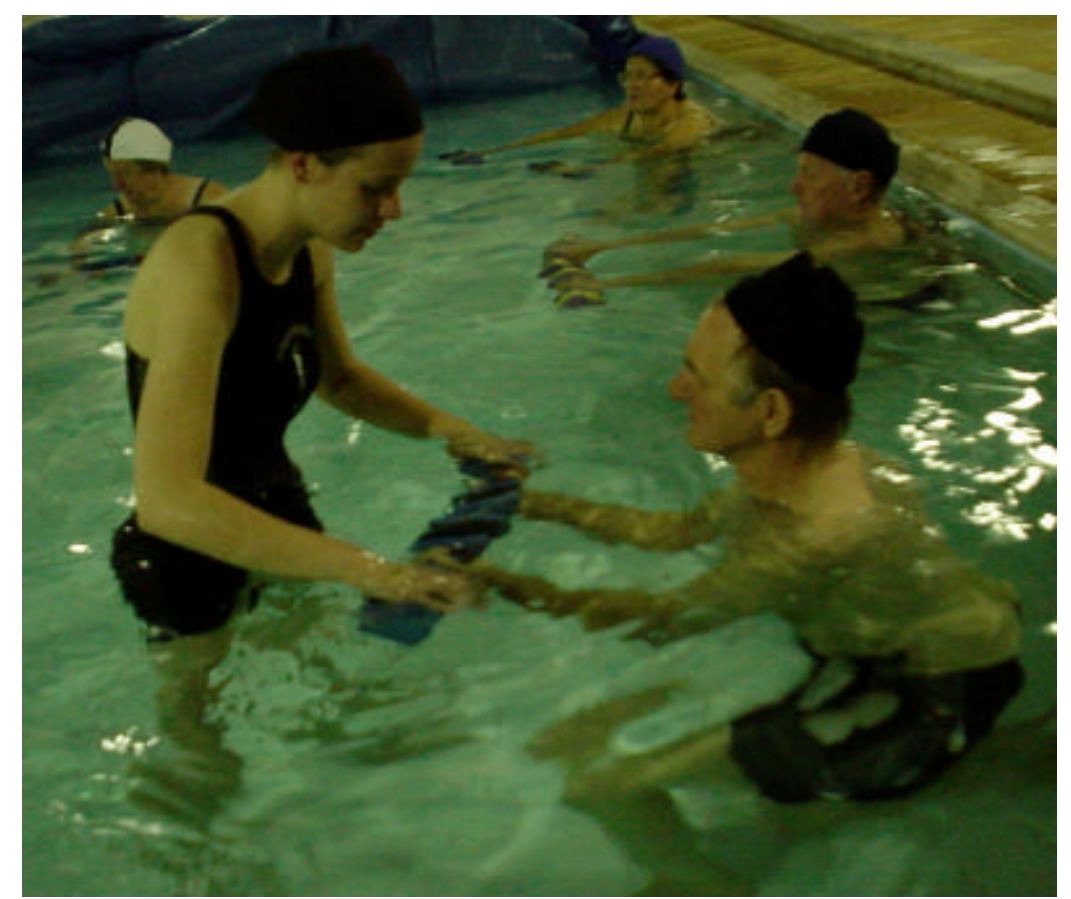

Figura 11. Realização do protocolo em grupo, com atenção individual e uso de recursos diversos 
Os voluntários do programa aquático também foram regularmente questionados a respeito de alterações dérmicas leves - como pruridos e eritemas decorrentes de irritação e possivelmente devido ao contato com a água clorada. Também foram constantemente pesquisadas alterações causadas por processos patológicos, como manchas decorrentes de contaminações por micoses fúngicas e bacterianas. Neste caso, o voluntário seria encaminhado a avaliação clínica e caso fosse realmente diagnosticada tal alteração, seria verificado o tempo necessário de afastamento do sujeito do ambiente aquático. Se este ultrapassasse dez dias, o mesmo seria imediatamente excluído do trabalho. Não houve relatos neste sentido.

Todas as ocorrências foram anotadas e caso sua freqüência se tornasse crônica, seria estudada a exclusão do participante do estudo. Tal exclusão seria executada se o voluntário apresentasse sintomas que o impedissem de realizar as atividades em mais de cinco das dez primeiras sessões, ou a qualquer momento, a critério do voluntário. Não relatou-se nenhum caso.

Os voluntários foram freqüentemente questionados a respeito de eventuais sinais e sintomas que pudessem referir. Sempre que se julgou necessário, tiveram mensuradas sua pressão arterial, freqüência cardíaca e temperatura. Com estas medidas pretendia-se reduzir, de maneira prática, o risco de que os voluntários apresentassem quaisquer complicações durante a execução dos protocolos. Caso fosse detectada qualquer alteração maligna que contra-indicasse a realização das atividades propostas, seria monitorado o retorno do voluntário à sua residência, bem como solicitação para que o sujeito realizasse avaliação clínica, em casos mais graves. Apenas um sujeito teve de ser encaminhado para o médico, em decorrência de uma crise de lombalgia. Após uma semana de afastamento, o mesmo retornou ao programa normalmente. 
Foi estipulado que a coleta de dados seria suspensa em caso de não totalidade de voluntários ou desistência de mais de $50 \%$ dos participantes. Também seria suspenso em caso de danos que impossibilitassem a utilização da piscina terapêutica em questão.

A execução dos protocolos pode ser observado pelas Figuras 12 a 17, contidas nos Anexos B e C.

\subsection{Variáveis analisadas}

Foram selecionados como desfechos a expansibilidade torácica, força muscular respiratória e flexibilidade anterior de tronco/pelve, conforme avaliação descrita no item 5.4.2.

\subsection{Análise estatística}

As variáveis $\mathrm{PI}_{\text {máx }}, \mathrm{PE}_{\text {máx }}$ e expansibilidade torácica em ambos níveis foram analisadas antes e depois do tratamento calculando-se a diferença pós-pré. Para cada uma das variáveis, a diferença foi analisada com o teste "t-student" para amostras pareadas, com objetivo de avaliar se a diferença média é significativamente diferente de zero. Com o objetivo de confirmar os resultados fornecidos pelo teste paramétrico foi também aplicado o teste não paramétricos do Sinal ("Sign test"). A comparação entre os grupos, utilizando a variável diferença (pós-pré), foi utilizado a técnica de análise de variância paramétrica e não paramétrica. Nas situações em que pelo menos uma diferença média foi diferente das demais foi utilizado o teste de Dunnett para comparar os grupos água e solo "versus" o grupo controle. 
A variável flexibilidade foi analisada a partir da análise de covariância, visto que observou-se dependência dos valores pós-pré com os valores apresentados pelo indivíduo na avaliação inicial. Buscou-se analisar se tal relação de dependência é a mesma para todos os tratamentos, o que equivale testar a hipótese de igualdade dos coeficientes de inclinação ou de que as retas de regressão são paralelas.

Todos os testes adotaram um nível de significância de 5\%. 


\section{RESULTADOS}

Apesar de sabidas as diferenças existentes no desempenho entre os sexos, não foram encontradas diferenças estatisticamente significativas quando os resultados obtidos pelos homens foram excluídos da análise. Deste modo, os escores descritos abaixo referem-se ao desempenho obtido pelos 59 indivíduos que completaram o tratamento.

\subsection{Força muscular respiratória $\left(\mathrm{PI}_{\text {máx }}\right.$ e $\left.P E_{\text {máx }}\right)$}

Os dados relativos ao comportamento da $\mathrm{PI}_{\operatorname{máx}}$ e $\mathrm{PE}_{\operatorname{máx}}$ nos sujeitos estudados estão descritos na Tabela 3 e Gráficos 1 a 6.

Tabela 3 - Pressão inspiratória máxima nos grupos água, solo e controle

\begin{tabular}{|c|c|c|c|c|c|c|}
\hline & & AVALIAÇÃO & MÉDIA ${ }^{(1)}$ & $\begin{array}{l}\text { DESVIO } \\
\text { PADRÃO }\end{array}$ & $\begin{array}{l}\text { PRESSÃO } \\
\text { MÍNIMA }^{(1)}\end{array}$ & $\begin{array}{l}\text { PRESSÃO } \\
\text { MÁXIMA }^{(1)}\end{array}$ \\
\hline \multirow{4}{*}{$\mathrm{G}_{1}$} & \multirow{2}{*}{$\mathrm{PI}_{\text {máx }}$} & Pré & 92,37 & 36,87 & 30,00 & 160,00 \\
\hline & & Pós & 100,00 & 34,88 & 55,00 & 160,00 \\
\hline & \multirow{2}{*}{$\mathrm{PE}_{\text {máx }}$} & Pré & 95,79 & 35,79 & 30,00 & 160,00 \\
\hline & & Pós & 100,26 & 30,11 & 30,00 & 160,00 \\
\hline \multirow{4}{*}{$\mathrm{G}_{2}$} & \multirow[t]{2}{*}{$\mathrm{PI}_{\text {máx }}$} & Pré & 86,05 & 26,70 & 45,00 & 140,00 \\
\hline & & Pós & 88,42 & 25,00 & 35,00 & 130,00 \\
\hline & \multirow{2}{*}{$P E_{\text {máx }}$} & Pré & 80,26 & 25,14 & 30,00 & 120,00 \\
\hline & & Pós & 85,00 & 29,67 & 25,00 & 150,00 \\
\hline \multirow{4}{*}{$\mathrm{G}_{3}$} & \multirow[t]{2}{*}{$\mathrm{PI}_{\text {máx }}$} & Pré & 100,95 & 30,60 & 45,00 & 170,00 \\
\hline & & Pós & 89,28 & 26,75 & 45,00 & 150,00 \\
\hline & \multirow{2}{*}{$P E_{\text {máx }}$} & Pré & 90,95 & 42,59 & 5,00 & 150,00 \\
\hline & & Pós & 95,48 & 30,57 & 30,00 & 150,00 \\
\hline
\end{tabular}

(1) Valores em $\mathrm{cmH}_{2} \mathrm{O}$ 
Gráfico 1 - Trajetórias da pressão inspiratória máxima dos sujeitos alocados no grupo água pré e pós intervenção

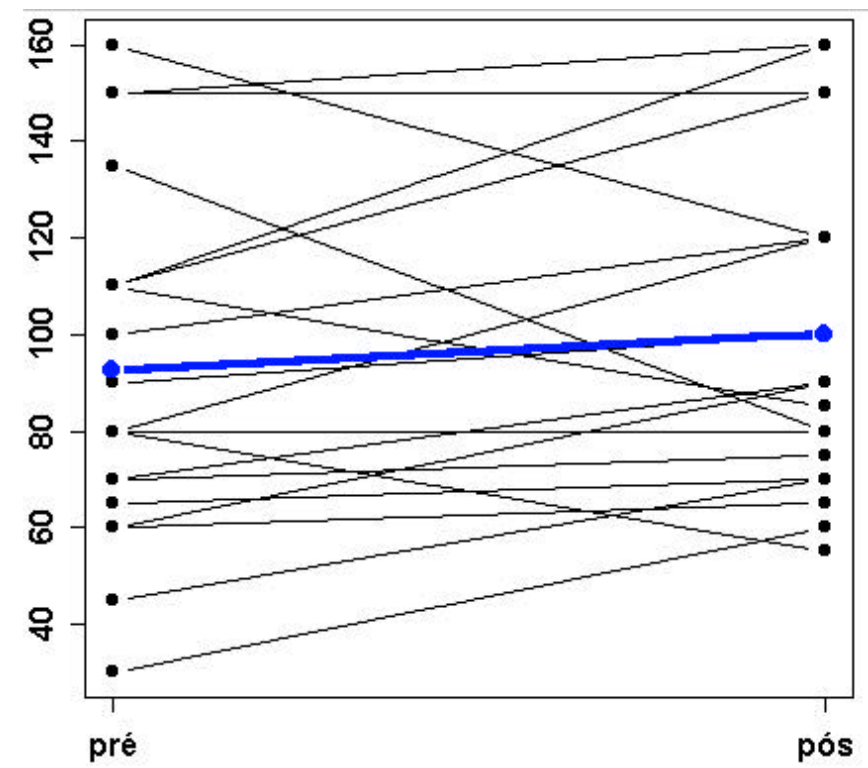

NOTA: A linha azul indica a trajetória média. Valores em $\mathrm{cm}_{2} \mathrm{O}$.

Gráfico 2 - Trajetórias da pressão inspiratória máxima dos sujeitos alocados no grupo solo pré e pós intervenção

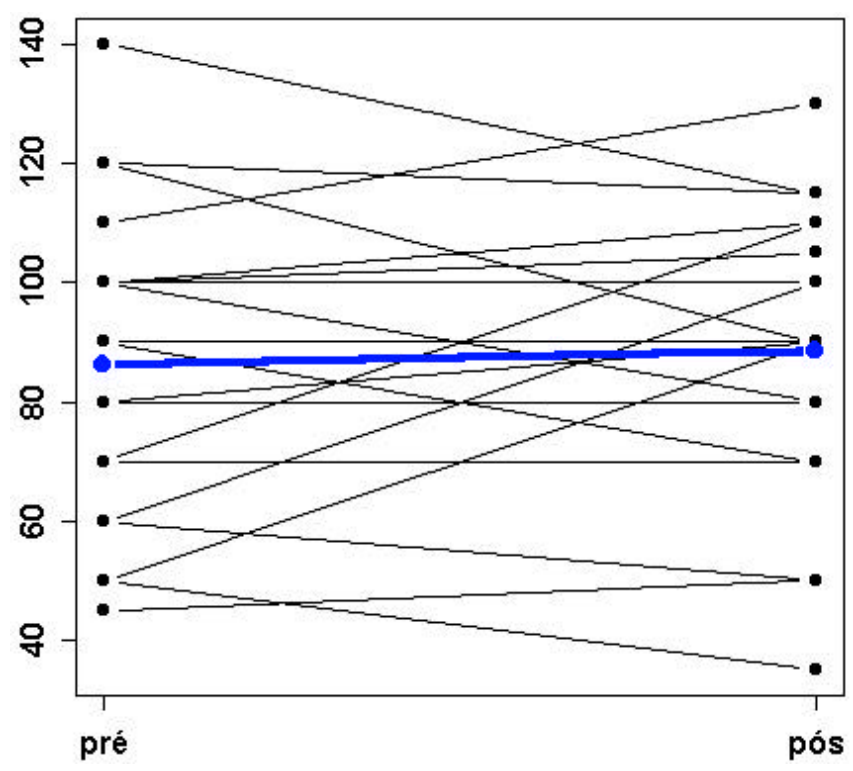

NOTA: A linha azul indica a trajetória média. Valores em $\mathrm{cm}_{2} \mathrm{O}$. 
Gráfico 3 - Trajetórias da pressão inspiratória máxima dos sujeitos alocados no grupo controle pré e pós intervenção

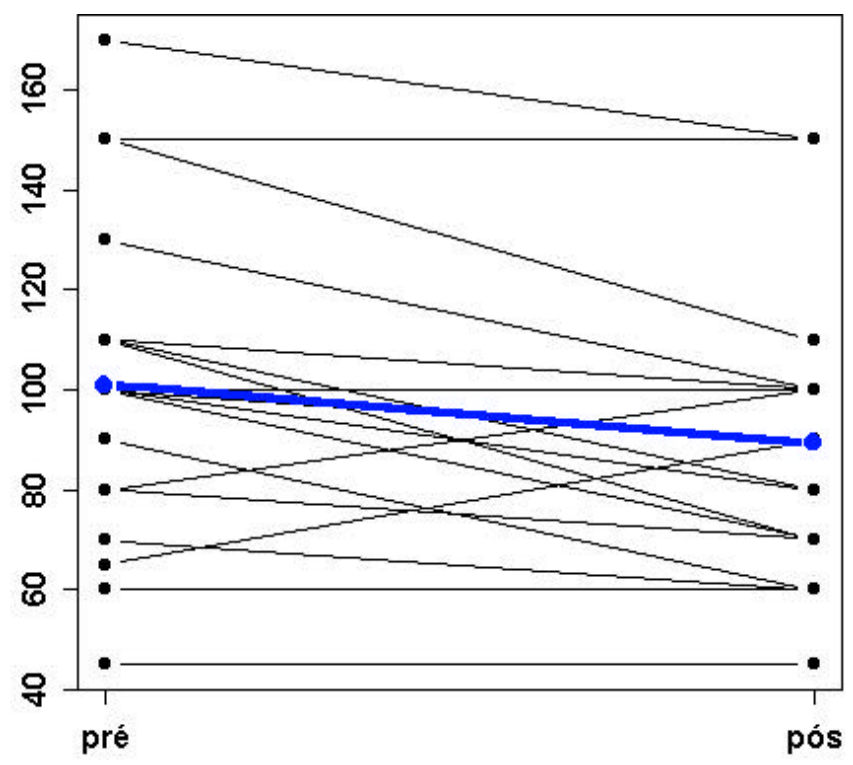

NOTA: A linha azul indica a trajetória média. Valores em $\mathrm{cm}_{2} \mathrm{O}$.

Gráfico 4 - Trajetórias da pressão expiratória máxima dos sujeitos alocados no grupo água pré e pós intervenção

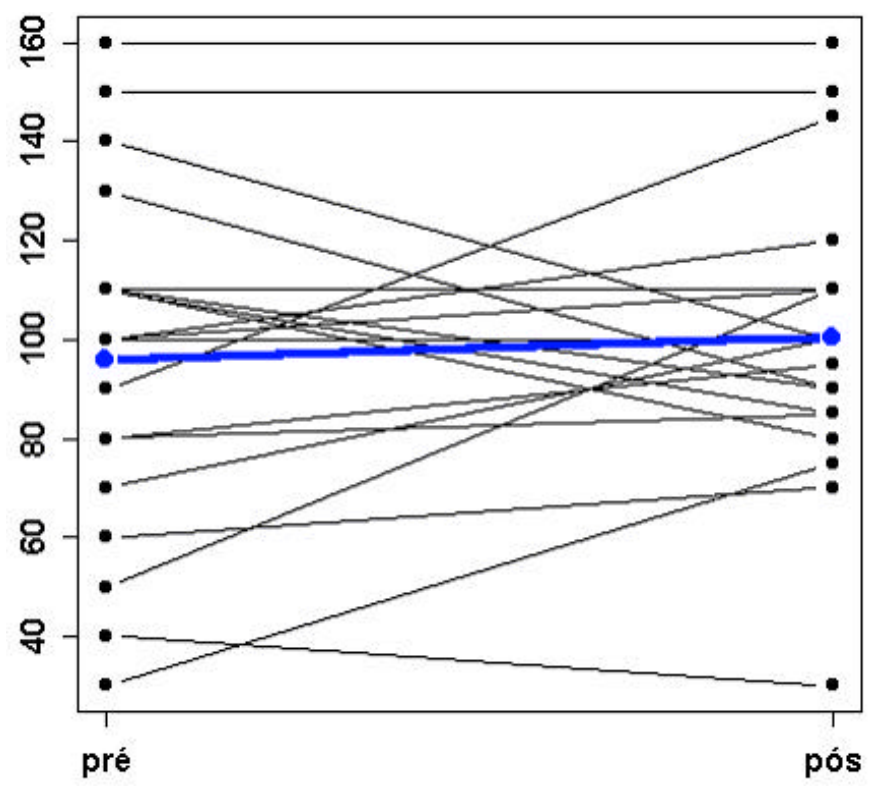

NOTA: A linha azul indica a trajetória média. Valores em $\mathrm{cmH}_{2} \mathrm{O}$. 
Gráfico 5 - Trajetórias da pressão expiratória máxima dos sujeitos alocados no grupo solo pré e pós intervenção

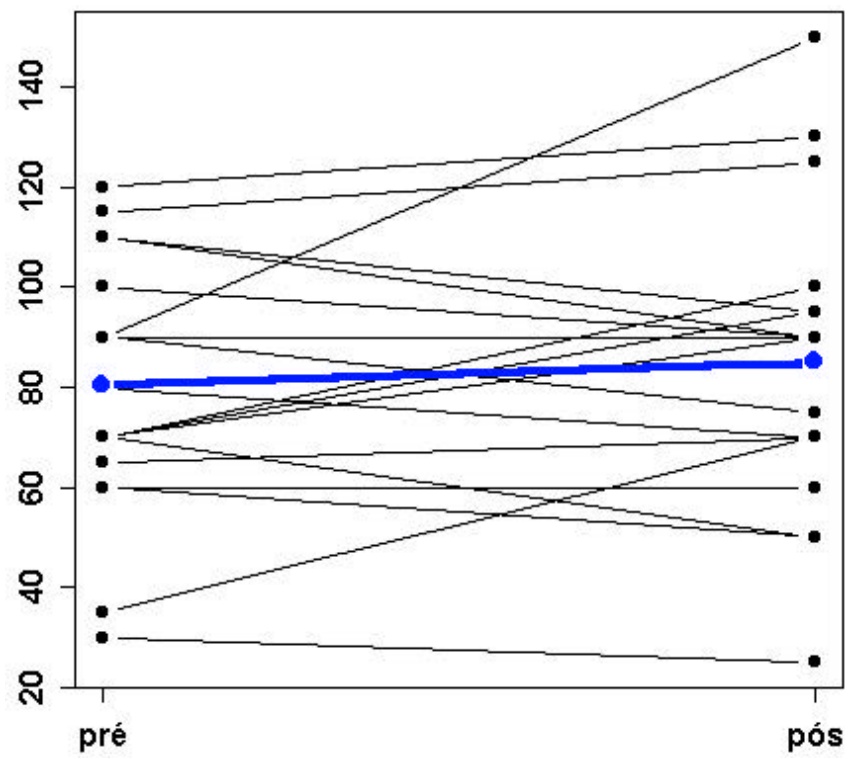

NOTA: A linha azul indica a trajetória média. Valores em $\mathrm{cm} \mathrm{H}_{2} \mathrm{O}$.

Gráfico 6 - Trajetórias da pressão expiratória máxima nos sujeitos alocados no grupo controle pré e pós intervenção

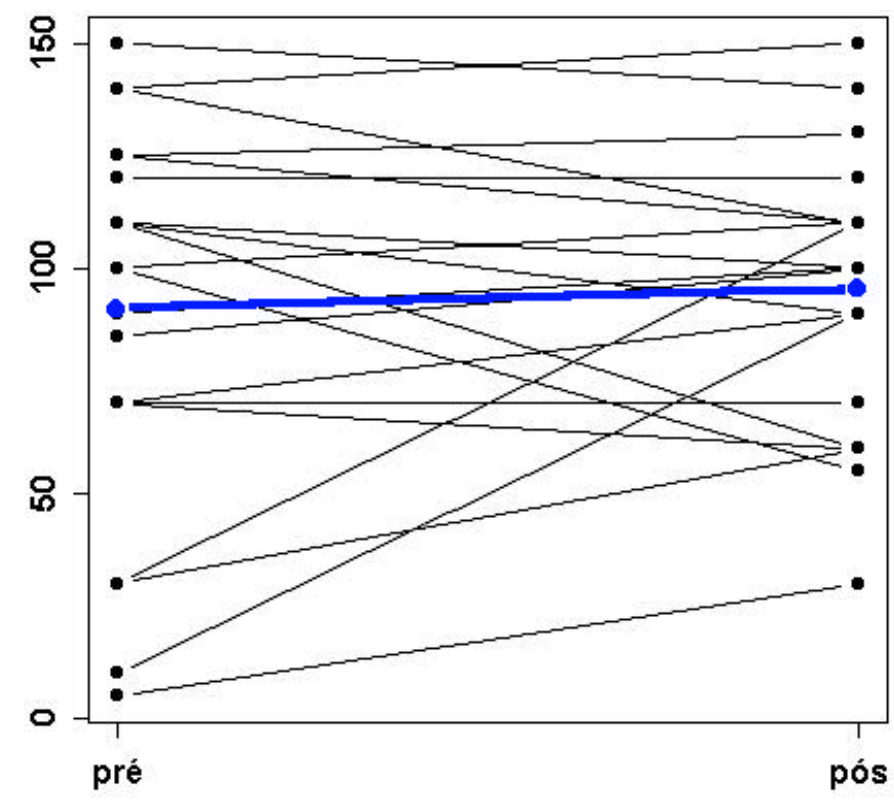

NOTA: A linha azul indica a trajetória média. Valores em $\mathrm{cm}_{2} \mathrm{O}$. 
Utilizou-se o teste paramétrico t-pareado para comparar a $\mathrm{PI}_{\text {máx }}$ e $\mathrm{PE}_{\text {máx }}$ pré e pós-intervenção em cada grupo individualmente. Os dados estão alocados na Tabela 4.

Através da análise do intervalo de confiança de 95\% ( $\left.\mathrm{IC}_{95 \%}\right)$ e nível descritivo $(\mathrm{p})$, pode-se afirmar que a $P E_{\text {máx }}$ não apresentou diferença estatisticamente significativa pré e pós-intervenção em nenhum dos grupos isoladamente. $\mathrm{A} \mathrm{PI}_{\text {máx }}$ apresentou redução estatisticamente significativa no grupo controle $(p<0,007)$. A comparação dos resultados entre os grupos pode ser observada nos Gráficos 7 e 8.

Tabela 4 - Comparação das pressões respiratórias máximas pós-pré intervenção nos grupos água, solo e controle utilizando o teste t-pareado

\begin{tabular}{|c|c|c|c|c|c|}
\hline & $\begin{array}{c}\text { DIFERENÇA } \\
\text { PÓS-PRÉ } \\
\text { MÉDIA }^{(1)}\end{array}$ & $\begin{array}{l}\text { INTERVALO DE } \\
\text { CONFIANÇA 95\% }\end{array}$ & $\begin{array}{c}\text { ERRO } \\
\text { PADRÃO }\end{array}$ & $\begin{array}{c}\text { TESTE T } \\
\text { PAREADO }\end{array}$ & $p$ \\
\hline $\mathrm{G}_{1} \mathrm{PI}_{\operatorname{máx}}$ & 7,63 & $-5,80$ a 21,06 & 6,40 & 1,19 & 0,25 \\
\hline $\mathrm{N}_{1} \mathrm{PE}_{\text {máx }}$ & 4,47 & $-9,55$ a 18,50 & 6,68 & 0,67 & 0,51 \\
\hline $\mathrm{G}_{2} P \mathrm{I}_{\text {máx }}$ & 2,37 & $-7,80$ a 12,54 & 4,84 & 0,49 & 0,63 \\
\hline$P E_{\text {máx }}$ & 4,74 & $-5,50$ a 14,98 & 4,87 & 0,97 & 0,34 \\
\hline $\mathrm{G}_{3} \mathrm{PI}_{\operatorname{máx}}$ & $-11,67$ & $-19,72$ a $-3,61$ & 3,86 & $-3,02$ & $0,01^{(2)}$ \\
\hline $\mathrm{PE}_{\text {máx }}$ & 4,52 & $-10,29$ a 19,34 & 7,10 & 0,64 & 0,53 \\
\hline
\end{tabular}

(1) Valores em $\mathrm{cmH}_{2} \mathrm{O}$ (2) Diferença estatisticamente significativa 
Gráfico 7 - Trajetórias médias da pressão inspiratória máxima nos grupos água, solo e controle

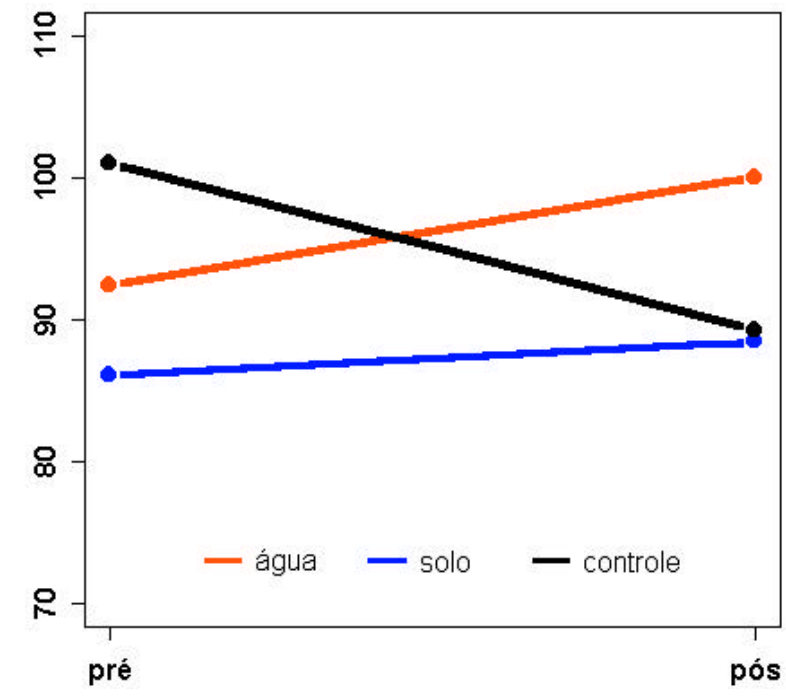

NOTA: Valores em $\mathrm{cmH}_{2} \mathrm{O}$.

Gráfico 8 - Trajetórias médias da pressão expiratória máxima nos grupos água, solo e controle

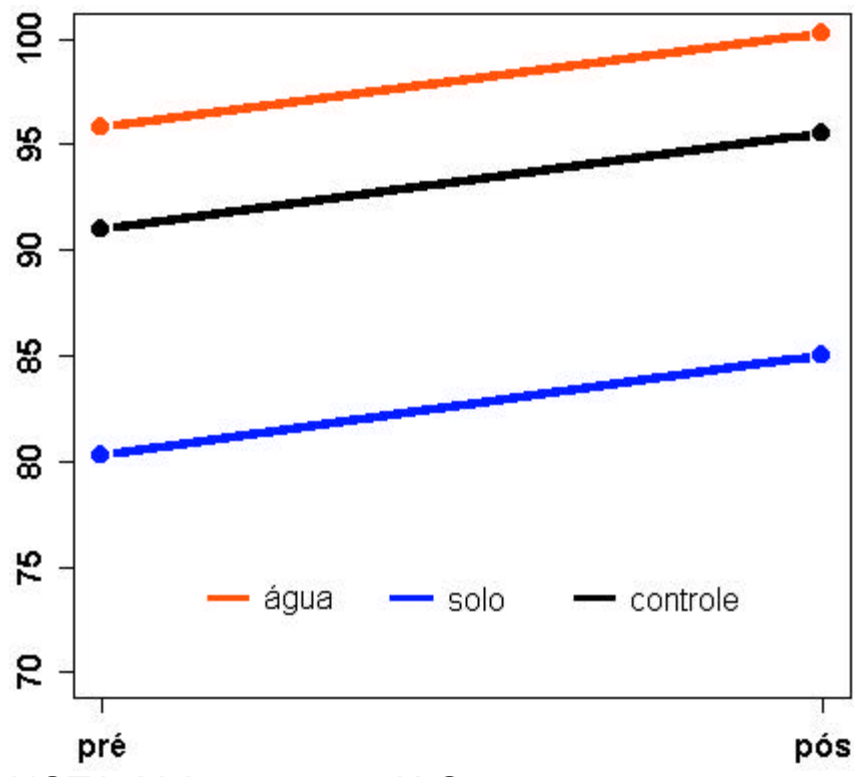

NOTA: Valores em $\mathrm{cmH}_{2} \mathrm{O}$. 
A respeito da validade dos testes aplicados em todas as comparações, não foi observado quebra na suposição de normalidade das diferenças. Os testes utilizados para verificação da normalidade foram o de Shapiro-Wilk, Kolmogorov-Smirsmirnorv, Cramer-von Mises e Anderson-Darling. Todos os cálculos foram realizados no "software" SAS, versão 8.2. Como alternativa ao teste t-pareado, também foram aplicados o teste do Sinal ("Sign test") e o teste das ordens assinaladas Wilcoxon "Signed Ranks Test"). Ambos os testes não paramétricos estão de acordo com as conclusões obtidas a partir do teste paramétrico t-pareado.

Para comparar as médias das diferenças dos grupos, foi utilizada a técnica de análise de variância paramétrica.

Para a $\mathrm{PI}_{\text {máx }}$ pode-se afirmar, com um nível de significância de 5\%, que as médias das diferenças (pós-pré) não são iguais entre os grupos $(p<0,03)$. Considerando que o objetivo é comparar os grupos água "versus" controle e solo "versus" controle temse, a partir do teste de Dunnett, que as diferenças médias entre os grupos água e controle são estatisticamente diferentes em nível de significância de $5 \%(p<0,02)$. 0 mesmo teste não detectou diferença estatisticamente significante entre as diferenças médias dos grupos solo e controle $(p<0,28)$. Os dados completos estão agrupados na Tabela 5.

Tabela 5 - Comparação da pressão inspiratória máxima pós-pré intervenção utilizando a análise de variância e Teste de Dunett

\begin{tabular}{cc}
\hline COMPARAÇÃO ENTRE OS GRUPOS & $P$ \\
\hline$G_{1} \times G_{2} \times G_{3}$ & $0,02^{(1)}$ \\
$G_{1} \times G_{3}$ & $0,02^{(1)}$ \\
$G_{2} \times G_{3}$ & 0,28 \\
\hline
\end{tabular}

(1) Diferenças estatisticamente significativas 
Também utilizando a análise de variância, não foi possível rejeitar a hipótese de igualdade entre as diferenças médias entre os grupos para a $\mathrm{PE}_{\text {máx }}(p>0,99)$.

A análise de variância não paramétrica (Kruskal-Wallis test”) não contradiz as conclusões obtidas pela análise de variância paramétrica, para ambas as pressões.

\subsection{Expansibilidade torácica}

Os dados referentes ao comportamento da expansibilidade torácica, em ambos níveis, estão descrito na Tabela 6. Observou-se aumento nos valores pós-intervenção em todos os grupos, nos dois níveis. As trajetórias de cada sujeito estão representadas nos Gráficos de 9 a 14.

Tabela 6 - Expansibilidade torácica dos sujeitos alocados no grupo água, solo e controle

\begin{tabular}{|c|c|c|c|c|c|c|}
\hline GRUPO & & AVALIAÇÃO & $\underset{(1)}{\text { MÉDIA }}$ & $\begin{array}{c}\text { DESVIO } \\
\text { PADRÃO }\end{array}$ & $\begin{array}{c}\text { VALOR } \\
\text { MÍNIMO }^{(1)}\end{array}$ & $\begin{array}{c}\text { VALOR } \\
\text { MÁXIMO }^{(1)}\end{array}$ \\
\hline \multirow{4}{*}{$\mathrm{G}_{1}$} & \multirow[t]{2}{*}{ Axilar } & Pré & 3,87 & 1,30 & 2,00 & 6,50 \\
\hline & & Pós & 4,87 & 1,68 & 2,00 & 7,00 \\
\hline & \multirow[t]{2}{*}{ Xifóide } & Pré & 2,71 & 1,26 & 1,00 & 5,00 \\
\hline & & Pós & 4,08 & 2,27 & $-1,00$ & 8,00 \\
\hline \multirow{4}{*}{$\mathrm{G}_{2}$} & \multirow[t]{2}{*}{ Axilar } & Pré & 4,24 & 2,12 & 1,00 & 8,00 \\
\hline & & Pós & 4,98 & 1,76 & 2,00 & 8,00 \\
\hline & \multirow[t]{2}{*}{ Xifóide } & Pré & 3,40 & 1,90 & 1,00 & 7,00 \\
\hline & & Pós & 4,11 & 1,81 & 1,00 & 8,00 \\
\hline \multirow{4}{*}{$\mathrm{G}_{3}$} & \multirow[t]{2}{*}{ Axilar } & Pré & 3,88 & 1,56 & 2,00 & 6,50 \\
\hline & & Pós & 5,05 & 2,35 & 2,00 & 7,00 \\
\hline & \multirow{2}{*}{ Xifóide } & Pré & 3,38 & 1,92 & 1,00 & 5,00 \\
\hline & & Pós & 4,43 & 2,34 & 1,00 & 8,00 \\
\hline
\end{tabular}

(1) Valores em cm 
Gráfico 9 - Trajetórias da expansibilidade ao nível axilar dos sujeitos alocados no grupo água pré-pós intervenção

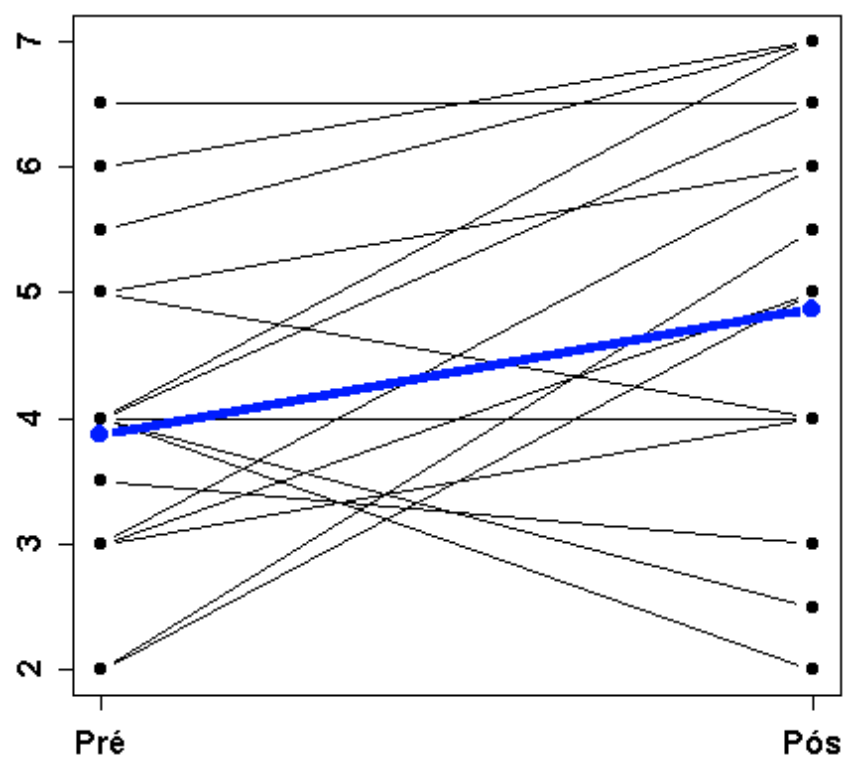

NOTA: Valores em $\mathrm{cm}$.

Gráfico 10 - Trajetórias da expansibilidade ao nível axilar dos sujeitos alocados no grupo solo pré-pós intervenção

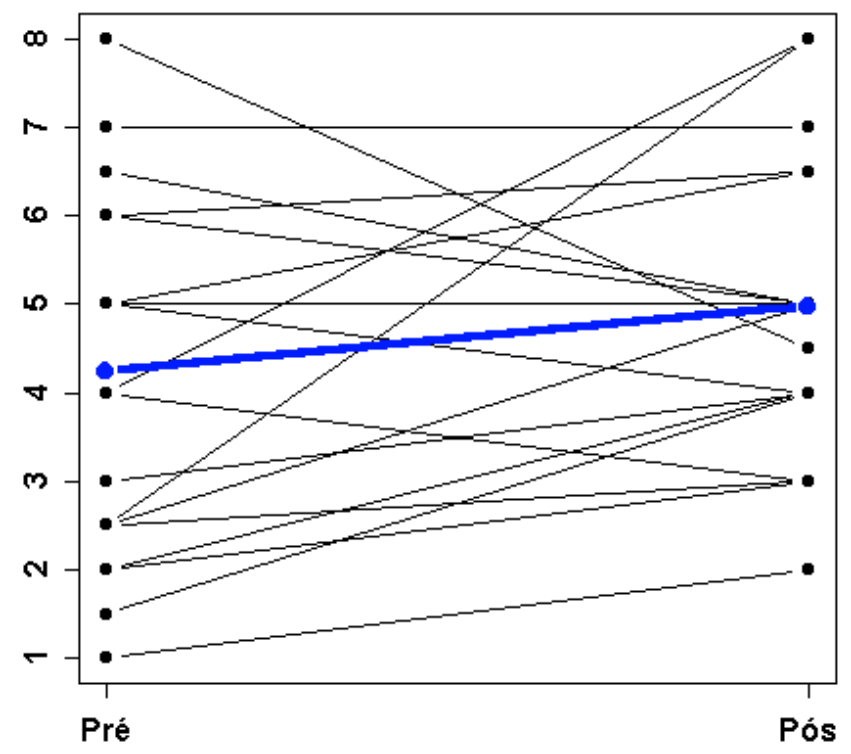

NOTA: Valores em cm. 
Gráfico 11 - Trajetórias da expansibilidade ao nível axilar dos sujeitos alocados no grupo controle pré-pós intervenção

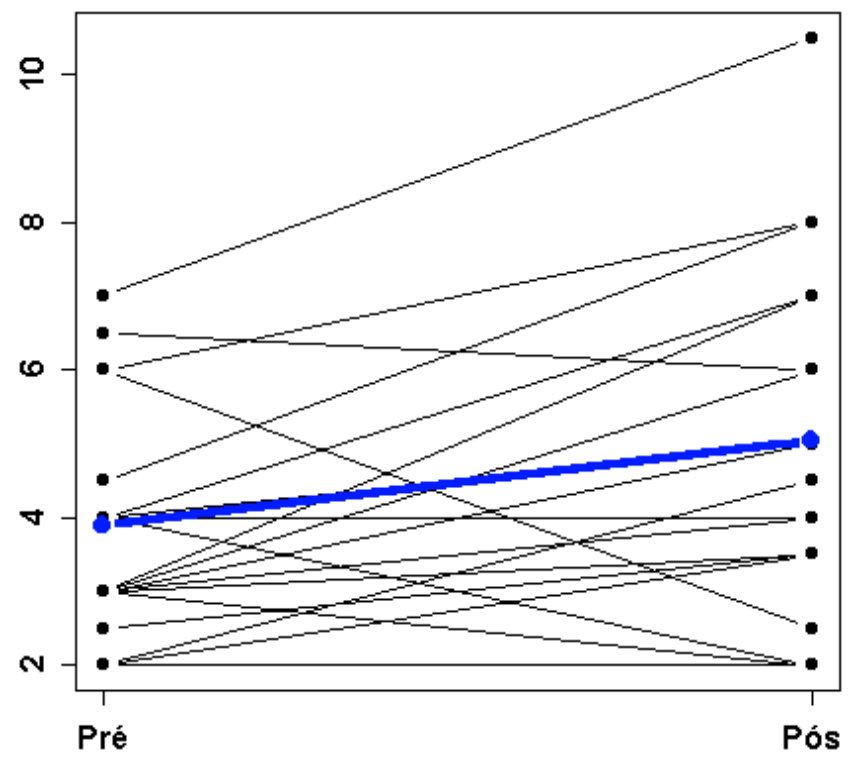

NOTA: Valores em cm.

Gráfico 12 - Trajetórias da expansibilidade ao nível xifóide dos sujeitos alocados no grupo água pré-pós intervenção

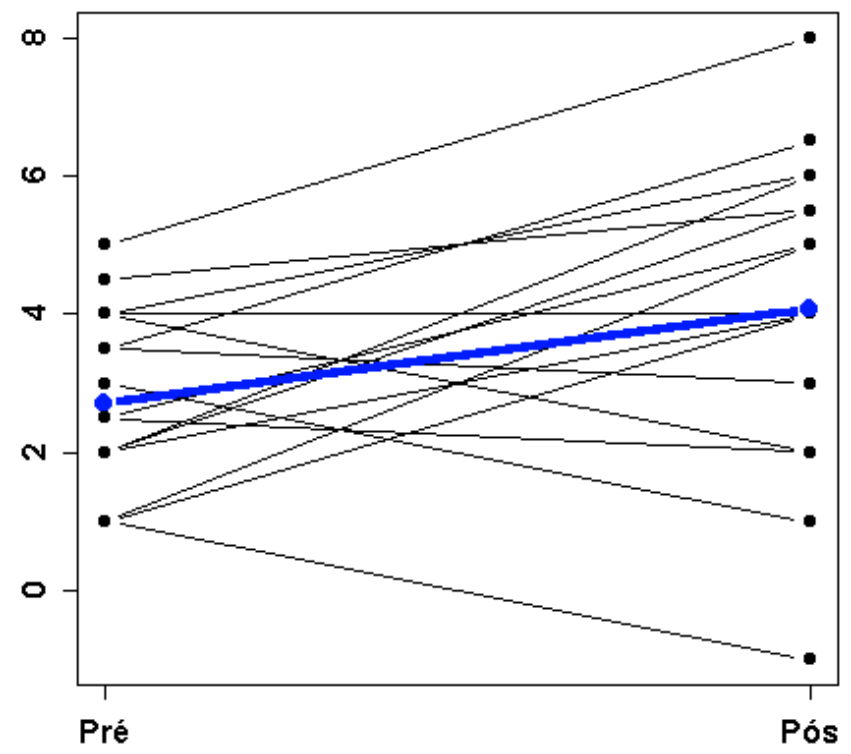

NOTA: Valores em cm. 
Gráfico 13 - Trajetórias da expansibilidade ao nível xifóide dos sujeitos alocados no grupo solo pré-pós intervenção

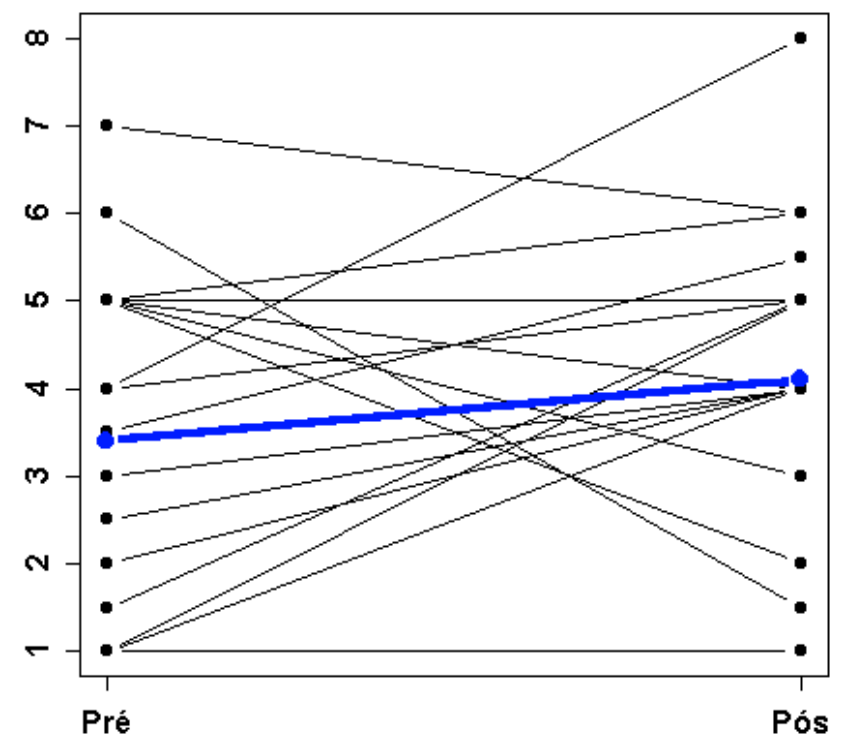

NOTA: Valores em $\mathrm{cm}$.

Gráfico 14 - Trajetórias da expansibilidade ao nível xifóide dos sujeitos alocados no grupo controle pré-pós intervenção

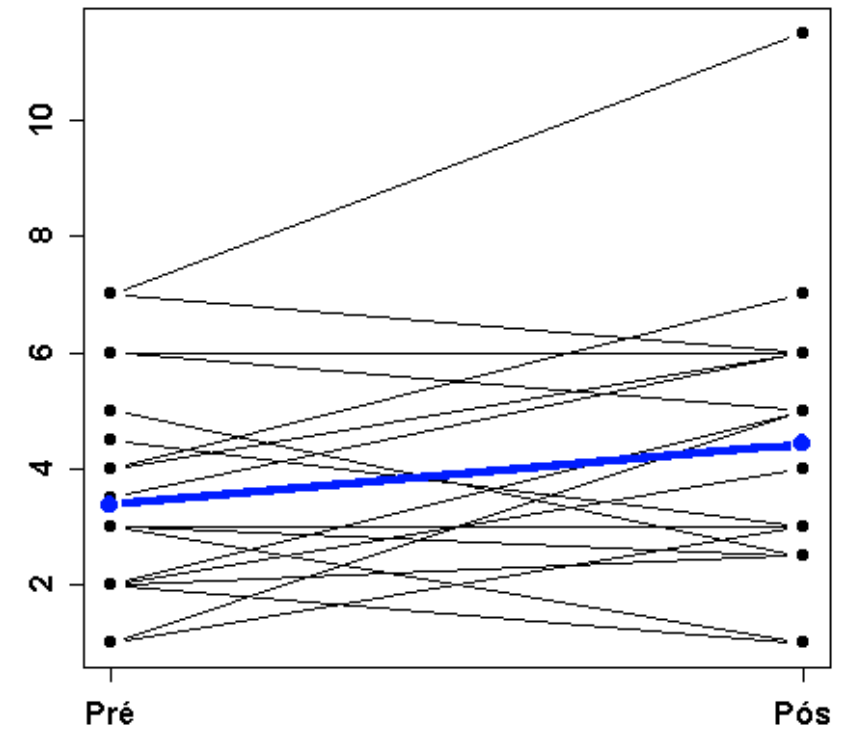

NOTA: Valores em cm. 
Utilizando o teste paramétrico t-pareado, foram analisadas individualmente as médias da expansibilidade torácica nos dois níveis avaliados (axilar e xifóide) dos três grupos - água, solo e controle - pré e pós a realização do protocolo de exercícios.

Considerando um nível de significância de 5\%, observou-se alteração estatisticamente significativa nos resultados dos grupos água e controle $\left(G_{1}\right.$ e $\left.G_{3}\right)$ em relação à expansibilidade nos dois níveis estudados, axilar e xifóide. O grupo solo não apresentou alteração estatisticamente significativa em nenhum dos níveis. Estes dados estão representados na Tabela 7.

Tabela 7 - Comparação da expansibilidade pós-pré intervenção nos grupos água, solo e controle utilizando o teste t-pareado

\begin{tabular}{ccccccc}
\hline NÍVEL & $\begin{array}{c}\text { DIFERENÇA ENTRE } \\
\text { MÉDIAS PÓS-PRÉ }^{(1)}\end{array}$ & $\begin{array}{c}\text { INTERVALO DE } \\
\text { CONFIANÇA 95\% }\end{array}$ & $\begin{array}{c}\text { ERRO } \\
\text { PADRÃO }\end{array}$ & $\begin{array}{c}\text { TESTE } \\
\text { T-PAR. }\end{array}$ & $\mathrm{p}$ \\
\hline $\mathrm{G}_{1}$ & Axilar & 1,00 & $-1,88 \mathrm{a}-0,12$ & 0,42 & $-2,38$ & $0,03^{(2)}$ \\
& Xifóide & 1,37 & $-2,46 \mathrm{a}-0,28$ & 0,52 & $-2,63$ & $0,02^{(2)}$ \\
& Axilar & 2,08 & $-0,78 \mathrm{a} 4,93$ & 1,36 & 1,53 & 0,14 \\
$\mathrm{G}_{2}$ & Xifóide & 2,095 & $-1,59 \mathrm{a} 5,77$ & 1,75 & 1,20 & 0,25 \\
& Axilar & $-1,17$ & $-2,03 \mathrm{a}-0,30$ & 0,41 & $-2,81$ & $0,01^{(2)}$ \\
$\mathrm{G}_{3}$ & Xifóide & $-1,05$ & $-2,01 \mathrm{a}-0,09$ & 0,46 & $-2,27$ & $0,03^{(2)}$ \\
\hline
\end{tabular}

(1) Valores em cm

(2) Diferenças estatisticamente significativas

Para definir se havia diferenças entre as médias pré e pós intervenção dos três grupos, utilizou-se a técnica de análise de variância com medidas repetidas. Em relação à expansibilidade ao nível axilar, com um nível de significância de 5\%, não foram encontradas diferenças estatisticamente significativas entre os grupos, apesar de haver um efeito significativo do tempo. Na comparação dos grupos o valor da estatística $F$ é igual a 0,11 , com $p=0,89$. Também em nível de significância de $5 \%$ a 
interação ocasião "versus" grupo é não significativa. Deste modo, conclui-se que as médias dos três grupos se alteram de maneira semelhante pré e pós a realização do protocolo de exercícios respiratórios. Os dados estão representados na Tabela 8. A análise da expansibilidade mensurada ao nível do processo xifóide demonstrou resultados semelhantes aos encontrados ao nível axilar. Pode-se avaliar o comportamento médio dos grupos em relação à expansibilidade torácica para cada um dos níveis nos Gráficos 15 e 16.

Tabela 8 - Comparação da expansibilidade pós-pré intervenção entre os grupos utilizando o teste t-pareado

\begin{tabular}{ccc}
\hline $\begin{array}{c}\text { COMPARAÇÃO ENTRE OS GRUPOS } \\
\mathrm{G}_{1} \times \mathrm{G}_{2} \times \mathrm{G}_{3}\end{array}$ & ANÁLISE DE VARIÂNCIA & $\mathrm{p}$ \\
\hline AXILAR & 0,11 & 0,89 \\
XIFOIDE & 0,52 & 0,60 \\
\hline
\end{tabular}

Gráfico 15 - Trajetórias médias da expansibilidade torácica ao nível axilar nos grupos água, solo e controle

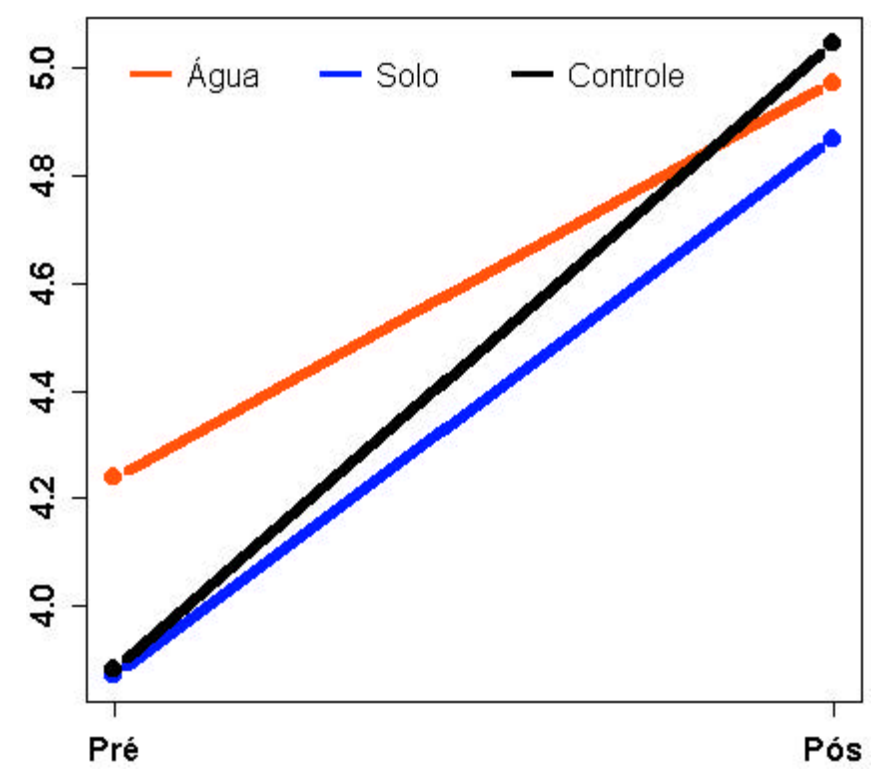

NOTA: Valores em cm.

Gráfico 16 - Trajetórias médias da expansibilidade torácica ao nível xifóide nos grupos água, solo e controle 


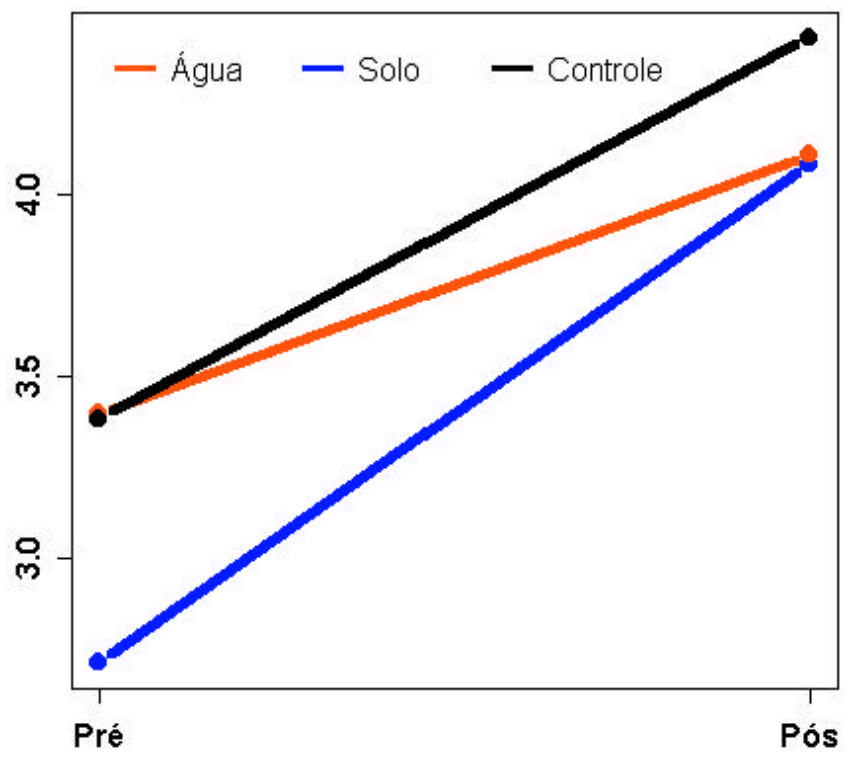

NOTA: Valores em cm.

\subsection{Flexibilidade de tronco/pélvis}

Os valores relativos ao comportamento da flexibilidade nos sujeitos pré e pós intervenção estão descritos na Tabela 9 e Gráficos de 17 a 19.

Tabela 9 - Flexibilidade de tronco/pélvis dos sujeitos alocados nos grupos água, solo e controle

\begin{tabular}{|c|c|c|c|c|c|c|c|c|c|}
\hline \multirow[t]{2}{*}{ GRUPO } & \multirow[t]{2}{*}{ SUJEITOS } & \multicolumn{2}{|c|}{ MÉDIA $^{(1)}$} & \multicolumn{2}{|c|}{$\begin{array}{c}\text { DESVIO } \\
\text { PADRÃO }\end{array}$} & \multicolumn{2}{|c|}{$\begin{array}{c}\text { VALOR } \\
\text { MíNIMO }^{(1)}\end{array}$} & \multicolumn{2}{|c|}{$\begin{array}{c}\text { VALOR } \\
\text { MÁXIMO }^{(1)}\end{array}$} \\
\hline & & Pré & & Pré & Pós & Pré & Pós & Pré & \\
\hline$G_{1}$ & 19 & 24,18 & & & & 6 & & 96 & 0, \\
\hline $\mathrm{G}_{2}$ & 1 & & & & & 3,10 & & 38,58 & 32, \\
\hline $\mathrm{G}_{3}$ & 21 & 20,84 & 20,43 & 10,74 & 11,61 & 5,50 & 0,00 & 45,96 & 43 \\
\hline
\end{tabular}

(1) Valores em cm

Gráfico 17 - Trajetórias da flexibilidade dos sujeitos alocados no grupo água prépós intervenção 


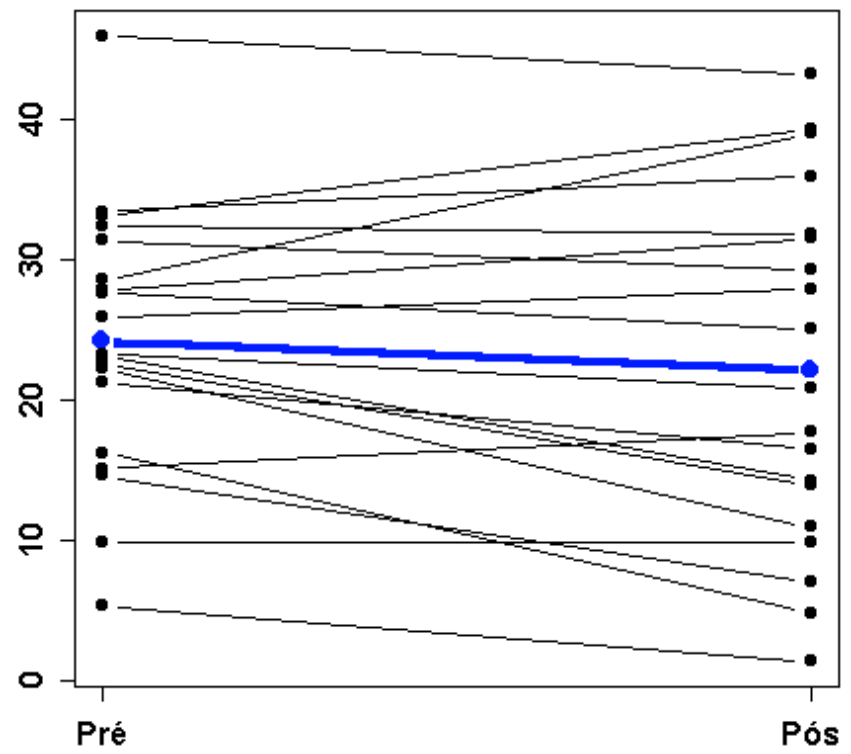

NOTA: Valores em cm.

Gráfico 18 - Trajetórias da flexibilidade dos sujeitos alocados no grupo solo prépós intervenção

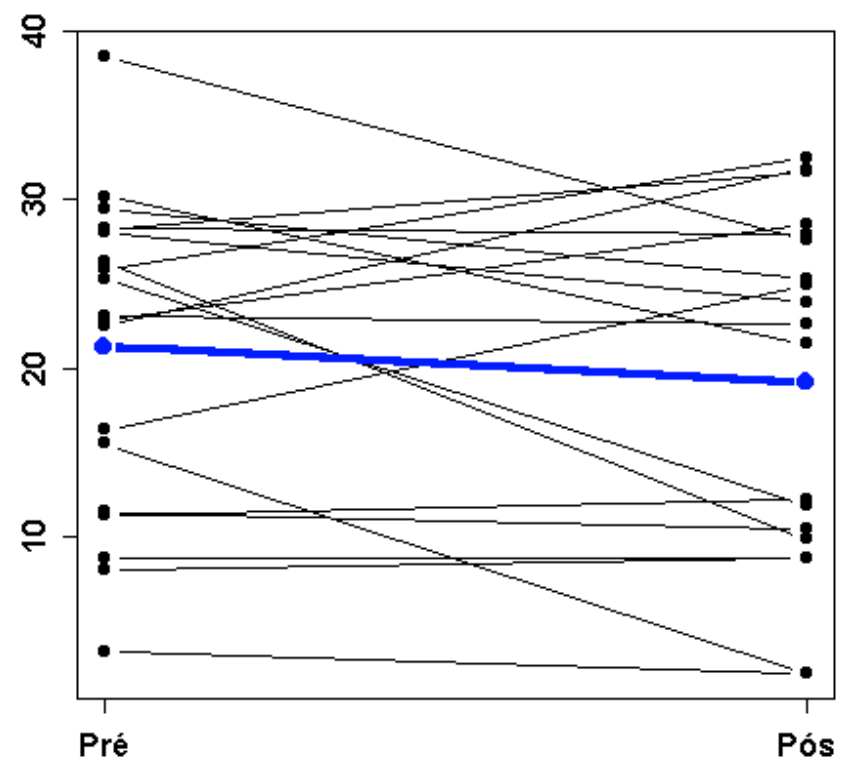

NOTA: Valores em cm.

Gráfico 19 - Trajetórias da flexibilidade dos sujeitos alocados no grupo controle pré-pós intervenção 


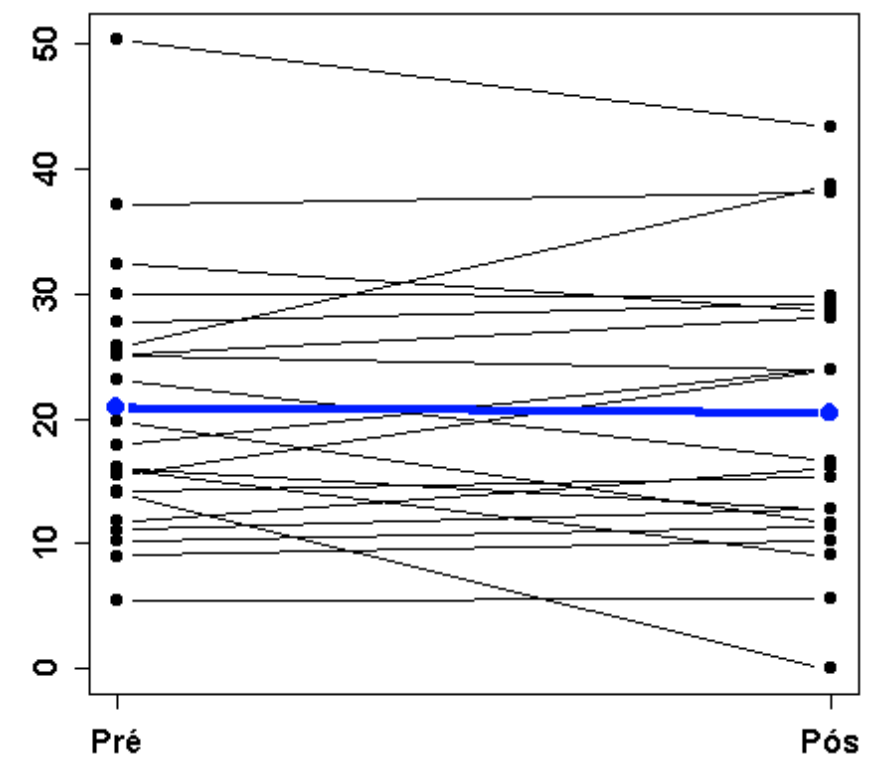

NOTA: Valores em cm.

A partir da análise de covariância, observa-se, com um nível de significância de $5 \%$, que em pelo menos um meio de tratamento o valor médio da diferença da flexibilidade pós-pré intervenção depende linearmente do valor da flexibilidade inicial (pré) do indivíduo ( $p<0,0001)$. Buscou-se analisar se tal relação de dependência é a mesma para todos os tratamentos, o que equivale testar a hipótese de igualdade dos coeficientes de inclinação ou de que as retas de regressão são paralelas.

Com a análise de covariância, detectou-se que a mudança média na flexibilidade pós-intervenção por unidade de mudança na flexibilidade pré-intervenção é a mesma em todos os grupos $(p>0,18)$. Uma vez detectado que as retas de regressão tem o mesmo coeficiente de inclinação, avaliou-se se os interceptos das retas são os mesmos. Também por meio da análise de covariância, detectou-se que as retas de regressão tem mesmo intercepto $(p>0,39)$.

Como conclusão final, tem-se que um único modelo de regressão pode ser considerado na avaliação da mudança da flexibilidade pós-intervenção por unidade de mudança na flexibilidade inicial. Deste modo, não há diferenças estatisticamente 
significativas no comportamento da flexibilidade pós-pré intervenção. As estimativas das médias da flexibilidade pós-intervenção ajustadas pela flexibilidade inicial estão apresentados na Tabela 10. A comparação entre os grupos pode ser observada no Gráfico 20.

Tabela 10 - Estimativa das médias da flexibilidade pós-intervenção ajustadas pelos valores de flexibilidade iniciais

\begin{tabular}{ccc}
\hline GRUPO & MÉDIAS $^{(1)}$ & ERRO PADRÃO \\
\hline $\mathrm{G}_{1}$ & 20,031 & 1,53 \\
$\mathrm{G}_{2}$ & 19,91 & 1,52 \\
$\mathrm{G}_{3}$ & 21,58 & 1,45 \\
\hline
\end{tabular}

(1) Valores em cm

Gráfico 20 - Flexibilidade média de tronco/pélvis nos grupos água, solo e controle pré e pós a realização dos protocolos propostos

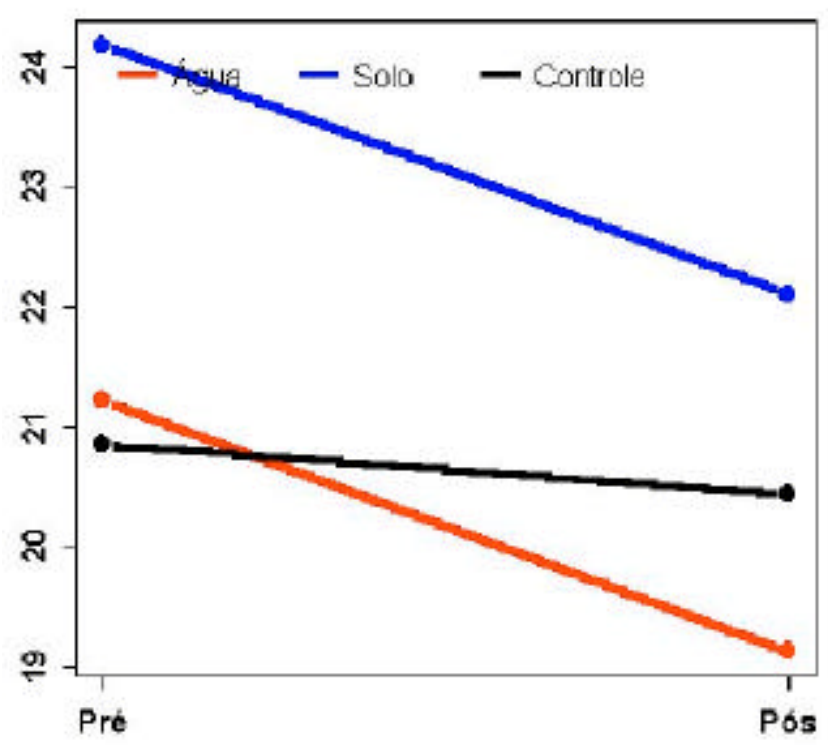

NOTA: Valores em cm.

\section{DISCUSSÃO}




\subsection{Força muscular respiratória $\left(P I_{\text {máx }}\right.$ e $\left.P E_{\text {máx }}\right)$}

\subsubsection{Comportamento da $\mathrm{PI}_{\text {máx }}$}

Analisando os resultados pós-pré intervenção dos grupos individualmente em relação a $\mathrm{PI}_{\operatorname{máx}}$, observou-se que apenas o grupo controle apresentou alteração estatisticamente significativa. A queda pronunciada nos valores encontrados não tem explicação clara, visto que esperava-se uma manutenção nos valores obtidos, ou até mesmo um aumento. Diversos autores relatam os efeitos do aprendizado na técnica de mensuração das pressões máximas (Smith et al., 1988; Black e Hyatt, 1969; Leith e Bradley, 1976).

Comparando os grupos, ainda em relação a $\mathrm{Pl}_{\operatorname{máx}}$, observou-se diferença estatisticamente significativa entre $\circ \mathrm{G}_{1}, \mathrm{G}_{2}$ e $\mathrm{G}_{3}$. Analisando os grupos intervenção $\left(G_{1}\right.$ e $\left.G_{2}\right)$ em relação ao grupo controle $\left(G_{B}\right)$, detectou-se que a diferença encontrada na análise anterior era referente ao grupo que realizou atividades aquáticas em relação ao grupo controle.

Deste modo, comprovou-se que o protocolo de cinesioterapia respiratória proposto foi capaz de fortalecer a musculatura inspiratória, mas somente quando realizado em meio aquático. Acredita-se que isto se deva a influência das propriedades físicas da água na quantidade de esforço realizado pelos voluntários. Conforme descrito, um indivíduo imerso até o nível do processo xifóide experimenta um aumento no trabalho respiratório de cerca de $60-65 \%$, causado principalmente por dois fatores: resistência à expansão torácica (dado pela pressão hidrostática) e aumento no volume sangüíneo torácico (dado pelo empuxo da água e pressão hidrostática). Acredita-se que estas resistências extras - somadas ao esforço da inspiração profunda solicitada aos sujeitos - durante todos os exercícios e incursões 
respiratórias, foram suficientes para melhorar consideravelmente a força muscular respiratória dos sujeitos tratados.

Especula-se ainda que, além da melhora na força muscular propriamente dita, os exercícios contidos no protocolo aprimoraram os demais músculos do tronco e membros superiores, não diretamente relacionados com a respiração. Também podem ter influenciado outras variáveis relacionadas - mas não específicas - do sistema respiratório, como amplitude de movimento, coordenação, agilidade e equilíbrio. Assim, acredita-se que a melhora na força muscular inspiratória pode ter sido influenciada por alterações benéficas na biomecânica global e respiratória, dadas pelo exercício e efeitos térmicos da água.

Entretanto, as conclusões acima devem ser cuidadosamente analisadas, visto que o aumento na $\mathrm{Pl}_{\text {máx }}$ pós-intervenção alcançou significância estatística com o auxílio de uma não explicada piora no resultados apresentados pelo grupo controle.

São encontrados diversos estudos objetivando verificar os efeitos do treino muscular inspiratório, seja ele voltado à melhora a força ou "endurance". Entretanto, poucos utilizam a cinesioterapia respiratória em meio aquático com tais fins. Encontrou-se somente um estudo que utilizou exclusivamente esta modalidade, mas seus resultados não puderam ser diretamente comparados com os obtidos por este trabalho, já que o tipo de amostra, variáveis avaliadas (os autores não avaliam diretamente a força muscular respiratória) e condições de tratamento são diferentes. $\mathrm{O}$ trabalho em questão foi desenvolvido por Kurabayashi et al. (1997) com 22 sujeitos com DPOC estável, com média de idade de aproximadamente 71 anos. Eles foram submetidos a exercícios respiratórios em uma estação de águas termais (temperatura de $38^{\circ} \mathrm{C}$ ), em dias alternados. Com imersão ao nível do ombro, os sujeitos realizavam aquecimento inicial de cinco minutos. Depois eram solicitadas inspirações profundas e expirações lentas pela boca por 30 minutos diários (10 de exercício e cinco de repouso 
fora da água). Após dois meses de exercício, todos os indivíduos relataram alívio nos sintomas da DPOC. Houve aumento significativo no $\mathrm{VEF}_{1}$, redução na $\mathrm{PaCO}_{2}$ e tendência de aumento no pico expiratório. Não houve aumento no pico de fluxo expiratório, fluxo expiratório máximo $25 \%$ nem $50 \%$. A redução na $\mathrm{PaCO}_{2}$ e aumento no $\mathrm{VEF}_{1}$, sem que houvesse aumento fluxo expiratório máximo $25 \%$ e $50 \%$ sugerem que o mecanismo de melhora provavelmente envolveu o fortalecimento da musculatura respiratória e melhora no "clearance" das vias aéreas de pequeno calibre.

Apesar de poucos estudos utilizarem a cinesioterapia respiratória como modalidade de treino muscular respiratório, são observados muitos trabalhos objetivando melhorar a força e/ou "endurance" mas que utilizam outros recursos, como aparatos de incentivo ou que causam resistência à passagem de ar, como "threshold" e circuitos de hiperpnéia isocápnica. Também são utilizados inspirômetros incentivadores e outros recursos. A grande maioria destes trabalhos dedica-se a treinar e avaliar os músculos inspiratórios.

Mesmo utilizando outras modalidades de treinamento, foi encontrado apenas um estudo dirigido especificamente à população idosa. O trabalho não avaliou as pressões respiratórias máximas, impossibilitando também comparações com o estudo realizado. Belman e Gaesser (1988) utilizaram o fortalecimento de musculatura respiratória para melhorar a "endurance" e o desempenho no exercício. Vinte e cinco sujeitos entre 65 e 70 anos foram submetidos a testes diversos, dentre eles testes espirométricos para avaliação da capacidade vital, $\operatorname{VEF}_{1}$ e ventilação voluntária máxima. Finalmente, foram randomizados em dois grupos. O primeiro grupo foi submetido a treino muscular ventilatório com hiperpnéia isocápnica voluntária, 30 minutos por dia, quatro dias por semana, por oito semanas. O segundo atuou como controle. Os resultados demonstraram que o programa de exercícios resultou em aumento significativo na capacidade ventilatória sustentada máxima $(20 \%)$, ventilação 
voluntária máxima (17\%), volume corrente (4\%) e $V F_{1}$ (24\%). Observou-se manutenção dos ganhos na capacidade ventilatória sustentada máxima após dois meses. Conforme relatado pelos autores, a melhora no volume corrente obtida por 11 dos 12 indivíduos treinados não ocorreu em estudos com jovens e indivíduos com DPOC, o que sugere que esse efeito seja exclusivo da população idosa. Observou-se, entretanto, que o treino respiratório não afetou a capacidade de exercício dos indivíduos tratados.

Vários outros estudos relacionando o treino de força e "endurance" muscular utilizando diferentes amostras foram encontrados. Grande parte deles envolve o estudo de sujeitos com DPOC. Os resultados obtidos pelos autores são bastante contraditórios. Estes efeitos não uniformes foram confirmados por Lacasse et al. (1997), que realizaram um estudo que analisou 22 ensaios clínicos aleatorizados a respeito de exercícios gerais, exercícios respiratórios, educação e apoio psicossocial em sujeitos com DPOC. Destes, sete estudos diziam respeito a programas de exercícios respiratórios adicionados a programas de exercícios convencionais. Concluiu que o treino muscular inspiratório e outros exercícios respiratórios, quando realizados junto a um programa de exercícios, tem resultados muito contraditórios.

Diversos trabalhos revelaram melhora na força muscular inspiratória de sujeitos treinados utilizando diferentes períodos de tempo, aparatos e esquemas de randomização da amostra. Os estudos estão descritos em detalhes no item 3.4.2. A maioria dos estudos analisa sujeitos com DPOC. Winer et al. (1992) relataram melhora significativa na $\mathrm{Pl}_{\text {máx }}$ de 12 sujeitos submetidos a treino inspiratório com "threshold". Esta melhora foi de 40 a 50\% no estudo conduzido por Sarmiento et al. (2002), também utilizando threshold. Patessio e colaboradores em 1989 encontraram melhora na $\mathrm{PI}_{\text {máx }}$ de nove sujeitos submetidos a treino de "endurance" inspiratória. Sturdy et al. (2003) detectaram melhora na $\mathrm{PI}_{\text {máx }}$ de sujeitos que realizaram exercícios de 
"endurance" de membros inferiores e treino inspiratório com threshold. Larson e Kim (1984) referem ter encontrado aumento significativo na $\mathrm{P}_{\text {máx }}$ de sujeitos submetidos a treino com incentivador inspiratório. Outras amostras foram estudadas. Leith e Bradley (1976) encontraram melhora de $55 \%$ na $\mathrm{Pl}_{\text {máx }}$ de três sujeitos normais submetidos a treino de fortalecimento inspiratório. Sampaio e colaboradores em 2002 referem melhora na $\mathrm{PI}_{\text {máx }}$ de asmáticos submetidos a treino com "threshold". Valle et al. (2002) observaram melhora significativa na força muscular respiratória de soldados que realizaram treino inspiratório com manovacuômetro. Volianitis et al. (2001) referem melhora de $22 \%$ na $\mathrm{Pl}_{\text {máx }}$ de remadoras profissionais submetidas a treino inspiratório, em comparação com a melhora de $6 \%$ obtida pelo grupo controle. Olgiati e colaboradores, em 1989, encontraram melhora de $31 \%$ na $\mathrm{Pl}_{\text {máx }}$ de pacientes com esclerose múltipla submetidos a treino muscular respiratório. Nomori et al. (1994) encontraram melhora significativa na $\mathrm{Pl}_{\text {máx }}$ de sujeitos no pré-operatório de cirurgia torácica submetidos a um protocolo que consistia de respiração diafragmática profunda com $2 \mathrm{~kg}$ de peso sobre o abdome, tosse eficaz com contração abdominal e treino com aparato que resistia a expiração. Azeredo (2002) encontrou ganho de $8 \%$ na $\mathrm{PI}_{\text {máx }}$ de sujeitos submetidos a treino por sustentação máxima da inspiração. Apesar dos diversos efeitos positivos relatados pelos estudos acima, Smith et al. (1988) concluíram em seu comentário que os benefícios do treino inspiratório resistido em sujeitos com distrofia muscular de Duchenne são poucos e difíceis de serem distinguidos de meros efeitos do aprendizado. Os autores citam ainda que sujeitos com melhor condição respiratória respondiam de maneira mais eficiente ao treinamento, sugerindo que os benefícios encontrados além de fracos eram pequenos.

Vários outros estudos relatam resultados negativos do uso de treino inspiratório. Estudando sujeitos com DPOC, três estudos foram encontrados. Scherer et al. (2000) não evidenciaram melhora na $\mathrm{PI}_{\text {máx }}$ de sujeitos que realizaram treino de "endurance" 
com hiperpnéia isocápnica. Goldstein e colaboradores (1989) relatam não ter encontrado melhora significativa na força muscular inspiratória de sujeitos que realizaram treino com "threshold". Harver et al. (1989) referem não ter encontrado melhora na $\mathrm{Pl}_{\text {máx }}$ de indivíduos que realizaram treino inspiratório com aparelho que permitia feedback visual de desempenho. Em relação a estudos com sujeitos normais, McEntire et al. (2003) referem não ter encontrado melhora na $\mathrm{Pl}_{\text {máx }}$ de sujeitos que realizaram treino inspiratório. Azeredo (2002) não encontrou melhora na $\mathrm{Pl}_{\text {máx }}$ de 15 indivíduos com doença restritiva pulmonar submetidos a treino com incentivador respiratório a volume. $\mathrm{O}$ autor cita que o treinamento muscular pode estender-se por meses até que surjam respostas significativas a terapia.

Observa-se que a quase totalidade dos estudos supracitados utilizam algum método de resistência a inspiração e/ou expiração (exceto o estudo de Kurabayashi et al., 1997), diferentemente do proposto neste trabalho, o que dificulta as comparações.

Pela escassez de estudos relacionados a treino respiratório utilizando cinesioterapia, particularmente quando relacionada ao meio aquático e envolvendo idosos, fica difícil estabelecer verdades sobre o real comportamento da $\mathrm{PI}_{\text {máx }}$ nestes casos. O estudo de tal relação foi ainda complicado pela piora apresentada pelo grupo controle, de difícil ou impossível explicação, o que deu rumos diferentes às conclusões do estudo. Acredita-se que a repetição ou a ampliação do tempo de intervenção do estudo possa clarear questões no que diz respeito ao comportamento da $\mathrm{Pl}_{\text {máx }}$ de sujeitos idosos submetidos a um protocolo de cinesioterapia respiratória voltado a melhorar a força muscular respiratória e expansibilidade torácica.

\subsubsection{Comportamento da $P E_{\text {máx }}$}


Quando analisado individualmente, a $\mathrm{PE}_{\operatorname{máx}}$ de nenhum dos grupos apresentou diferença estatisticamente significativa em relação ao comportamento pré-intervenção. Acredita-se que o aumento leve no escore obtido por todos os grupos se deva tão somente ao aprendizado, que fez com que realizassem o teste com maior intimidade. Smith et al. (1988) citam esse efeito em seu estudo realizado com sujeitos portadores de distrofia muscular de Duchenne, bem como Black e Hyatt em 1969 e Leith e Bradley em 1976.

Os achados concordam com Naus et al. (1990) ${ }^{*}$, Powers et al. (1992) ${ }^{* *}$ e Uribe et al. (1992) ${ }^{\star * \star}$ apud HALSETH et al. (1995), que demonstraram que exercícios gerais de "endurance" aumentam a capacidade oxidativa dos músculos inspiratórios e expiratórios. Entretanto, apesar de mudanças expressivas na porção costal do músculo diafragma, relatam mudanças relativamente pequenas ou inexistentes nos músculos abdominais.

Em relação à cinesioterapia aplicada à musculatura expiratória, cita-se novamente o estudo realizado por Kurabayashi et al. (1997). Concordando com os resultados obtidos por este estudo, o autor também não encontrou melhora relacionada a parâmetros expiratórios, como $V F_{1}$, fluxo expiratório máximo $25 \%$ e $50 \%$ e pico de fluxo expiratório em sujeitos com DPOC que realizaram um programa de exercícios respiratórios aquáticos em uma estação termal por dois meses.

Um outro estudo utilizando exercícios expiratórios em meio aquático realizado pelo mesmo grupo analisou parâmetros relacionados à expiração. Kurabayashi et al. (2000) revelaram melhora na função pulmonar e análise dos gases sangüíneos de

\footnotetext{
"Naus F, Sharrat M, McGill S, Hughson R. An EMG confirmation of active respiration The FASEB Journal.1990;4:293.

** Powers SK, Grinton S, Lawler J, Criswell D, Dodd S. High intensity exercise traininginduced metabolic alterations in respiratory muscles. Resp Phys.1992;89:169-77.

${ }^{* * *}$ Uribe JM, Stump CS, Tipton CM, Fregosi RF. Influence of exercise training on the oxidative capacity of rat abdominal muscles. Resp Phys.1992;88:171-80.
} 
enfisematosos submetidos a um programa que envolvia expirar abaixo do nível da água. Acredita-se que este programa ofereceu resistência semelhante a resistência dada pela expiração freno-labial. Tal qual nesta modalidade, a expiração sofreu resistência mecânica da água, com valores de aproximadamente três a $5 \mathrm{cmH}_{2} \mathrm{O}$. Trata-se de uma pequena, mas constante, pressão na via aérea, evitando o colabamento das vias aéreas de menor calibre. Adicionalmente, o aumento de pressão na superfície abdominal provavelmente assistiu o diafragma na expiração e reduziu o espaço morto anatômico. O estudo em questão propôs dois diferentes programas de exercícios expiratórios, ambos realizados em meio aquático. O grupo A realizou inspiração diafragmática profunda na posição ortostática e expiravam com o nariz e boca de 3 a $5 \mathrm{~cm}$ abaixo do nível da água. No grupo $B$, os sujeitos os sujeitos expiravam com nariz e boca fora da água. Os exercícios foram realizados em piscina a $38^{\circ} \mathrm{C}, 30$ minutos por dia, cinco dias por semana, por dois meses em 17 sujeitos (11 homens e seis mulheres) com enfisema crônico estável. No grupo A, observou-se um aumento significativo no $\mathrm{VEF}_{1}$, pico de fluxo expiratório, $\mathrm{PaO}_{2}$ e tendência de aumento na capacidade vital forçada. Notou-se ainda uma redução na $\mathrm{PaCO}_{2}$. Não foram observadas alterações no grupo B.

Em relação ao treino muscular exclusivamente expiratório utilizando incentivadores, foi encontrado um estudo realizado por Suzuki et al. (1995). Seis sujeitos foram submetidos a treino de musculatura expiratória por 15 minutos, duas vezes por dia, durante quatro semanas, utilizando "threshold" com carga de $30 \%$ do máximo (foi solicitado aos indivíduos que expirassem no orifício oposto ao tradicional). Outros seis atuaram como controle. $A \mathrm{PE}_{\text {máx }}$ aumentou $25 \%$ no grupo tratado em relação ao grupo controle.

Também exclusivo à musculatura expiratória, encontrou-se o estudo realizado por Walker e Cooney (1987) com sujeitos tetraplégicos. Submeteram 15 sujeitos a um 
programa de reabilitação pulmonar e exercícios resistidos por 7 a 12 semanas. A parte pulmonar do programa consistia de exercícios de espirometria de incentivo por 15 minutos por dia, três a cinco dias na semana. Os exercícios eram realizados com bicicleta ergométrica de membros superiores por 30 minutos, três vezes por semana. Encontrou-se melhora na capacidade vital e volume de ar expirado durante o exercício.

Outros estudos de fortalecimento expiratório são encontrados, e abordam também o comportamento da $\mathrm{PI}_{\text {máx }}$. Foram descritos em detalhes no item 3.4.2.

Resumindo estes estudos, citamos o trabalho de Leith e Bradley (1976) que encontraram melhora na $\mathrm{PE}_{\text {máx }}$ de sujeitos normais submetidos a treino de força utilizando "threshold". Belman e Gaesser (1988) demonstraram melhora de 24\% na $V F_{1}$ e $20 \%$ na capacidade ventilatória sustentada máxima de idosos saudáveis submetidos a treino muscular ventilatório com hiperpnéia isocápnica voluntária. Scherer et al. (2000) utilizaram o mesmo recurso para treinar sujeitos com DPOC e limitação ventilatória. Observou-se melhora significativa na $P E_{\text {máx }}$ do grupo tratado em relação ao controle. Olgiati et al. (1989) relataram melhora significativa (31\%) na $P E_{\text {máx }}$ de sujeitos com esclerose múltipla submetidos a treino com um aparato que causava resistência ao fluxo de ar. Sampaio e colaboradores, em 2002, obtiveram aumento significativo na $P E_{\text {máx }}$ de asmáticos submetidos a treino inspiratório (combinado ou não ao exercício físico) utilizando "threshold". Os autores acreditam que o ganho expiratório observado quando o treino inspiratório era realizado deve-se ao fato de que a ação mecânica aumentada nos músculos inspiratórios proporcionou uma maior mobilidade tóraco-abdominal e conseqüente reorganização mecânica de todos os músculos envolvidos na respiração. Além disso, acreditam que o fato de ter se direcionado os treinamentos para o músculo diafragma provavelmente tenha proporcionado maior mobilidade dos músculos abdominais, conseqüentemente vindo a 
recrutar mais os músculos da parede abdominal, que atuam como acessórios da respiração.

Esta sobrecarga expiratória não foi observada, em nenhum dos meio utilizados. Conclui-se que a sobrecarga expiratória dada pelo treino inspiratório não ocorre quando são realizados exercícios de cinesioterapia respiratória em idosos saudáveis.

Interessante notar que três dos cinco estudos que demonstraram melhora significativa na $\mathrm{PE}_{\text {máx }}$ utilizaram sujeitos com alguma patologia e nos quais se espera uma $\mathrm{PE}_{\text {máx }}$ inicialmente reduzida em relação a parâmetros de normalidade. Acredita-se que sujeitos nestas condições sejam beneficiados mais rápida e intensamente por programas de intervenção.

Acredita-se que a não alteração na $P E_{\text {máx }}$ detectada neste trabalho pode ser justificada por três principais fatores. Primeiro, os músculos responsáveis pela expiração forçada (músculos reto abdominal, oblíquos interno e externo e transverso do abdome) são músculos tônicos e muito potentes, não exclusivos da ventilação. Deste modo, acredita-se que seu fortalecimento não pode ser obtido com simples incentivos expiratórios. Segundo Azeredo (2002), na inspiração forçada, o fluxo máximo a ser atingido a cada volume depende em grande parte de esforço empreendido pelos músculos inspiratórios. Entretanto, a expiração forçada não utiliza o mesmo mecanismo. No início, a expiração forçada depende do esforço do indivíduo, mas a partir de então esforços maiores não conduzem a fluxos proporcionais, podendo até ser acompanhados de pequena redução no mesmo devido à compressão dinâmica das vias aéreas, favorecendo um gasto aumentado de energia para a respiração e até mesmo prejudicando a ventilação. E em terceiro e último lugar, os sujeitos que realizaram o protocolo em imersão tiveram sua musculatura abdominal, e conseqüentemente a expiração, favorecida do ponto de vista biomecânico pelas propriedades físicas da água. A pressão hidrostática tende a fazer com que o tórax 
inspirado retorne a sua posição inicial, de repouso. Além disto, esta mesma propriedade, que exerce pressão circular nos corpos imersos, tende a auxiliar a musculatura expiratória em mais uma de suas funções: a contenção dos órgãos pélvicos e abdominais.

Uma melhora na $P E_{\text {máx }}$ seria de grande relevância clínica, uma vez que a integridade da musculatura expiratória é essencial para algumas manobras que envolvam a expiração forçada, como no caso da tosse. A tosse também requer integridade da musculatura inspiratória, sendo uma alternativa fisiológica eficiente para remover eventuais secreções e impedir a instalação de quadros patológicos mais graves.

\subsection{Expansibilidade torácica}

Apesar de nitidamente voltado a melhorar a força muscular respiratória, acreditase que o protocolo proposto exerceu influência sobre aspectos relacionados à mobilidade e expansibilidade torácica, já que estes parâmetros eram necessários para a realização eficaz dos exercícios propostos.

Quando comparada intra-grupo, a expansibilidade torácica do grupo que realizou atividades aquáticas, em ambos níveis, obteve aumento estatisticamente significativo, melhora esta não observada no grupo solo. Entretanto, tal comportamento também foi observado no grupo controle, de modo que não se pôde determinar uma alteração significativa quando os três grupos foram comparados.

A diferença obtida pós-intervenção pelo grupo aquático não foi observada no grupo solo. Apesar de não comparável estatisticamente, visto que o objetivo era comparar os grupos intervenção em relação ao controle, tal fato supõe que o meio aquático influenciou os resultados obtidos pelo protocolo de cinesioterapia. 
Acredita-se que estes resultados mais satisfatórios devam-se ao efeito das propriedades térmicas e mecânicas da água sobre o indivíduo imerso, que maximizaram o exercício, além dos efeitos psicológicos dados pela terapia aquática. Sabe-se que o efeito térmico da água é responsável por uma melhora na complacência dos tecidos moles e articulações. $O$ calor também promove relaxamento, o que auxilia na melhora das amplitudes de movimento articular. Todos estes efeitos são maximizados quando o calor é aplicado de forma constante e em todo o organismo, como o proporcionado pela terapia em piscina terapêutica. Estes efeitos, exercidos sobre as articulações da caixa torácica e cintura escapular, podem ter sido responsáveis pela melhora encontrada no grupo aquático.

Caso o protocolo fosse aplicado por uma maior quantidade de tempo, em uma amostra maior, resultados estatisticamente mais satisfatórios poderiam ser obtidos. Observa-se ainda que a análise estatística foi influenciada pela melhora obtida pelo grupo controle, atenuando os efeitos dos escores obtidos pelo grupo aquático.

Foi encontrado um estudo semelhante ao realizado, com utilização de cinesioterapia respiratória como modalidade isolada de tratamento. O programa aplicado era voltado especificamente a melhorar a mobilidade torácica de sujeitos com DPOC. Este trabalho, realizado por Paulin et al. (2003), incluiu trinta sujeitos com DPOC moderada e grave, randomizados em dois grupos. O primeiro atuou como controle e o segundo foi submetido a um programa de exercícios em decúbitos diversos, envolvendo movimentos de tronco associados à respiração diafragmática. $\mathrm{A}$ expansibilidade foi avaliada através da cirtometria, realizada em três níveis: axilar, xifóide e basal. Também foram avaliados parâmetros relacionados à capacidade funcional e qualidade de vida. A expansibilidade torácica apresentou melhora significativa no grupo tratado após os dois meses de intervenção. O programa era aplicado três vezes por semana. 
Um estudo realizado por Heikkilä et al. (2000) avaliou o comportamento da expansibilidade torácica frente a um programa terapêutico. O estudo não detalha exatamente a intervenção proposta, citando apenas que se tratava de tratamento fisioterapêutico que incluía exercícios para coluna e quadril. Este tratamento foi proposto a 112 sujeitos com espondiloartropatias soronegativas e aplicado por três semanas. Além da expansibilidade torácica, foram avaliadas outras 12 variáveis relacionadas à flexibilidade e mobilidade de coluna (dentre elas o índice de Schober, flexão tóraco-lombar, rotação tóraco-lombar, flexão lateral tóraco-lombar, distância occipito-parede, distância dedo-chão, expansibilidade torácica e rotação cervical). Observou melhora em todas as variáveis, com melhora média de 18,98\% na expansibilidade torácica.

\subsection{Flexibilidade anterior de tronco/pélvis}

A flexibilidade não apresentou alteração estatisticamente significativa nos indivíduos submetidos a qualquer um dos programas de exercício propostos aquático ou terrestre - em relação ao grupo controle. Com isto, conclui-se que um protocolo de exercícios voltado a melhorar a amplitude de movimento da caixa torácica e força muscular respiratória não influencia a flexibilidade anterior de tronco e pélvis, seja ele realizado em imersão ou não.

Entretanto, recomenda-se cuidado ao analisar os resultados. Observou-se inicialmente sujeitos com índices muito baixos e outros extremamente altos, que continuaram a comportar-se da mesma maneira pós-intervenção. Entretanto, esta variação ampla pode influenciar os efeitos da análise estatística.

Estudos nas mais diferentes áreas da fisioterapia, envolvendo prevenção e reabilitação, citam as vantagens de se promover um programa aquático para melhorar 
a flexibilidade de um indivíduo. Estas facilidades são atribuídas às propriedades térmicas da água, que permitem um aquecimento global e constante, conduzindo a efeitos fisiológicos e terapêuticos como redução da rigidez articular, redução de possíveis quadros álgicos e melhora da complacência de tecidos moles. A redução na descarga de peso dada pela flutuação também auxiliaria, possibilitando que o exercício seja realizado em posturas mais confortáveis e facilitando a graduação da intensidade mais adequada a cada indivíduo.

Diversos autores citam e justificam os efeitos do envelhecimento sobre a flexibilidade. Apesar de não descrever níveis ideais, sabe-se que uma boa qualidade de vida depende, de certo modo, de uma flexibilidade razoável. O teste utilizado para avaliação da flexibilidade neste trabalho (dedo-chão modificado) espera que os adultos jovens apresentem valores de aproximadamente $20 \mathrm{~cm}$ da distância do processo estilóide da ulna a extremidade distal do pé com tornozelo dorsifletido. Desta maneira, a amostra apresentou resultados semelhantes ao esperado para adultos jovens (a média obtida pelos 81 sujeitos na avaliação inicial foi de $22,57 \mathrm{~cm})$. Conclui-se que, apesar dos efeitos do envelhecimento sobre o indivíduo, estes parecem não influenciar a flexibilidade de idosos entre 60 e 65 anos, quando a variável é avaliada através do teste dedo-chão.

Tal resultado contrasta com a tendência que se observa de imaginar que as alterações fisiológicas do envelhecimento conduzem a mudanças profundas na flexibilidade. Os resultados aqui encontrados concordam e confirmam os achados de Einkauf et al. (1987), que realizaram um estudo com 109 mulheres americanas normais, com idades entre 20 e 84 anos. Elas foram divididas em seis grupos, de acordo com a idade. Tiveram mensuradas a flexão anterior, flexão lateral direita e esquerda e extensão. A flexão anterior foi mensurada através do teste de Schober. As demais medidas foram obtidas com a goniometria. O estudo provou que a mobilidade 
espinal diminui com a idade, tanto no plano sagital quanto coronal, mas só foram detectadas diferenças significativas nos movimentos dos extremos de idade. A extensão foi o movimento mais afetado com a idade.

Não foram encontrados estudos relacionando a cinesioterapia respiratória com flexibilidade, em qualquer população. Entretanto, encontrou-se um estudo relacionando os efeitos de exercícios aquáticos na flexibilidade desta população. $O$ trabalho realizado por Madureira e Lima, em 1998, ministrou exercícios aquáticos gerais a 25 mulheres com idades entre 57 e 77 anos. O programa foi aplicado três vezes por semana, 50 minutos por dia, por quatro meses. Dentre outras variáveis avaliadas, a flexibilidade da coluna e quadril (mensurada através do teste sentar e alcançar) - apesar de apresentar valores melhores que os iniciais - não apresentaram relevância estatística.

Um outro estudo realizado por Rider e Daly (1991) comprovaram a capacidade de melhora na flexibilidade de indivíduos idosos quando submetidos a um programa direcionado a este objetivo. Eles analisaram os efeitos de um programa de 10 semanas de exercícios de flexibilidade em idosos, aplicados três vezes por semana, 20 a 30 minutos por dia. Vinte mulheres com idade média de 71,8 anos foram randomizadas para receber ou não intervenção. Foi mensurada a flexibilidade total (flexão e extensão) de tronco de todos os indivíduos. O grupo controle realizou um programa de exercícios alternativos, que envolviam dança, caminhadas e natação. Encontrou-se uma melhora significativa na mobilidade espinal do grupo tratado.

O estudo realizado apresentou algumas limitações que podem ter influenciado suas principais conclusões. Primeiramente, acredita-se que os resultados poderiam ser mais uniformes caso o tempo de intervenção fosse mais prolongado, tornando-os menos discutíveis e mais logicamente explicados. 
Além disso, o ambiente de avaliação e tratamento não sofreu controle de pressão e temperatura, o que pode ter influenciado os resultados. O controle expresso destas variáveis é de difícil realização, impossível no local das intervenções utilizado para este estudo.

O fato dos sujeitos não terem sido atendidos concomitantemente talvez tenha influenciado os resultados, visto que alguns integraram o estudo por um tempo maior ou menor durante o período do inverno. O clima frio da região da coleta de dados pode ter dificultado ou até mesmo desestimulado os sujeitos a realizarem os protocolos propostos.

Sugere-se a continuação deste estudo, com o objetivo de verificar e confirmar os reais efeitos deste protocolo de exercícios na $\mathrm{PI}_{\text {máx }}$ e expansibilidade torácica, bem como os efeitos do meio de realização sobre os mesmos.

Analisando os resultados, observa-se que o protocolo de cinesioterapia respiratória proposto é capaz de melhorar a força muscular inspiratória de sujeitos idosos, desde que os exercícios sejam realizados em meio aquático. Assim, pode ser aplicado na prática clínica como medida de prevenção da deterioração da função respiratória. Acredita-se que o mesmo possa reduzir as chances de que o idoso desenvolva patologias ou complicações relacionadas ao sistema respiratório. Acreditase também que pode acelerar o processo de recuperação do indivíduo, ao otimizar o processo de tosse, bem como a função respiratória geral.

\section{CONCLUSÕES}

Analisando os resultados obtidos, podemos concluir que: 
- O protocolo de cinesioterapia respiratória proposto e realizado em meio aquático melhora a $\mathrm{Pl}_{\text {máx }} \mathrm{e}$, conseqüentemente, a força muscular inspiratória de idosos saudáveis. Acredita-se que esta melhora seja resultado da influência das propriedades físicas da água, visto que tal melhora não foi observada no grupo que realizou as mesmas atividades no meio terrestre.

- Em relação à expansibilidade torácica, apesar da significativa melhora obtida pelo grupo que realizou o protocolo de cinesioterapia respiratória em meio aquático, não se pode afirmar que o mesmo melhore a expansibilidade torácica - ao nível axilar ou xifóide - visto que não houve alteração estatisticamente significativa na comparação entre os grupos. São necessários mais estudos a respeito deste assunto.

- O protocolo proposto não exerce efeitos sobre a força muscular expiratória de idosos saudáveis, independente do meio de realização.

- Um protocolo voltado a exercitar a amplitude de movimento da caixa torácica e força muscular respiratória não exerce efeito sobre a flexibilidade anterior de tronco/pélvis, independente do meio de realização.

\section{ANEXOS}


Anexo A - Protocolo de entrevista geral

1) Identificação - nome, idade, data de nascimento, sexo, cor, nacionalidade, estado civil, profissão, endereço e telefone.

2) História pregressa - registro de:

- Patologias anteriores - respiratórias ou não;

- Medicamentos e vacinas;

- Intervenções cirúrgicas anteriores;

- Hábitos e vícios - tabagismo, alcoolismo;

- Hábito/estado nutricional;

- Prática de atividade física - tipo, intensidade, duração, freqüência e histórico de tempo.

- Relação com a água - possível existência de fobias à imersão, traumas relacionados à água, etc..

3) História familiar

4) Anamnese

- Principais possíveis queixas relacionadas ao sistema respiratório - dispnéia, tosse, escarro e hemoptise, sibilos, dor torácica (Pryor e Webber, 2002);

- Outros sintomas não relacionados ao sistema respiratório.

5) Exame do aparelho respiratório

- Anormalidades na caixa torácica;

- Ausculta pulmonar;

- Tipo, padrão e freqüência respiratória;

Anexo B - Fotos das atividades desenvolvidas pelos grupos de intervenção (água e solo) 


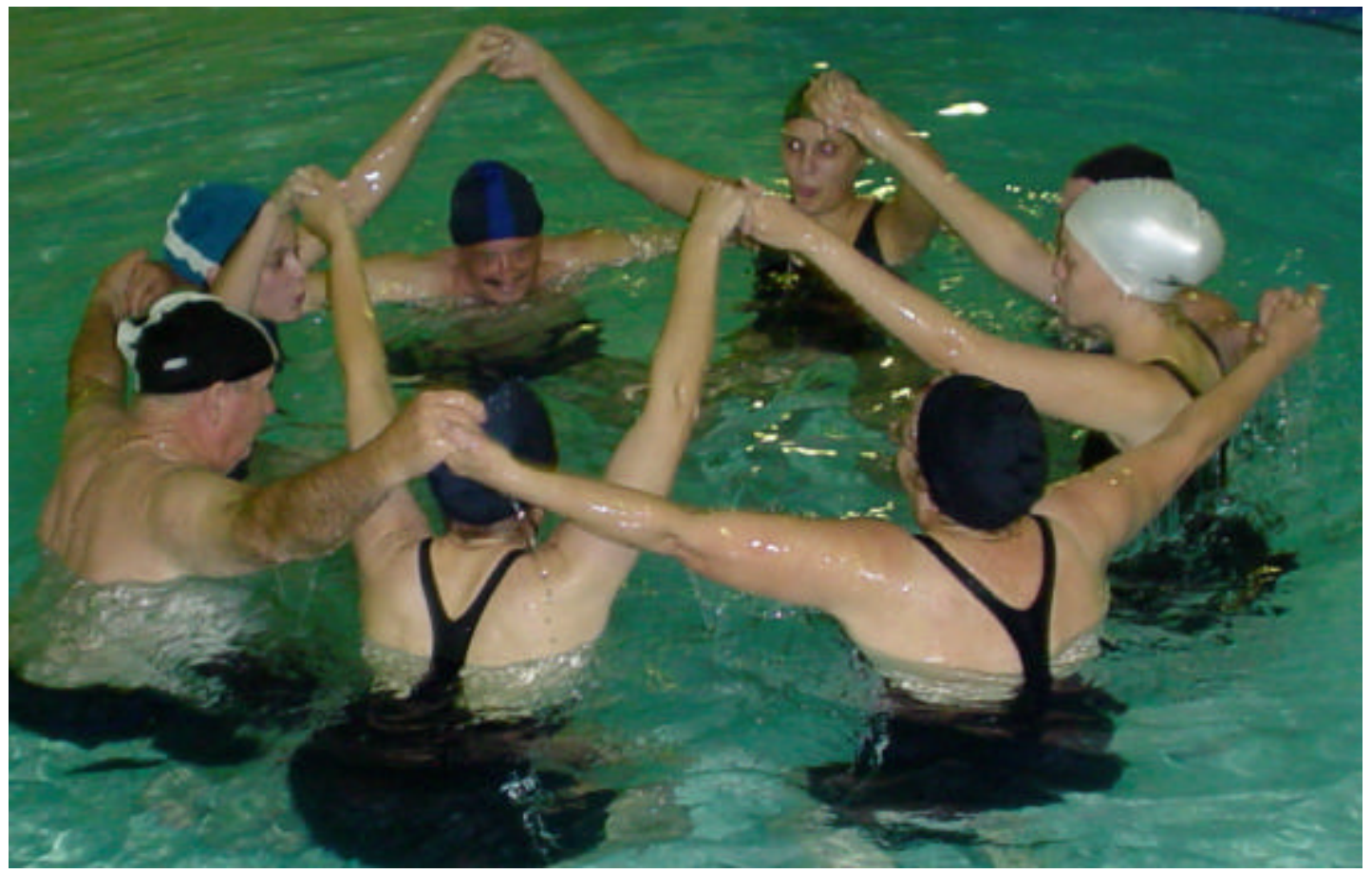

Figura 12. Atendimento do grupo água

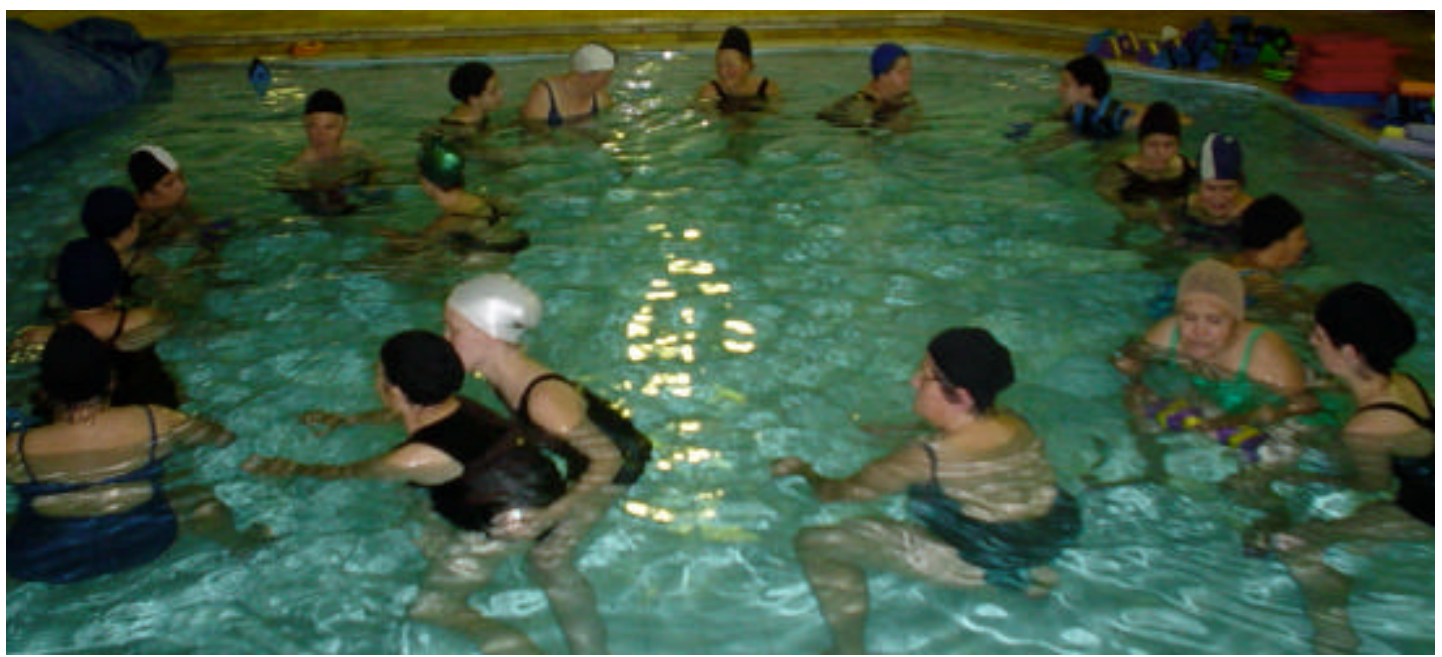

Figura 13. Atendimento do grupo água 


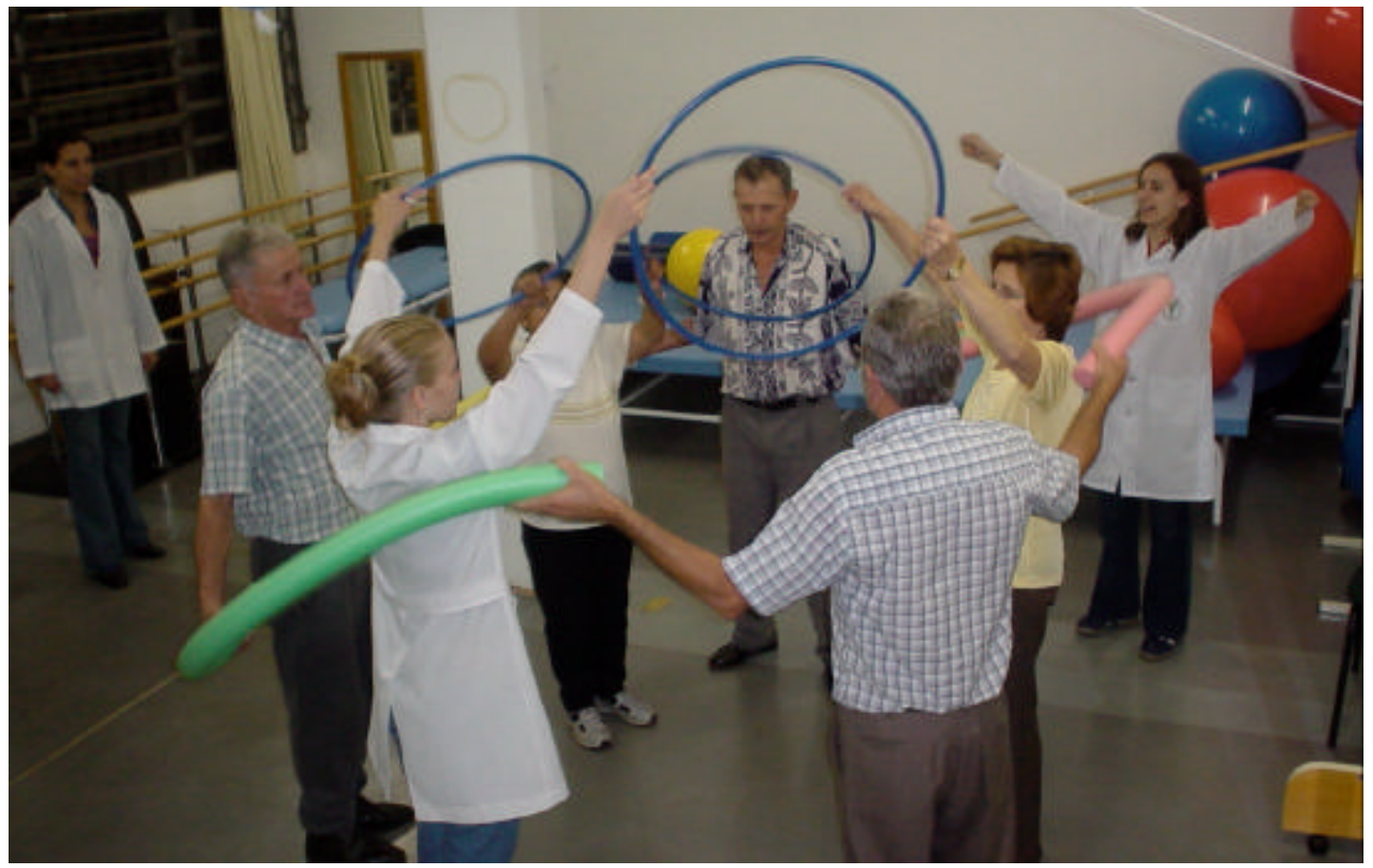

Figura 14. Atendimento do grupo solo

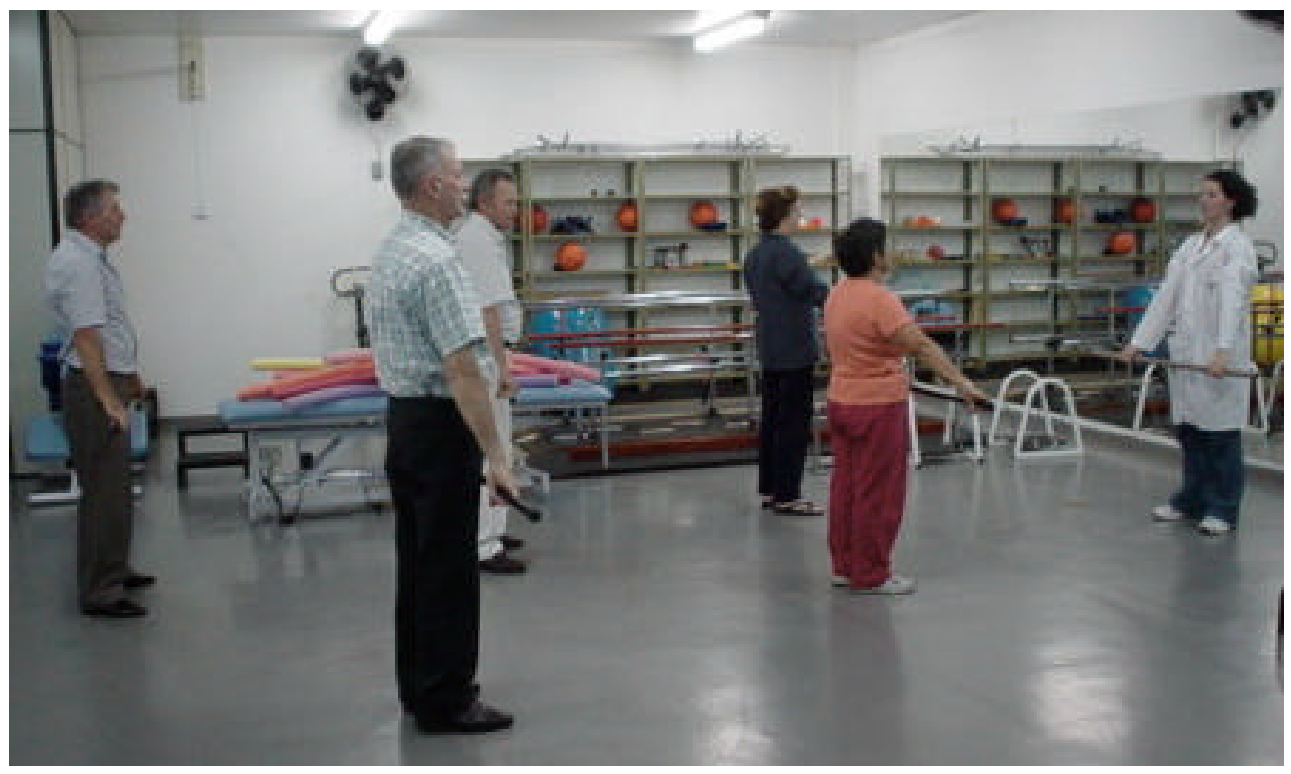

Figura 15. Atendimento do grupo solo 
Anexo $\mathrm{C}$ - Fotos das atividades desenvolvidas pelo grupo controle

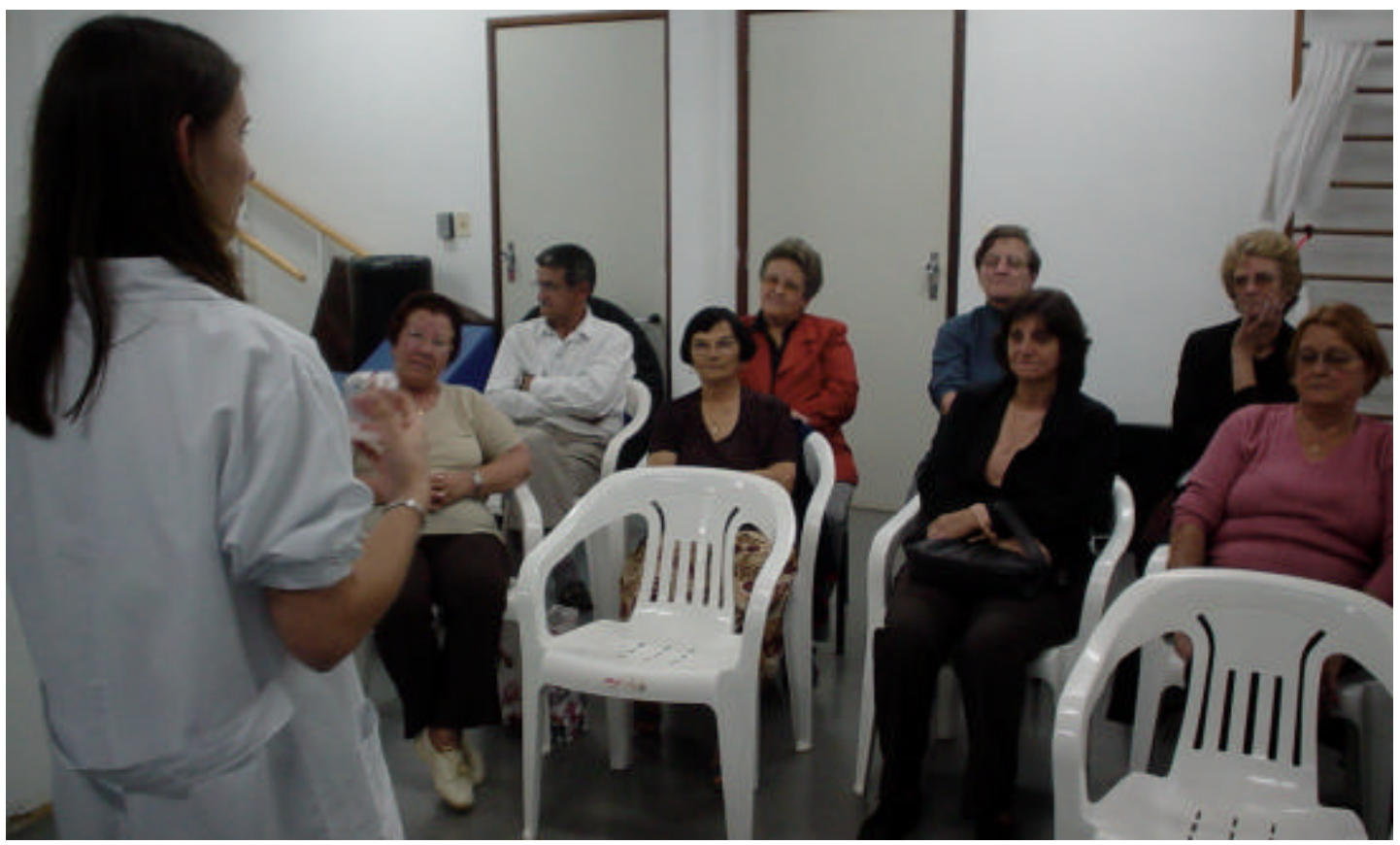

Figura 16. Palestra ministrada ao grupo controle

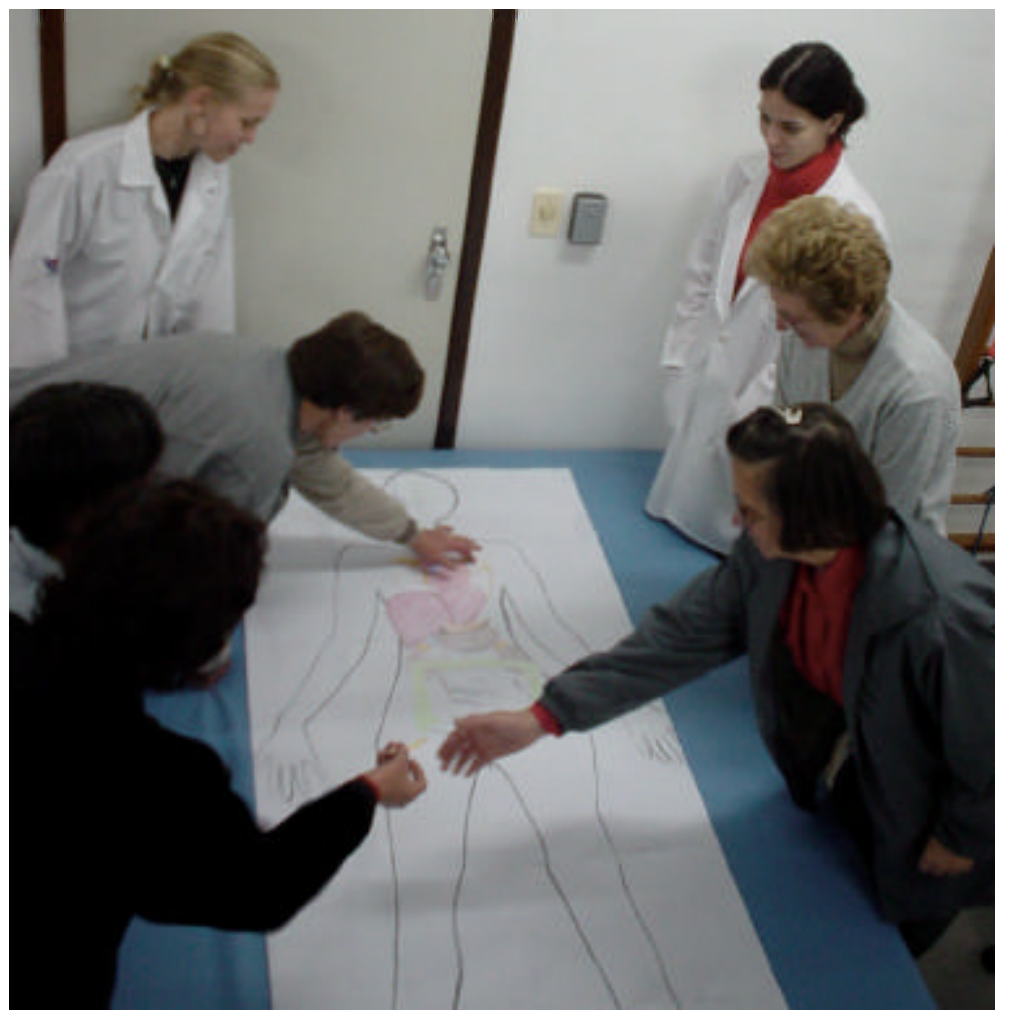

Figura 17. Dinâmica aplicada ao grupo controle 


\section{REFERÊNCIAS BIBLIOGRÁFICAS}

Abbrecht PH, Rajagopal KR, Kyle RR. Expiratory muscle recruitment during inspiratory flow-resistive loading and exercise. American Review of Respiratory Disease. 1991;144:113-20.

Arabadjis PG, Heffner RR, Pendergast DR. Morphologic and functional alterations in aging rat muscle. Journal of Neuropathology and Experimental Neurology. 1990;49:600-9.

Araújo CGS. Correlação entre diferentes métodos lineares adimensionais de avaliação da mobilidade articular. Rev Bras Ciên e Mov. 2000;8:25-32.

Ashley F, Kannel WB, Sorlie PD, Masson R. Pulmonary function: relation to aging cigarette habit and mortality. Annals of Internal Medicine. 1975;82:739-45.

Astrand PO, Rodahl K. Tratado de fisiologia do exercício. São Paulo: Interamericana; 1980.

Azeredo CAC. Fisioterapia respiratória moderna. São Paulo: Manole; 2002.

Bates A, Hanson N. Exercícios aquáticos terapêuticos. São Paulo: Manole; 1998.

Batti'e MC, Bigos SJ, Sheehy A, Wortley MD. Spinal flexibility and individual factors that influence it. Physical Therapy. 1987;67:653-8.

Becker BE. Princípios físicos da água. In: Ruoti RG, Morris DM, Cole AJ Reabilitação aquática. São Paulo: Manole; 2000. p.17-26.

Becker BE, Cole AJ. Terapia aquática moderna. São Paulo: Manole; 2000.

Bellanti JA, Azem M, Macdowell CAL, Tutuncuoglu SO, Wallerstedt DB. Possible mechanisms of late-life onset allergic diseases and asthma in senior citizen. Allergy and Asthma Proceedings. 2000;21:267-70.

Belman MJ, Gaesser GA. Ventilatory muscle training in the elderly. Journal of Applied Physiology. 1988;64:899-905.

Berquó E. Algumas considerações sobre o envelhecimento da população do Brasil. In: I Seminário Internacional; 1996; Brasília, DF. 
Black LF, Hyatt RE. Maximal respiratory pressures: normal values and relationship to age and sex. American Review of Respiratory Disease. 1969;90:696-702.

Black LF, Hyatt RE. Variability in the maximal expiratory flow volume curve in assymptomatic smokers and nonsmokers. American Review of Respiratory Disease. 1974;110:282.

Blair SN, Conelly A. How much physical therapy should we do? The case of moderate amounts and intensities of physical activities. Research Quarterly for Exercise and Sports. 1996;67:93-205.

Bookspan J. Efeitos fisiológicos da imersão em repouso. In: Ruoti RG, Morris DM, Cole AJ. Reabilitação aquática. São Paulo: Manole; 2000. p.29-38.

BRASIL. Fundação Nacional de Saúde. Vacinação do idoso contra a gripe. Brasília: FUNASA; 2003.

Bréchat PH, Wolf JP, Simon-Rigaud MI, Bréchat N, Kantelip JP, Berthelay S, Regnard $\mathrm{J}$. Influence of immersion on respiratory requirements during 30-min cycling exercise. The European Respiratory Journal. 1999;13:860-6.

Brennan FH. Exercise prescription for active seniors: a team approach for maximizing adherence. The Physician and Sportsmedicine. 2002;30.

Buckwalter A. Decreased mobility in the elderly: the exercise antidote. The Physician and Sportsmedicine. 1997;25:127-33.

Burgos VR, Castelazo DG, Orozco JA, Garduño EJ, Clark P, Sanabria L. Chest expansion in healthy adolescents and patients with the seronegative enthesopathy and arthropathy syndrome or juvenile ankylosing spondylitis. Journal of Rheumatology. 1993;20:1957-60.

Busby-Whitehead J. Exercícios físicos para idosos. In: Gallo JJ, Busby-Whitehead J, Rabins PV, Silliman RA, Murphy JB. Aspectos clínicos do envelhecimento. Rio de Janeiro: Guanabara Koogan; 2001.p.112.

Camelo JS, Terra JF, Manço JC. Pressões respiratórias máximas em adultos normais. Journal de Pneumologia. 1985;11:181-4.

Campion MR. Hidroterapia: Princípios e prática. São Paulo: Manole; 2000.

Caromano FA, Candeloro JM. Fundamentos de hidroterapia para idosos. Arquivos Ciências da Saúde da UNIPAR. 2001;5:187-95. 
Caromano FA, Mendes FAS. Efeito de um programa de reeducação funcional na flexibilidade de idosos saudáveis. Revista de Terapia Ocupacional da USP. 2000;11:90-4.

Caromano FA, Nowotny JP. Princípios físicos que fundamental a hidroterapia Fisioterapia Brasil. 2002;3:394-402.

Caromano FA, Themudo Filho MRF, Candeloro JM. Efeitos fisiológicos da imersão e do exercício na água. Fisioterapia Brasil. 2003;4:60-5.

Chaimowicz F. A saúde dos idosos brasileiros às vésperas do século XXI: problemas projeções e alternativas. Revista de Saúde Pública. 1997;31:184-200.

Cipriano JJ. Manual fotográfico de testes ortopédicos e neurológicos. São Paulo: Manole; 1999.

Crausman RS. Problemas pulmonares no idoso. In: Gallo JJ, Busby-Whitehead J, Rabins PV, Silliman RA, Murphy JB. Aspectos clínicos do envelhecimento. Rio de Janeiro: Guanabara Koogan; 2001. p.123-6.

Cureton KJ. Respostas fisiológicas ao exercício na água. In: Ruoti RG, Morris DM, Cole AJ. Reabilitação aquática. São Paulo: Manole; 2000. p.43-60.

Daniels MAL, Worthinghan C. Provas de função muscular: técnicas de exame manual. São Paulo: Interamericana; 1981.

Devons CAJ. Comprehensive geriatric assessment: making the most of the aging years. Current Opinion in Clinical Nutrition and Metabolic Care. 2002;5:19-24.

Dipietro L, Dziura J. Exercise: a prescription to delay the effects of aging. The Physician and Sportsmedicine. 2000;28:77-8.

Einkauf DK, Gohdes ML, Jensen GM, Jewell MJ. Changes in spinal mobility with increasing age in women. Physical Therapy. 1987;67:370-5.

Faludi AA, Mastrocolla LE, Bertolami M. Atuação do exercício físico sobre os fatores de risco para doenças cardiovasculares. Revista da Sociedade de Cardiologia de São Paulo. 1996;1:1-5.

Feltelius N, Hedenstrom H, Hillerdal G, Hallgren R. Pulmonary involvement in ankylosing spondylitis. Annals of the Rheumatic Diseases. 1986;45:736-40.

Ferruci L, Guralnick JM, Blazer D. Progressive versus catastrophic disability: a longitudinal view of the disablement process. Journal of Gerontology. 1996;64:283. 
Fielding RA. Effects of exercise in the elderly: impact of progressive-resistance training on skeletal muscle and whole-body protein metabolism. The Proceedings of the Nutrition Society. 1995;54:655-75.

Fisher LR, Cawley MI, Holgate ST. Relation between chest expansion pulmonary function and exercise tolerance in patients with ankylosing spondylitis. Annals of the Rheumatic Diseases. 1990;29:921-5.

Fried LP, Ettinger WH, Lind B. Physical disability in older adults: a physiological approach. Journal of Clinical Epidemiology.1994;47:747-60.

Fried LP, Storer DJ, King DE, Lodder F. Diagnosis of illness presentation in the elderly: a comparison of self-report and performance-based methods. Journal of the American Geriatric Society. 1991;39:117-23.

Fuentes GR, Santos RT. Bases físicas de la hidroterapia. Fisioterapia. 2002;24:14-21.

Gardner E, Gray DJ, O'Rahilly R. Anatomia: estudo regional do corpo humano. Rio de Janeiro: Guanabara Koogan; 1975.

Goldstein R, Rosie J, Long S, Dolmage T, Avendano MA. Applicability of a threshold loading device for inspiratory muscle testing and training in patients with COPD. Chest. 1989;96:564-71.

Griffith K A, Sherrill DI, Siegel EM, Manolio TA, Bonekat HW, Enright PL. Predictors of Loss of Lung Function in the Elderly. American Journal of Respiratory and Critical Care Medicine. 2001;163:61-8.

Grimby G. Physical activity and effects of muscle training in the elderly. Annals of Clinical Research. 1988;20:62-6.

Gross PA, Hermogenes AW, Sacks HS, Lau J, Levandowski RA. The efficacy of influenza vaccine in elderly persons: a meta-analysis and review of the literature. Annals of Internal Medicine. 1995;123:518-27.

Guralnik JM, Lacroix AZ, Abott RD, Berkman LF, Satterfield S, Evans DA, Wallace RB. Maintaining mobility in late life. American Journal of Epidemiology. 1993;137:845-57.

Gutierrez EB, Li HY, Santos ACS, Lopes MH. Effectiveness of influenza vaccination in elderly outpatients in São Paulo city Brazil. Revista do Instituto de Medicina Tropical de São Paulo. 2001;43:317-20.

Hagberg JM A. hemodynamic comparison of young and old endurance athletes during exercise. Journal of Applied Physiology. 1985;58:2041. 
Halseth AE, Fogt DL, Fregosi RF, Henriksen EJ. Metabolic responses of rat respiratory muscles to voluntary exercise training. Journal of Applied Physiology; 1995;79:902-7.

Harik-Khan RI Wise RA, Fozard JL. Determinants of maximal inspiratory pressure: the Baltimore longitudinal study of aging. American Journal of Respiratory and Critical Care Medicine. 1998;158:1459-64.

Harver A, Mahler DA, Daubenspeck JA. Targeted inspiratory muscle training improves respiratory muscle function and reduces dyspnea in patients with chronic obstructive pulmonary disease. Annals of Internal Medicine. 1989;111:117-24.

Hautmann $\mathrm{H}$, Hefele $\mathrm{S}$, Schotten $\mathrm{K}$, Huber RM. $\mathrm{PI}$ máx : lower limits of the normal range. Respir Med. 2000;94:689-93.

Heikkila S, Viitanen JV, Hannu K, Kauppi M. Sensivity to change of mobility tests effects of short term intensive physiotherapy and exercise on spinal hip and shoulder measurements in spondyloarthropathy. Journal of Rheumatology. 2000;27:1251-6.

Hilmann DR. A model for respiratory pump. J Applied Physiology.1982;5;524-9.

Jacob Filho W, Souza RR. Anatomia e fisiologia do envelhecimento. In: Carvalho Filho ET, Papaléo MN. Geriatria: fundamentos clínica e terapêutica. São Paulo: Atheneu; 2000.

Jardim JRB. Pressões respiratórias quando passaremos a usá-las? Journal of Pneumology.1985;11:34.

Kalache A, Veras RP, Ramos LR. O envelhecimento da população mundial. Revista de Saúde Pública.1987;21:200-10.

Kapandji LA. Fisiologia articular: esquemas comentados da mecânica humana. São Paulo: Manole; 1980.

Kendall FP, McCreary EK, Provance PG. Músculos: provas e funções. São Paulo: Manole; 1995.

Kim MJ. Respiratory muscle training: implications for patient care. Heart Lung. 1984;13:333-40.

Kurabayashi H, Kubota K, Machida I, Tamura K, Take H, Shirakura T. Effective physical therapy for chronic obstructive pulmonary disease. American Journal of Physical Medicine and Rehabilitation.1997;76:204-7.

Kurabayashi H, Machida I, Tamura K, Iwai F, Tamura J, Kubota K. Breathing out into water during subtotal immersion: a therapy for chronic pulmonary emphysema. American Journal of Physical Medicine \& Rehabilitation. 2000;79:150-3. 
Lacasse Y, Guyatt GH, Goldstine RS. The components of a respiratory rehabilitation program. Chest. 1997;111:1077-88.

Lareau SC, Zuwallac R, Carlin B, Cell B, Fahy B, Gosselink R, Jones P, Larson JL, Meek P, Rohester C, Sassi-Dambron D, Stubbing D. American thoracic society: pulmonary rehabilitation American Journal of Respiratory and Critical Care Medicine. 1999;159:1666-82.

Larson M, Kim MJ. Respiratory muscle training with the incentive spirometer resistive breathing device. Heart \& Lung. 1984;13:341-5.

Leith DE, Bradley M. Ventilatory muscle strength and endurance training. Journal of Applied Physiology. 1976;41:508-16.

Madureira AS, Lima SMT. Influência do treinamento físico no meio aquático para mulheres na terceira idade. Revista Brasileira Atividade Física \& Saúde. 1988;3:59-66.

Mahler DA, Belman MJ. Controversies in pulmonary medicine: respiratory muscle training should be instituted in all COPD patients. American Review of Respiratory Disease. 1988;138:1072.

Martinez AS, Liboa CB, Jalil JM, Munoz VD, Díaz OP, Casanegra PP, Corbolán RH, Vásquez AM, Levia AG. Entrenamiento selectivo de los músculos respiratorios en sujeitos con insuficiencia cardiaca crónica. Revista Medica de Chile. 2001;129:133-9.

McArdle WD, Katch L, Katch VL. Fisiologia do exercício: energia nutrição e desempenho humano. Rio de Janeiro: Guanabara Koogan; 1996.

McClaran SR, Babcock MA, Pegelow DF, Reddan WG, Dempsey JA. Longitudinal effects of aging on lung function at rest and exercise in healthy active fit elderly adults. Journal of Applied Physiology. 1995;78:1957-68.

McEntire SJ, Ferguson CS, Brown KR, Harms CA. The effect of respiratory muscle training in combination with whole body exercise on exercise performance. Medicine and Science in Sports and Exercise. 2003;35:150.

Mckenzie DK, Gandevia SC. Strength and endurance of inspiratory expiratory and limb muscles in asthma. American Review of Respiratory Disease. 1986;134:999-1004.

Meirelles ES, Kitadai FT. Espondilite anquilosante: aspectos epidemiológicos e clínicos. Acta Ortopédica Brasileira. 1998;6:173-9.

Mellin G. Correlations of spinal mobility with degree of chronic low back pain after correction for age and anthropometric factors. Spine. 1987;12:464-8.

Meyer BR. Infectious diseases in the elderly. Geriatrics. 1989;44:4-6. 
Miller JD, Beck KC, Joyner MJ, Brice AG, Johnson BD. Cardiorespiratory effects of inelastic chest wall restriction. Journal of Applied Physiology. 2002;92:2419-28.

Mills EM. The effect of low intensity aerobic exercise on muscle strength flexibility and balance among sedentary elderly persons. Nursing Research. 1994;43:207-11.

Moll JMH, Wright V. The pattern of chest and spinal mobility in ankylosing spondylitis. Rheumatology and Rehabilitation. 1973;12:115-34.

Moll JMH, Wright V. An objective clinical study of chest expansion. Annals of the Rheumatic Diseases, 1972;31.

Morey MC, Pieper CF, Sullivan RJ, Crowley GM, Cowper PA, Robbins MS. Five-year performance trends for older exercisers: a hierarchical model of endurance strength and flexibility. Journal of the American Geriatric Society. 1996;44:1226-31.

Murphy JB, Cicilline M. Medidas preventivas para os idosos. In: Gallo JJ, BusbyWhitehead J, Rabins PV, Silliman RA, Murphy JB. Aspectos clínicos do envelhecimento. Rio de Janeiro: Guanabara Koogan; 2001.8.

Neder JA, Dal Corso S, Malaguti C, Reis S, De Fuccio MB, Schmidt H, Fuld JP, Nery LE. The pattern and timing of breathing during incremental exercise: a normative study. The European Respiratory Journal. 2003;21:530-8.

Nomori H, Kobayashi R, Fuyuno G, Morinaga S, Yashima H. Preoperative respiratory muscle training: assessment in thoracic surgery patients with special reference to postoperative pulmonary complications. Chest. 1994;105:1782-8.

Nonaka L, Caromano FA, Mendes FAS. Avaliação de dois testes de flexibilidade em idosos do sexo feminino: método fotográfico. Revista de Terapia Ocupacional da USP. 1999;10:75-80.

Olgiati R, Girr A, Hugi L, Haegi V. Respiratory muscle training in multiple sclerosis: a pilot study. Schweiz Arch Neurol Psychiatr. 1989;140:46-50.

Organização Mundial de Saúde. Aplicaciones de la epidemiología al estudio de los ancianos: informe de un grupo científico de la OMS sobre la epidemiología del envejecimiento. Genebra: OMS; 1984.

Papaléo NM. Gerontologia: a velhice e o envelhecimento em visão globalizada. São Paulo: Atheneu; 2002.

Pardy RL, Reid WD, Belman MJ. Respiratory muscle training. Clinics in Chest Medicine. 1988;9:287-96. 
Patessio A, Rampulla C, Fracchia C, Ioli F, Majani U, Marchi A, Donner CF. Relationship between the perception of breathlessness and inspiratory resistive loading: report on a clinical trial. The European Respiratory Journal. 1989;2:1989.

Paulin E, Brunetto AF, Carvalho CRF. Efeitos de programa de exercícios físicos direcionado ao aumento da mobilidade torácica em pacientes portadores de doença pulmonar obstrutiva crônica. Jornal de Pneumologia. 2003;29:287-94.

Payton OD, Poland JL. Aging process: implications for clinical practice. Physical Therapy. 1983;63:41-8.

Perk J, Perk L, Bodén C. Cardiorespiratory adaptation of COPD patients to physical training on land and in water. The European Respiratory Journal. 1996;9:248-52.

Perret C, Poiraudeau S, Fermanian J, Colau MML, Benhamou MAM, Revel M. Validity reliability and responsiveness of the fingertip-to-floor test. Archives of Physical Medicine and Rehabilitation. 2001;82:1566-70.

Pickies B, Vandervoort A. Fisioterapia na terceira idade. São Paulo: Santos; 1998.

Pierce JB. The epidemiology of physical activity and physical function in older people. Medicine and Science in Sports and Exercise. 1996;28:596-600.

Pocock SJ. Clinical trials - a practical approach. Chichester: John Wiley \& Sons; 1983.

Powers SK, Criswell D, Lieu F, Dodd S, Silverman H. Diaphragmatic fiber type specific adaptations to endurance exercise. Resp Phys.1992;89:195-207.

Powers SK, Howley ET. Fisiologia do exercício: teoria e aplicação ao condicionamento e ao desempenho. São Paulo: Manole; 2000.

Pryor JA, Webber BA. Fisioterapia para problemas respiratórios e cardíacos. Rio de Janeiro: Guanabara Koogan; 2002.

Pyle KD, Laurent MR, Salmond CE, Best MJ, Pyle EA, Moloney RO. Clinical assessment of ankylosing spondylitis: a study of observer variation in spinal measurements. British Journal of Rheumatology. 1991;30:29-34.

Ramos LR, Rosa TEC, Oliveira ZM, Meidna MCG, Santos FRG. Perfil de idosos na área metropolitana na região sudeste do Brasil: resultados de inquérito familiar. Revista de Saúde Pública. 1993;27:87-94.

Rauchbach R. A atividade física para a terceira idade. Curitiba: Lovise; 1990.

Rego RA, Berardo FAN, Rodrigues SSR, Oliveira ZMA, Oliveira MN, Vasconcellos C, Aventurato LYB, Moncau JEC, Ramos LR. Fatores de risco para doenças crônicas 
não-transmissíveis, inquérito domiciliar no município de São Paulo: metodologia e resultados preliminares. Revista de Saúde Pública. 1990;24:277-85.

Reichel W, Gallo JJ. Princípios fundamentais de assistência ao idoso. In: Gallo JJ, Busby-Whitehead J, Rabins PV, Silliman RA, Murphy JB. Aspectos clínicos do envelhecimento. Rio de Janeiro: Guanabara Koogan; 2001. p.3-14.

Rider RA, Daly, J. Effects of flexibility training on enhancing spinal mobility in older women. The Journal of Sports Medicine and Physical Fitness. 1991;31:213-7.

Riehl O. Fotogrametria humana: um instrumento antropométrico. [Dissertação]. São Paulo: Escola de Educação Física Universidade de São Paulo; 1988.

Roberts CM, Macrae KD, Winning AJ, Adams L, Seed WA. Reference values and prediction equations for normal lung function in a non-smoking white urban population. Thorax. 1991;46:643-50.

Rochester DF. Inspiratory effects of respiratory muscle weakness and atrophy. American Review of Respiratory Disease. 1986;134:1078-93.

Romer LM, McConnell AK, Jones DA. Inspiratory muscle fatigue in trained cyclists: effects of inspiratory muscle training. Medicine and Science in Sports and Exercise. 2002;34:785-92.

Rosales JMP, Represas AG. Técnicas de hidroterapia: hidrocinesioterapia Fisioterapia. 2002;24:34-42.

Rosemond C, Mercer VS. Educational programs to maximize function and mobility in long term care. Topics in Geriatric Rehabilitation. 2002;17:42-52.

Sampaio LMM, Jamami M, Pires VA, Silva AB, Costa D. Força muscular respiratória em sujeitos asmáticos submetidos ao treinamento muscular respiratório e treinamento físico. Revista de Fisioterapia da Universidade de São Paulo. 2002;9:43-8.

Santana H, Zoico E, Turcato E, Tosoni P, Bissoli L, Olivieri M, Bosello O Zamboni M. Relation between body composition fat distribution and lung function in elderly men. The American Journal of Clinical Nutrition. 2001;73:827-31.

Sarmiento AR, Levi MO, Guell R, Barreiro E, Hernandez N, Mota S, Sangenis M, Broquetas JM, Casan P, Gea J. Inspiratory muscle training in patients with chronic obstructive pulmonary disease. American Journal of Respiratory and Critical Care Medicine. 2002;166:1491-97.

Scherer TA, Spengler CM, Owassapian D, Imhof E, Boutellier U. Respiratory muscle endurance training in DBPOC: impact on exercise capacity dyspnea and quality of life. American Journal of Respiratory and Critical Care Medicine. 2000;162:1709-14. 
Seçkin Ü, Bolukbasi N, Gursel G, Eroz S, Sepici V, Ekim N. Relationship between pulmonary function and exercise tolerance in patients with ankylosing spondylitis. Clinical and Experimental Rheumatology. 2000;18:503-6.

Sekizawa K. Mechanisms and prevention of pneumonia in the elderly. Tohoku Journal of Experimental Medicine. 1998;184:73-84.

Shaffer TH, Wolfson MR, Bhutani VK. Respiratory muscle function assessment and training. Physical Therapy. 1981;61:1711-23.

Sheldahl LM, Tristani FE, Hastings JE, Wenzler RB, Levandoski SG. Comparison of adaptations and compliance to exercise training between middle-aged and older men. Journal of the American Geriatric Society. 1993;41:795-801.

Skinner AT, Thomson AM. Duffield: exercícios na água. São Paulo: Manole; 1985.

Smith PEM, Coakley JH, Edwards. RHT Respiratory muscle training in Duchenne muscular dystrophy. Muscle \& Nerve. 1988;11:784-5.

Sonne LJ. Respiratory muscle training. Chest. 1984;86:939-40.

Sorlie PD, Kannel WB, O'Connor G. Mortality associated with respiratory function and symptoms in advanced age. American Review of Respiratory Disease. 1989;140:37984.

Souza RB Pressões respiratórias estáticas máximas Jornal de Pneumologia. 2002;28:155-65.

Stuberg WA, Metcalf WK. Reliability of quantitative muscle testing in healthy children and with Duchenne muscular dystrophy using a hand-held dynamometer. Physical Therapy. 1988;68:977-82.

Sturdy G, Hillman D, Green D, Jenkins S, Cecins N, Eastwood P. Feasibility of highintensity interval-based respiratory muscle training in COPD. Chest. 2003;123:142-50.

Suzuki S, Sato M, Okubo T. Expiratory muscle training and sensation for respiratory effort during exercise in normal subjects. Thorax. 1995;50:366-70.

Teixeira JAC. Atividade física na terceira idade. Arquivos de Geriatria e Gerontologia. 1996;15-7.

The Australian Lung Foundation. Frith P. Evidence base and standards for pulmonary rehabilitation in Australia. Australia; 2002.

Thompson LV. Effects of age and training on skeletal muscle physiology and performance. Physical Therapy. 1994;71:71-7. 
Timo laria C. Envelhecimento. In: Jacob Filho W. Envelhecimento do sistema nervoso e a dor no idoso. São Paulo: Faculdade de Medicina da USP; 1996.

Tolep K, Kelsen SG. Effect of aging on respiratory skeletal muscles. Clinics in Chest Medicine.1993;14:363-78.

Turner JM, Mead J, Wohl ME. Elasticity of human lungs in relation to age. Journal of Applied Physiology.1968;25:664-71.

Valle PHC, Winkelmann ER, Dern E, Silva AMV, Marchi PB, Costa D. Efeitos do treinamento e destreinamento da força muscular respiratória em soldados. Revista Brasileira Atividade Física \& Saúde. 2002;7:46-54.

Vanderschueren D, Decramer M, Daele PVD, Dequeker J. Pulmonary function and maximal transrespiratory pressures in ankylosing spondylitis. Annals of the Rheumatic Diseases.1989;48:632-5.

Veras RP, Ramos LR, Kalache A Crescimento da população idosa no Brasil: transformações e conseqüências na sociedade Revista de Saúde Pública. 1987;21:225-33.

Viitanen JV, Kautiainen H, Suni J, Kokko ML, Lehtinen K. The relative value of spinal and thoracic mobility measurements in ankylosing spondylitis. Scandinavian Journal of Rheumatology. 1995;24:94-7.

Volianitis S, McConnell AK, Koutedakis Y, Mcnaughton L, Backx K, Jones DA. Inspiratory muscle training improves rowing performance. Medicine and Science in Sports and Exercise, 2001;33:803-9.

Walker J, Cooney MN. Improved respiratory function in quadriplegics after pulmonary therapy and arm ergometry. The New England Journal of Medicine. 1987;316:486-7.

Ware JH, Dockery DW, Louis TA, Xu X, Ferris BG, Speizer FE. Longitudinal and crosssectional estimates of pulmonary function decline in never-smoking adults. American Journal of Epidemiology. 1990;132:685-700.

World Health Organization. Physical status: the use and interpretation of anthropometry. Genebra: WHO; 1995.

Williams $\mathrm{P}$, Lord SR. Predictor of adherence to a structural exercise program for older women Psychology and Aging.1995;10:617-24.

Winer P, Azgad Y, Ganam R. Inspiratory muscle training combined with general exercise reconditioning in patients with COPD. Chest. 1992;102:1351-6. 


\section{Apêndice}

1) Termo de aprovação do comitê de ética 
2) Termo de consentimento livre e esclarecido

\section{HOSPITAL DAS CLÍNICAS}

DA

FACULDADE DE MEDICINA DA UNIVERSIDADE DE SÃO PAULO

\section{TERMO DE CONSENTIMENTO LIVRE E ESCLARECIDO}

(Instruções para preenchimento no verso)

\section{I - DADOS DE IDENTIFICAÇÃO DO SUJEITO DA PESQUISA OU RESPONSÁVEL LEGAL}

1. NOME DO PACIENTE.

DOCUMENTO DE IDENTIDADE № :

SEXO:.$M() F()$

DATA NASCIMENTO: ........................

ENDEREÇO

BAIRRO:

CEP:

TELEFONE: DDD

CIDADE

APTO:

№ )

2.RESPONSÁVEL LEGAL

NATUREZA (grau de parentesco, tutor, curador etc.)

DOCUMENTO DE IDENTIDADE :

SEXO: $M($ ) $F($ )

DATA NASCIMENTO.: ....................

ENDEREÇO:

№

APTO:

BAIRRO:

CEP:

TELEFONE: DDD

CIDADE:

\section{II - DADOS SOBRE A PESQUISA CIENTÍFICA}

1. TÍTULO DO PROTOCOLO DE PESQUISA: Estudo comparativo dos efeitos da fisioterapia respiratória em imersão e em terra sobre a função pulmonar em idosos

PESQUISADOR: Fátima Aparecida Caromano

CARGO/FUNÇÃO: Coordenadora Crefito №

UNIDADE DO HCFMUSP: Fisioterapia

3. AVALIAÇÃO DO RISCO DA PESQUISA:

$\begin{array}{lll}\text { SEM RISCO } & \text { x RISCO MÍNIMO } & \text { RISCO MÉDIO } \\ \text { RISCO BAIXO } & \text { RISCO MAIOR } & \end{array}$

(probabilidade de que o indivíduo sofra algum dano como conseqüência imediata ou tardia do estudo)

4.DURAÇÃO DA PESQUISA : 2003 e 2004 


\section{III - REGISTRO DAS EXPLICAÇÕES DO PESQUISADOR AO PACIENTE OU SEU REPRESENTANTE LEGAL SOBRE A PESQUISA, CONSIGNANDO:}

1. Justificativa e os objetivos da pesquisa:

O envelhecimento acarreta alterações fisiológicas em todo o organismo, particularmente no sistema pulmonar, causa de prejuízos sociais e financeiros. Os exercícios respiratórios são muito utilizados pela fisioterapia. Acredita-se que podem amenizar os efeitos do envelhecimento sobre o sistema respiratório. Este estudo objetivou analisar os efeitos do exercício respiratório sobre a força muscular respiratória, expansibilidade torácica e flexibilidade em idosos saudáveis. Objetivouse também verificar os efeitos do meio de realização sobre o mesmo.

2. Procedimentos que serão utilizados e propósitos, incluindo a identificação dos procedimentos que são experimentais:

Através de testes simples, serão avaliadas a força muscular respiratória, expansibilidade torácica e flexibilidade. Todos os participantes serão divididos em três grupos, através de sorteio. Dois grupos participarão de programas de exercícios respiratórios. Um destes realizará os exercícios em piscina aquecida e o outro em terra. $\mathrm{O}$ terceiro grupo participará de palestras relacionadas à saúde $\mathrm{e}$ atividades culturais diversas. Após este período, todos serão novamente avaliados e informados dos resultados.

3. Desconfortos e riscos esperados:

Os sujeitos que foram sorteados para participarem do grupo de exercícios em piscina aquecida podem apresentar efeitos colaterais do calor, como oscilações na pressão arterial, cefaléias, vertigens e náuseas. Também pode ocorrer alterações dérmicas, como coceira e vermelhidão ou até casos patológicos como manchas decorrentes de contaminações por micoses fúngicas e bacterianas. Em todos os casos o voluntário terá suas atividades imediatamente suspensas e será encaminhado a avaliação clínica.

4. Benefícios que poderão ser obtidos

Espera-se que os sujeitos que participarem dos exercícios apresentem melhora na força muscular respiratória, expansibilidade torácica e flexibilidade. Espera-se ainda que o grupo que participar das palestras obtenha melhor conhecimento sobre seu organismo e saúde.

5. Procedimentos alternativos que possam ser vantajosos para o indivíduo:

São conhecidos os efeitos da utilização de aparelhos que promovam resistência à ventilação. Entretanto, eles não serão utilizados, visto que este estudo objetiva verificar os efeitos do exercício respiratório isolado na força respiratória, expansibilidade torácica e flexibilidade.

\section{IV - ESCLARECIMENTOS DADOS PELO PESQUISADOR SOBRE GARANTIAS DO SUJEITO DA PESQUISA:}

1.Todos os participantes poderão ter acesso, em qualquer momento, à informações sobre procedimentos, riscos e benefícios relacionados à pesquisa, inclusive para eventuais dúvidas. 
2.Todos os participantes tem liberdade de retirar seu consentimento a qualquer momento e de deixar de participar do estudo, sem que isto traga prejuízo à continuidade da assistência.

3.Garante-se a confidencialidade, sigilo e privacidade dos resultados obtidos.

4.Garante-se a assistência por parte do Hospital Universitário da Universidade Estadual do Oeste do Paraná e HCFMUSP, por eventuais danos à saúde, decorrentes da pesquisa.

5. Garante-se a viabilidade de indenização por eventuais danos à saúde decorrentes da pesquisa.

\section{INFORMAÇÖES DE NOMES, ENDEREÇOS E TELEFONES DOS RESPONSÄVEIS PELO ACOMPANHAMENTO DA PESQUISA, PARA CONTATO EM CASO DE INTERCORRÊNCIAS CLÍNICAS E REAÇÕES ADVERSAS.}

Fátima Aparecida Caromano, Av. Jaguaré, 249, São Paulo-SP,(11)3641-4175

Maiza Ritomy Ide, Rua do Comércio, 670, Cascavel-PR, (45)223-8341

\section{OBSERVAÇÖES COMPLEMENTARES:}

\section{VII - CONSENTIMENTO PÓS-ESCLARECIDO}

Declaro que, após convenientemente esclarecido pelo pesquisador e ter entendido o que me foi explicado, consinto em participar do presente Protocolo de Pesquisa

São Paulo, de de 200 